\title{
Recyclable organocatalysts based on hybrid silicas
}

\author{
M. Ferré, ${ }^{a}$ R. Pleixats, ${ }^{a} *$ M. Wong Chi Man, ${ }^{b}$ and X. Cattoën ${ }^{c *}$ \\ ${ }^{a}$ Department of Chemistry and Centro de Innovación en Química Avanzada (ORFEO-CINQA), Universitat Autònoma de Barcelona, 08193- \\ Cerdanyola del Vallès, Barcelona, Spain. Fax: 3493 5812477; e-mail: roser.pleixats@uab.cat. \\ ${ }^{b}$ Institut Charles Gerhardt Montpellier, UMR5253 CNRS-UM2-ENSCM-UM1, 8, rue de l'école normale 34296 Montpellier, France. \\ ${ }^{c}$ Inst. Néel, CNRS and Univ Grenoble-Alpes, 38042 Grenoble, France. e-mail: xavier.cattoen@neel.cnrs.fr.
}

\begin{abstract}
The quest for efficient and "greener" catalysts for chemical processes has set a precedent for the development of reliable methods for their synthesis. Those methods based on heterogeneous platforms present an excellent opportunity as they allow recyclability and easy work-up and handling. Hybrid organosilica-based materials are of interest particularly as heterogeneous platforms which can operate with a synergy between the well-defined properties of the organocatalytic fragments and the structural and mechanical stability as well as the presumed chemical inertness of the silica matrices. This review focuses on the recent advances on the incorporation methods to strongly bound organocatalysts into organosilica scaffolds and their promising applications in supported organocatalysis.
\end{abstract}

Post-print of: Ferré, M., et al. "Reciclable organocatalysts base don hybrid silicas" in Green chemistry (Ed. RSC), vol. 18, issue 4 (Feb. 2016) p. 881-922. The final versión is available at DOI 10.1039/c5gc02579f 


\section{Table of contents}

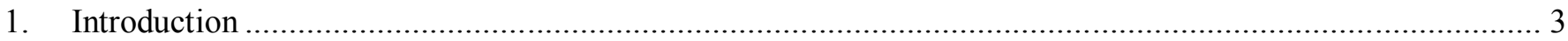

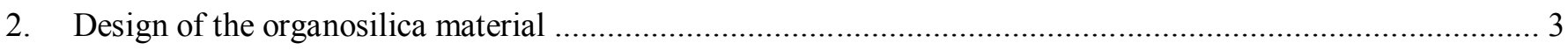

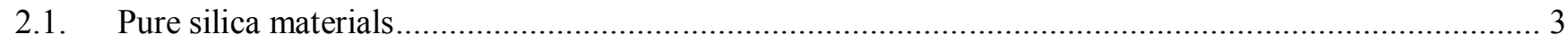

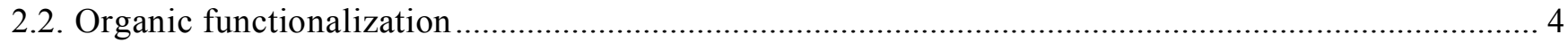

2.2.1. SYNTHESIS OF FUNCTIONAL ORGANOSILANES BEARING ORGANOCATALYSTS ................................... 5

2.2.2. FUNCTIONALIZATION DURING THE SOL-GEL PROCESS..................................................................... 5

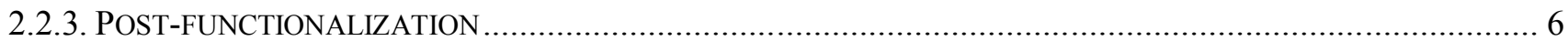

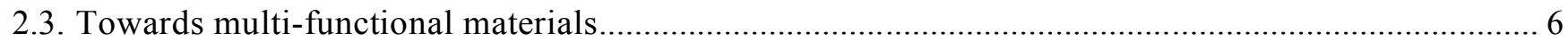

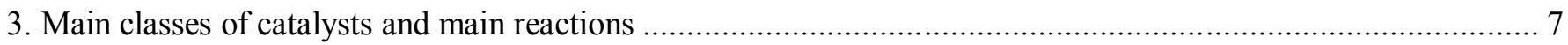

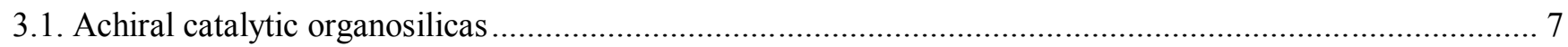

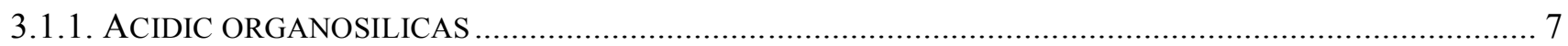

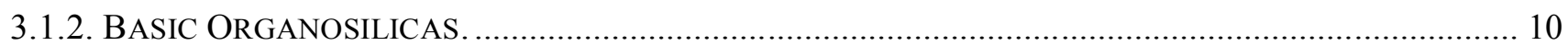

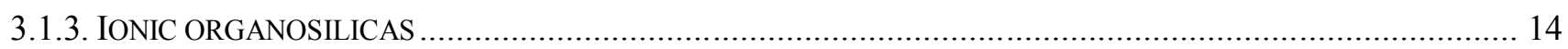

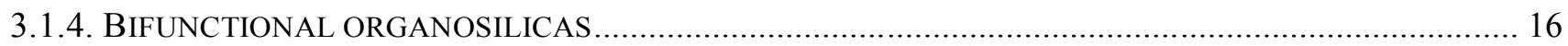

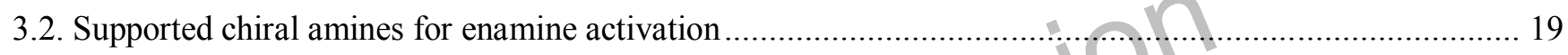

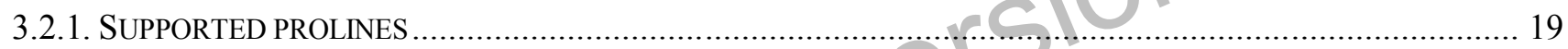

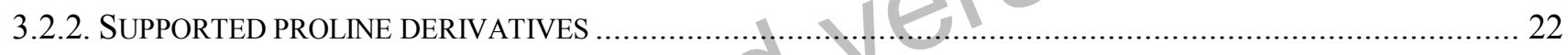

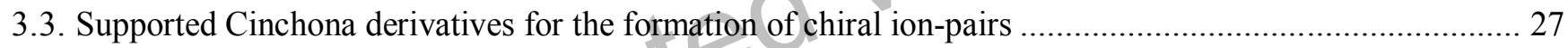

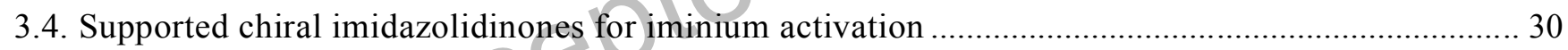

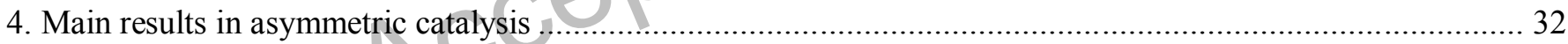

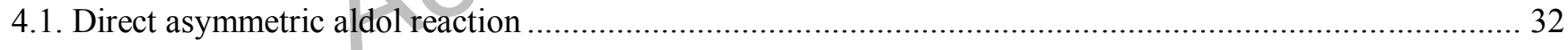

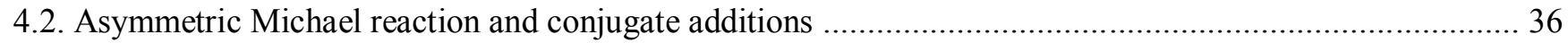

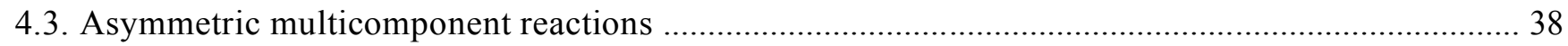

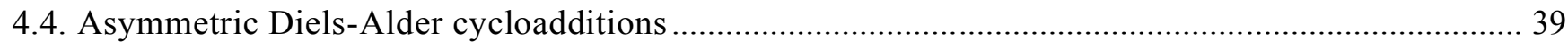

4.5. Other asymmetric reactions with organosilicas derived from proline, Cinchona alkaloids or

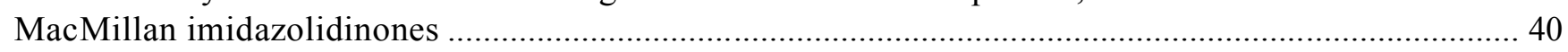

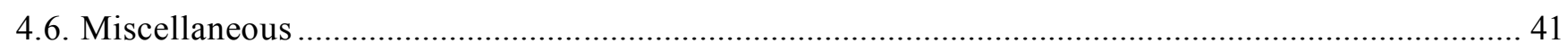

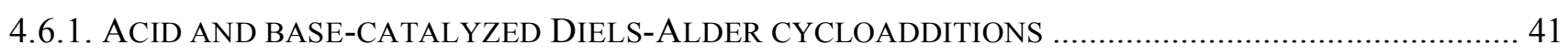

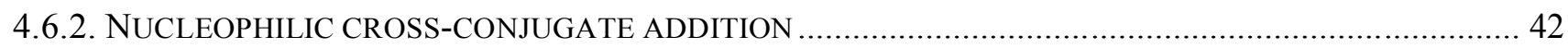

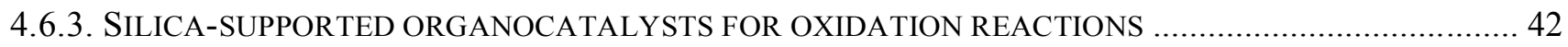

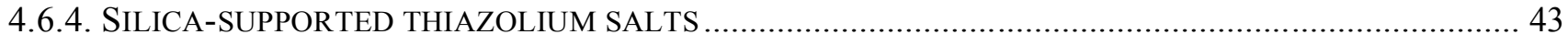

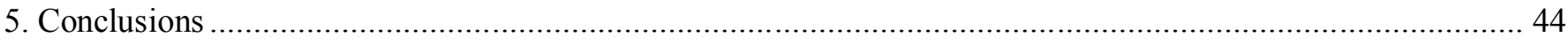

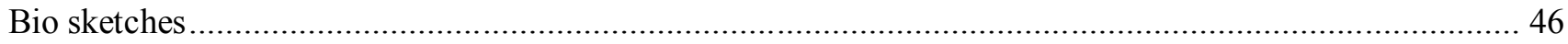

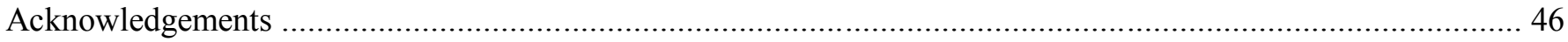

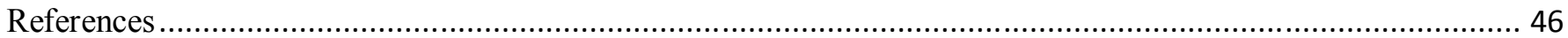




\section{Introduction}

Organocatalysis involves the acceleration of a chemical reaction by a substoichiometric amount of a metal-free organic compound. Although this type of catalysis has for long been overlooked, most probably due to the prominence of organometallic catalysis, the recent past decades have witnessed a tremendous growth of this field. ${ }^{1-3}$ Moreover, the availability of natural organic molecules in optically active form has enabled the extremely fast development of asymmetric organocatalysis for the synthesis of highly valuable chiral building blocks. ${ }^{4-12}$ Organocatalysis represents an eco-friendly and cost-effective methodology for fine chemical synthesis, especially when metal traces are of real concern, particularly for pharmaceutical industry. Ideal organocatalysts must be robust, readily available through easy synthesis and are commonly small molecules that can be rapidly degraded in the environment without significant effluent generation. Still then, the usual work-ups (e.g. column chromatography) remain a major drawback with tedious separation of the catalyst from the reaction media. Besides, the reactions often require high catalyst loadings and the reuse of the organocatalyst becomes of economic interest. A straightforward step to ensure low environmental impact and to facilitate an easy recovery and recycling is to tether organocatalysts on solid polymeric supports, in particular hybrid silicas, to benefit from the usual advantages of heterogeneous catalysis. ${ }^{13-18}$ In order to achieve more sustainable catalytic processes by improving the yield, productivity and energy efficiency, recent contributions have also been made on immobilized organocatalysts in continuous-flow systems. ${ }^{19,20}$

The formation of hybrid silica materials is attractive as a means to achieve supported catalysts, as these materials combine the advantages of a silica matrix (high surface area, thermal and mechanical stability and presumed chemical inertness) with the properties of the organic moiety. $^{21,22}$ Thus, hybrid organic-inorganic materials have attracted synthetic chemists offering the possibility to engineer interesting properties, particularly in the field of asymmetric organometallic catalysis via judicious combination of chiral organic ligands and transition metals. ${ }^{23}$ Over the past decade, soon after the boom of homogeneous asymmetric organocatalysis, numerous organocatalysts have been anchored on solid supports. Compared to organic polymers, hybrid silica materials offer the advantage to enable engineering at will the solid matrix on which the catalyst is anchored, by tuning the surface properties and the pore size and geometry. Indeed, since the advent of mesostructured silica materials in the $1990 \mathrm{~s},{ }^{24}$ organically-modified mesoporous silicas are being widely investigated as catalyst supports. ${ }^{18}$, ${ }^{25-27}$ The sol-gel synthesis enables to design materials with controlled pore size and shape, which can then be functionalized with various organic functionalities to tune the surface properties. Depending on the application envisioned for the supported catalyst, the hybrid silica support can thus be designed at will to improve the catalytic activity and selectivity. Factors such as the pore size in mesostructured materials, the hydrophilic/hydrophobic balance and the presence of surface silanol groups may indeed strongly influence the catalytic activity and selectivity. In addition to the opportunities usually associated with supporting catalysts on inert supports, such as simplified purification procedures and the recovery or the continuous use of the catalysts, the use of hybrid silicas as supports may enhance the catalytic properties if the material is suitably designed. Therefore, the design of efficient organocatalytic silica materials requires not only a good understanding of the mechanisms behind the catalytic processes, but also mastering the synthesis and characterization tools for silica-based materials. In this review, jointly written by sol-gel and organist chemists with experience in the field, we first aim to present the different possibilities for synthesising the organocatalyst-containing hybrid silicas in order to design efficient supported systems, and taking into consideration the greenness of the synthesis. Then the main classes of catalysts and the main reactions are summarized starting from achiral to chiral ones to end up with a discussion on the main catalytic results, covering the recent literature until the end of 2014.

\section{Design of the organosilica material}

Over the past decade, a multitude of silica-based materials have been designed to immobilize organocatalysts, aiming at developing eco-friendly and cheap heterogeneous systems for chemical transformations. The main features for these materials are: easy synthesis; low cost; easy recovery of the catalytic material; good reusability; good diffusion of the reactants within the structure; low dispersity of catalytic sites; controlled interaction between the surface and the reactants. In addition, the synthesis of the modified organocatalyst and of the materials should be performed following the green chemistry principles. ${ }^{28}$ In the following paragraphs, we will present the different types of silica-based materials that have been used for supporting organocatalysts as well as the functionalization strategies; then we will emphasize on the control of the surface properties.

\subsection{Pure silica materials}

Silicas are easily synthesized by the sol-gel process, or can be purchased from commercial sources. Indeed, besides silica gels for chromatography, MCM-41 and SBA-15 mesostructured materials are now commercially available. However, only for pure silica a myriad of materials have already been described, which differ by their shape, porosity and pore organization or surface properties. Therefore, careful descriptions of the morphological and textural properties (specific surface area, pore volume and pore size distribution) of the materials are of the upmost importance and should be given in all cases. This includes particles size and shape, $\mathrm{N}_{2}$-sorption experiments as well as the description of the thermal treatments applied. Indeed, the pore size can affect drastically the rate of diffusion of the reactants within the porous structure. Additionally, thermal treatments are known to increase the condensation of the silica gels, and to decrease the amount of silanol groups on the surface. These are examples of major parameters which may affect the properties of the resulting materials.

Simple silica gels are obtained industrially by the sol-gel process by the acidic condensation of sodium silicate. They usually feature high specific surface areas and pore volumes and small mesopores (for example, for the commercial Merck Si-60 silica gel: ca $500 \mathrm{~m}^{2} \mathrm{~g}^{-1}$ BET specific surface area, $0.68 \mathrm{~cm}^{3} \mathrm{~g}^{-1}$ pore volume and average pore diameter of $\left.7.0 \mathrm{~nm}\right){ }^{29}$ However, their pore size distribution is not uniform, which means that they feature an important dispersity of environments. Therefore, a large diversity of catalyst environments is expected for organocatalysts grafted on these types of silica. Note that a wide variety of different mesoporous silica materials can be obtained in the laboratory by simple sol-gel reactions, and that the resulting surface area, pore 
sizes and distribution may vary a lot depending on the type of catalyst (acid, base or nucleophile) and on the synthetic conditions used. $^{30}$

Mesostructured silicas were first reported in the early 1990s and have become soon after extremely popular. ${ }^{31-33}$ They are obtained by the sol-gel hydrolysis and condensation of silica sources in the presence of surfactants acting as soft templates thanks to a cooperative self-assembling mechanism of surfactant molecules and oligomeric silicates during the synthesis. ${ }^{34-37}$
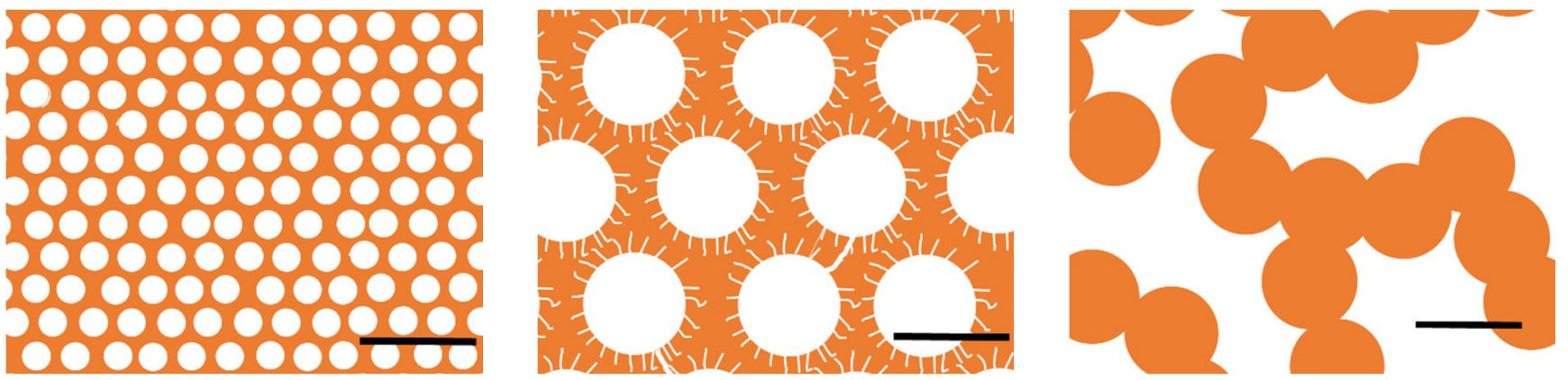

Figure 1: Schematic representation of typical (a) MCM-41 (pore size $2.5 \mathrm{~nm}$, wall thickness $1 \mathrm{~nm}$ ); (b) SBA-15 (pore size $9 \mathrm{~nm}$, pore thickness $3 \mathrm{~nm}$ ) and (c) porous, non-structured silica (average pore size $7 \mathrm{~nm}$ ). Orange: silica, white: pores. Scale bar: $10 \mathrm{~nm}$.

MCM-41 and SBA-15 are the two main families of mesostructured silicas that are being used for supporting catalysts. Typically, MCM-41 materials are prepared by the hydrolysis and condensation of a silica source in the presence of an alkyltrimethylammonium surfactant in basic medium. After extraction or calcination of the template, the material is obtained with a 2D-hexagonal arrangement of cylindrical mesopores, with a long-range organization. The structure of MCM-41 materials looks particularly interesting for catalysis as long, regularly aligned cylindrical pores with smooth surfaces are present in these materials, which allows the grafted functions to have close environments. If the parent materials (synthesized from hexadecyltrimethylammonium bromide) have small pore diameters of ca 2-3 nm depending on the synthesis conditions, analogous mesostructured silicas can also be prepared with diameters up to $10 \mathrm{~nm}$. ${ }^{32}$ However, these materials feature thin pore walls $(0.5-1.0$ $\mathrm{nm}$ at the thinnest), ${ }^{38,39}$ which results in a poor hydrothermal stability (total vanishing of the pore order in less than $6 \mathrm{~h}$ in refluxing water). ${ }^{40,41}$ Although procedures have been developed to increase this water stability, this may limit the recyclability of MCM-41based materials. SBA-15 materials are obtained under acidic conditions and using a triblock copolymer (usually Pluronic P123, $\left.(\mathrm{PEO})_{20}(\mathrm{PPO})_{70}(\mathrm{PEO})_{20}\right)$ as structure-directing agent. Similarly to MCM-41, SBA-15 features an organized porosity with a $2 \mathrm{D}-$ hexagonal structure $(P 6 \mathrm{~mm}$ space group). However, wider pores and thicker pore walls are usually obtained (typically, pore diameter of $8.9 \mathrm{~nm}$ and wall thickness of $3.0 \mathrm{~nm}) .^{40}$ This confers a very high hydrothermal stability to these materials. Although many papers represent an ideal structure for SBA-15, with perfect cylindrical pores, XRD and physisorption analyses completed by transmission electron tomography revealed the presence of microporosity and two interconnected porous structures, the main cylindrical pores being highly corrugated.

Apart from SBA-15 and MCM-41, a wide variety of mesostructured silica materials exist with diverse morphologies and texture. Indeed, silicas can be obtained with cubic porous structures or hollow sphere morphologies, but the use of silica supports with such original structures has remained almost unexplored. ${ }^{44}$

Silica nanoparticles can also easily be obtained using classical sol-gel techniques. The nanometric size provides the advantages of enhanced surface over volume ratio, and shorter pore length, thus easier diffusion in the case of mesoporous MCM-41 silica nanoparticles. On the one hand, dense silica nanoparticles are easily produced either by the Stöber method or by reverse microemulsion. These techniques also enable the formation of core-shell $\mathrm{Fe}_{3} \mathrm{O}_{4} @ \mathrm{SiO}_{2}$ nanoparticles. ${ }^{45}$, ${ }^{46}$ On the other hand, the synthesis of MCM-41 nanoparticles with tunable morphologies is now well documented, and core-shell structures with magnetic cores are also described. ${ }^{47}$

\subsection{Organic functionalization}

Covalently anchoring the organic functionalities in the solid material can affect importantly the catalytic properties. When designing a catalytic material, several functionalization strategies should be considered (Figure 2). It is indeed possible to perform the functionalization at the stage of the synthesis of a material from molecular organosilane precursors (sol-gel routes), or to start from a preformed silica or organosilica, then perform the functionalization (post-functionalization strategies). 


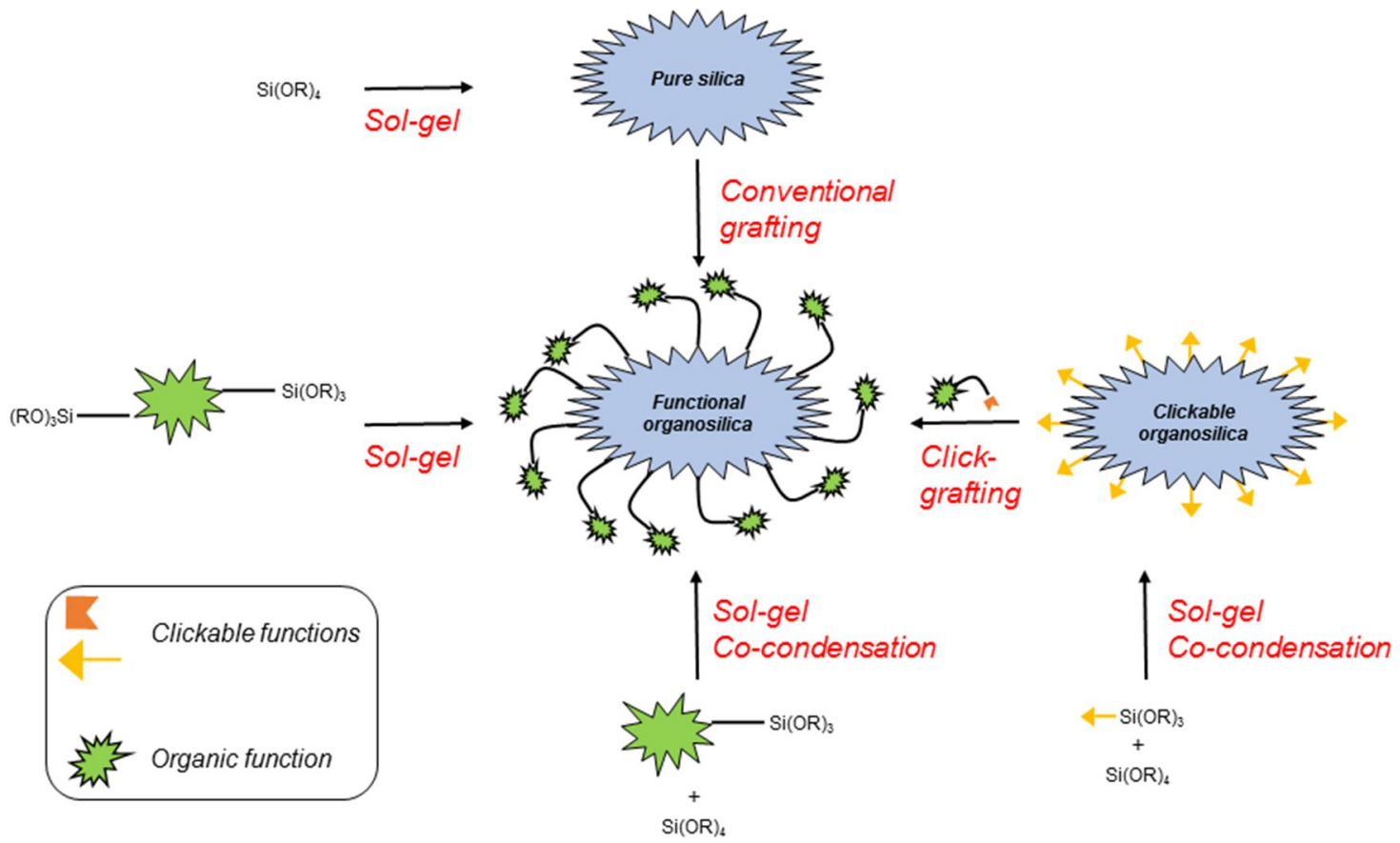

Figure 2: Overall scheme of the synthetic strategies for the formation of functional organosilicas.

\subsubsection{SYNTHESIS OF FUNCTIONAL ORGANOSILANES BEARING ORGANOCATALYSTS}

Regardless of the functionalization method envisioned, the covalent incorporation of organic groups can only be efficient if strong $\mathrm{Si}-\mathrm{C}$ bonds are present between the siloxane network and the organocatalyst, as the immobilization of organics through $\mathrm{C}-\mathrm{O}-\mathrm{Si}$ linkages results in very poor hydrolytic stability. The availability of appropriate organo(alkoxy)silanes is therefore a prerequisite for catalyst immobilization. Several organo(alkoxy)silanes bearing simple functionalities, such as amino, mercapto, iso(thio)cyanato, are commercially available and widely used to produce materials that can be post-functionalized (See section 2.2.3). However, the formation of more sophisticated organosilanes requires more elaborated synthesis conditions, as organo(alkoxy)silanes are known to be moisture-sensitive, and must therefore be prepared and stored under inert conditions. The classical reactions leading to such compounds are the hydrosilylation of alkenes, using a platinum catalyst. This reaction is very straightforward for simple functional alkenes, but might undergo limitations when catalyst-poisoning groups or easily reduced functions are present. This strategy has been used to prepare proline-derived organosilanes, ${ }^{48}$ but also to functionalize silicones with cinchona alkaloids thanks to the presence of double bonds in the structure of these compounds. ${ }^{49}$ Simple reactions such as peptide formation $^{50}$ or addition of alcohols ${ }^{51,52}$ or amines ${ }^{53}$ on silylated isocyanates have also been used to form proline or prolinamide-based precursors. The use of (3-azidopropyl)triethoxysilane (AzPTES) upholsters growing interest, either to form $\mathrm{P}=\mathrm{N}$ linkages through the Staudinger reaction, ${ }^{54}$ or to create strong triazole linkers by the reaction with organic alkynes through the copper-catalyzed azide-alkyne cycloaddition reaction (termed CuAAC). This new methodology enables a very fast preparation of organo(alkoxy)silanes in high yield thanks to microwave activation. ${ }^{55,56}$ In particular, bridged organosilanes can be easily produced thanks to ramified clickable organo(alkoxy)silanes. ${ }^{57}$ Another click methodology for the production of sol-gel precursors was developed simultaneously using the thiol addition to alkenes under UV irradiation, enabling the formation of protected proline or cinchona alkaloids-based organosilanes. ${ }^{58}$ This method has been extended to the UV-promoted thiol-alkyne coupling to form bridged organosilanes. ${ }^{59}$ The use of moisture-sensitive alkoxysilane compounds can sometimes be avoided through substitution by allylsilanes, which enables easy purification by chromatography. In these groups, the allyl to silicon bond can be slowly hydrolyzed to silanols, which can be used in situ for sol-gel reactions ${ }^{60}$ or post-functionalization. ${ }^{61}$ Alternatively, the use of triisopropoxy groups offers similar advantages in terms of stability of sol-gel precursors. ${ }^{62}$ These methodologies may be particularly adapted for immobilizing polar organocatalysts in sol-gel derived materials.

\subsubsection{FUNCTIONALIZATION DURING THE SOL-GEL PROCESS}

Similarly to the sol-gel synthesis of pure silica, mixed organosilicas can be obtained by the co-condensation of silica precursors ( $\mathrm{SiO}_{4}$ environments: tetraalkoxysilanes or silicate solutions) with organo(alkoxy)silanes ( $\mathrm{R}-\mathrm{SiO}_{3}$ environments). For catalytic materials, the molar ratio between the former and the latter compounds usually lies in the range of 5 to 100 . Depending on this ratio, as well as on the structure of the organic fragments involved, the materials can feature very different morphological and textural properties. For example, for prolinamide-based materials obtained by the co-condensation of $n$ equivalents of tetraethoxysilane (TEOS) with one equivalent of organosilane, a BET specific surface area of $400 \mathrm{~m}^{2} \mathrm{~g}^{-1}$ was obtained for $n=19$, whereas for $n=5$, no surface was detectable by routine $\mathrm{N}_{2}$-sorption measurements at $77 \mathrm{~K}^{52}$ This trend is quite general, as the organic moieties at high loadings may prevent the diffusion of nitrogen at such a low temperature. ${ }^{63}$ However, even if no surface area can be detected, such materials can often exhibit very interesting catalytic properties. ${ }^{51,52,64}$ 
Notably, the sol-gel co-condensation reactions can also be performed in the presence of surfactants in order to create ordered porosity. ${ }^{65}$ This co-condensation synthesis can be performed using various types of surfactants (CTAB, P123, F127, dodecylamine...) to afford a myriad of porous materials. ${ }^{66}$ With simple functional organo(alkoxy)silanes such as 3mercaptopropyl-, 3-chloropropyl- or 3-cyanopropyltriethoxysilane, well-organized materials can be obtained with up to 25 mol\% of functional silane. However, when larger organic fragments are incorporated, the maximum amount for which a mesostructure is obtained is reduced drastically, due to stronger interactions between the organics and the surfactant.

Pure organosilicas, featuring only $\mathrm{C}-\mathrm{SiO}_{3}$ silicon environments, can also be obtained by the sol-gel process through the hydrolysis and condensation of organo(alkoxysilanes). Only a handful of materials can be obtained from precursors containing a single trialkoxysilyl group, as usually their hydrolysis-condensation leads to small oligomers. To avoid this issue, bridged organosilanes where organic functionalities are anchored to at least two trialkoxysilyl groups can be used. Through the sol-gel process, they are transformed into bridged silsesquioxanes, of general formula $\mathrm{R}-\left[\mathrm{SiO}_{1.5}\right]_{\mathrm{n}}$ with $\mathrm{n} \geq 2 .{ }^{67,68}$ This confers them the regular and the highest possible organic loading of all organosilica materials, as the inorganic charge is minimized. Bridged silsesquioxanes synthesized without structure directing agent and bearing bulky organic functionality usually feature negligible porosity. ${ }^{51,}{ }^{64}$ However, several reports have demonstrated good catalytic activities for such materials despite this low porosity. In order to get porous materials, it is possible to use surfactants during the sol-gel process, but porosity is only obtained when small or rigid organic units are used. The resulting materials, called periodic mesoporous organosilicas (PMOs), ${ }^{69}$ feature high surface areas and pore volumes. They can result from the interaction between the silicate groups and the surfactant, but also between the organic fragments and the surfactant. ${ }^{70}$ The hydrophobic nature of the PMO matrix might result in improved catalytic properties, but such matrices have only been scarcely studied as catalyst support. Indeed, it is possible to synthesize mixed PMOs by a co-condensation approach, and even clickable PMOs (see section 2.2.3.). ${ }^{57,71}$ Furthermore, simple $^{72}$ or elaborated core-shell ${ }^{73}$ or even multipodal $^{74}$ nanostructures have very recently been reported, which may find valuable application for supporting organocatalysts.

\subsubsection{Post-functionalization}

The difficult control over the texture when using the sol-gel co-condensation method or when preparing bridged silsesquioxanes or PMOs can be a serious issue for those who want to design a catalytic material with well-defined pore structure and morphology. Since a plethora of procedures have already been described in the literature for the synthesis of silica materials with tunable shapes and porosity, it is tempting to start from a commercial or well-defined silica material, then post-functionalize it with an appropriate organosilane. A typical post-functionalization procedure consists in stirring a mixture of a silica material and an organo(alkoxy)silane in refluxing toluene. Indeed, surface silanol groups as well as siloxane bridges react with the alkoxysilane functions to create siloxane linkages. ${ }^{75,76}$ Alternatively, it is also possible to react surface silanol groups with hydrogenosilanes using tris(pentafluorophenyl)boron as catalyst. This reaction takes place in only 5 minutes in the case of MCM-41, with important functionalization rates of $0.5-1.5 \mathrm{mmol} \mathrm{g}^{-1}$ depending on the grafted entity. ${ }^{77}$ Although quite general, the grafting methods suffer several important drawbacks. Indeed, due to diffusion issues, the grafting preferentially occurs on the external surface and at the pore entrance, before taking place inside the pores. This can even lead to pore blocking phenomena when voluminous functions are incorporated. Furthermore, the amount of grafted functions is hardly predictable, as this will depend on the steric hindrance of the silane used, the solvent ${ }^{78}$ and other reaction parameters. Aggregation of the grafted organics can also be observed, when organic groups able to self-assemble are used. This factor was exemplified by Asefa et al, by grafting (3aminopropyl)triethoxysilane (APTES) on MCM-41 in toluene or ethanol. While grafting in ethanol yielded materials with isolated amine groups, the grafting in toluene gave a higher density of amine functions in close proximity, due to the strong hydrogen bonding between them in this non-polar solvent. ${ }^{79}$

To circumvent the latter issues, many groups have opted for chemical reactions on organic fragments incorporated within organosilicas. Starting from organosilicas possessing well-located reactive functions (included for example by co-condensation reactions involving small-size, non-self-assembling organosilanes) it is indeed possible to conduct chemical reactions leading to more complex grafted fragments. For example, mesoporous materials bearing thiol, amine, chloride, azide or propargyl groups can be reacted with organocatalysts derivatized with an appropriate organic function. The functionalization reaction should thus be highly selective, high-yielding, occurring under mild conditions and easy to monitor. Click reactions, as defined by Sharpless in $2001,{ }^{80}$ constitute a set of chemical transformations fulfilling all these requirements. The click chemistry concept was introduced in the context of drug discovery, but was very soon extended to all fields of chemistry to refer to the Lego construction of functional molecules, polymers or materials, including silica-based materials. ${ }^{81}$ Amongst all click reactions, the addition of thiols to alkenes and the copper-catalyzed azide-alkyne cycloaddition reaction are the most popular, and have been widely applied to support homogeneous catalysts on silica supports. ${ }^{82}$ Indeed, synthetic protocols have been reported for mesoporous organosilicas (based on SBA-15 or MCM-41 structures) obtained by the co-condensation method, with tunable morphologies and loadings of reactive groups. ${ }^{83-86}$ Interestingly, it has been demonstrated that SBA-15- $\mathrm{N}_{3}$ materials obtained by co-condensation with low loadings of azide functions $(<2 \mathrm{~mol} \%)$ can easily be transformed into materials with site-isolated catalysts through the CuAAC reaction, by contrast to $\mathrm{SBA}-15-\mathrm{N}_{3}$ obtained by the grafting method. ${ }^{87}$ Furthermore, an important advantage of the CuAAC reaction over the other click transformations is the easy monitoring of the grafting conversion, thanks to the strength and localization of the $\mathrm{N}_{3}$ band in FTIR.

\subsection{Towards multi-functional materials}

Catalytic organosilica materials are much more than simple supported catalysts, as the catalytic properties result not only from the functionality introduced on the support, but also from the siloxane framework. Indeed, the organosilica surface exhibits accessible silanol functions, that have a mild acidic character (the isoelectric point of silica lies between 1.5 and 3.5 ). ${ }^{30,88}$ Thus, this enables electrophilic activation of carbonyl groups or nitroalkenes resulting in enhanced reactivity towards nucleophiles. Efforts have thus 
been made either to inhibit such an electrophilic assistance by passivation of the surface, or to control these surface interactions for bifunctional catalysis. ${ }^{89}$ Multi-functional materials have also been designed using more complex strategies.

The passivation of the surface of organosilica materials with trimethylsilyl groups is classically carried out through the treatment of the material with chlorotrimethylsilane or hexamethyldisilazane as a milder reagent. Alternatively, diphenyldichlorosilane can lead to passivated surfaces through bridging and bulkier $\mathrm{Ph}_{2} \mathrm{Si}$ groups. As a result of the pore size decrease and of the higher density, a decrease of the specific surface area and pore volumes is observed. This passivation strategy is generally used to inhibit hydrogen bonding activation of the substrate by the silica surface, ${ }^{90,}{ }^{91}$ but it is also believed to facilitate the diffusion of organic species, particularly in very polar environments, through enhanced hydrophobicity of the materials. ${ }^{92}$

Amine-grafted silicas are being intensively studied as heterogeneous catalysts for Henry and aldol reactions. ${ }^{78}$ It is now well established that cooperative activation of the ketone by the base and of the aldehyde by the surface silanol groups takes place in Henry reactions. This was proven either by passivating the surface, or by modifying the linker length between the surface and the amine group. Indeed, when short C1 linkers are used, amine-silanol quenching would occur, whereas longer distances (C3-C5) would allow for efficient cooperative catalysis. ${ }^{93}, 94$ The enantioselectivity levels reached by supported asymmetric catalysts are also greatly affected by the state of the surface. For instance, for proline-catalyzed aldol reactions between propanone and 4nitrobenzaldehyde, the surface is believed to easily form hydrogen bonds with the aldehyde, competing with the stereo-directing carboxylic acid group, and thereby creating a racemic pathway. ${ }^{48}$ More recently, it was shown that the enantiomeric excesses obtained with cinchonidine for the Michael addition of thiols on cyclohexenone decreased upon immobilization on aerosil or SB A15 materials due to competitive catalysis by the acidic surface silanol groups or the silanol groups localized on the grafted fragment or direct interaction between the hydroxyl function of cinchonidine and the silica surface. Therefore, passivation of the surface by TMS groups and mild washings of the material with ethanol led to the recovery of the enantioselectivity reached in homogeneous catalysis. ${ }^{91}$ The extent of hydrogen-bonding interactions between the substrate and the surface may also vary according to the pore size, thus the curvature of the surface. ${ }^{89,} 90$ These confinement effects should be taken into account when designing supported organocatalysts.

The implementation of multiple functionalities on a silica surface can also be mastered during the synthesis of the materials. Cooperative basic/acidic activation by an amine and a $\mathrm{H}$-bond donor was first investigated by Lin using secondary amines and urea groups incorporated within MSNs by co-condensation, for Henry, aldol and cyanation reactions. ${ }^{95}, 96$ Later on, inspired by the structure of the Takemoto catalyst, Puglisi et al designed a catalytic material containing bis(trifluoromethyl)phenylthiourea and tertiary amine functions, that were shown to work hand-in hand during the catalytic Michael addition of acetylacetone on $\beta$ nitrostyrene. ${ }^{97}$ Randomly-distributed independent functions can also be implemented through click reactions from a single parent material. ${ }^{98,99}$ This approach was recently developed by the group of Studer, with the synthesis of materials featuring both azide and alkene, or azide and alkoxyamine functions. ${ }^{99}$ This allows for a diversity-oriented synthesis of bifunctional materials. Moreover, the synthesis of mesoporous silica nanoparticles with homogeneously distributed pairs of communicating functions was recently reported thanks to two consecutive CuAAC reactions. ${ }^{100}$

Finally, in order to precisely control the distance between two catalytic functions, it is possible to incorporate a parent organosilane during the synthesis (either by grafting or co-condensation), and to release functional groups from it. This can be done by the ring opening of a sultone with sodium bisulfide, resulting in neighbouring thiol and sulfonic acid groups, ${ }^{101,102}$ or by the thermolysis of a multifunctional fragment containing carbamate and xanthate groups for the generation of amines and thiols. ${ }^{103}$

To conclude this section, a myriad of silica-based materials can be prepared for supported organocatalysis. Many synthetic factors can be varied, to tune the morphology, porosity and interfacial properties, which all play a key role in the catalytic properties. An important issue is now to implement multiple functionalization or to control the interactions between the surface and the transition state. From a green chemistry perspective, the eco-design of the catalyst should take into account the need of atom economy during the materials synthesis, and avoid energy-consuming calcination steps. Therefore, catalysis with simple silicas, or organosilicas obtained through the co-condensation method without structure-directing agents should be privileged unless better catalytic results are obtained using templated meso-structured materials (such as MCM-41 or SBA-15) thanks to confinement effects.

\section{Main classes of catalysts and main reactions}

\subsection{Achiral catalytic organosilicas}

\subsubsection{ACIDic organosilicas}

Efficient and recyclable silica-based heterogeneous organocatalysts containing covalently attached acidic functions such as sulfonic $\left(-\mathrm{SO}_{3} \mathrm{H}\right)$ or carboxylic $(-\mathrm{COOH})$ groups have been described (Figure 3) Thus, sulfonic-acid functionalised silica-gel, (M1a) ${ }^{104}$ and mesostructured silicas MCM-41, (M1b), ${ }^{105,106}$ SBA-15 (M1c) ${ }^{102,107-110}$ and HMS (M1d) $)^{105,107,109}$ have been mostly obtained by post-grafting of (3-mercaptopropyl)trialkoxysilanes to preformed silicas followed by thiol oxidation, although direct template-assisted co-condensation of mercaptoalkoxysilanes with tetraethyl orthosilicate (TEOS) has also been reported (M1e). ${ }^{105}$, 107-109 Benzenesulphonic acid groups have been introduced by co-condensation of TEOS with 2-(4chlorosulphonylphenyl)ethyltrimethoxysilane followed by hydrolysis of the sulfonyl chloride group (M2). ${ }^{107}$ 
$\stackrel{\substack{\mathrm{O}=\mathrm{Si}^{\prime} \\ \mathrm{EtO}}}{\mathrm{O}} \leadsto \mathrm{SO}_{3} \mathrm{H}$

$\mathbf{M}=\mathrm{SiO}_{2}(\mathbf{M} 1 \mathbf{a}) ; \mathrm{MCM}-41$ (M1b), SBA-15 (M1c); HMS (M1d)

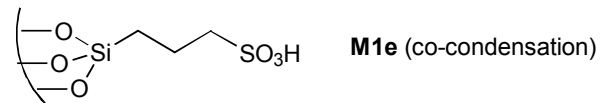

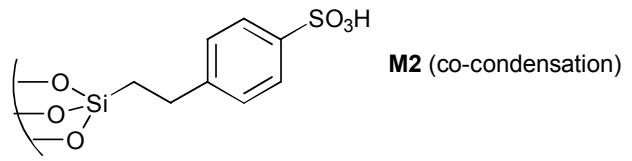

(co-condensation)

商|

M4a (ortho); M4b (meta); M4c (para)

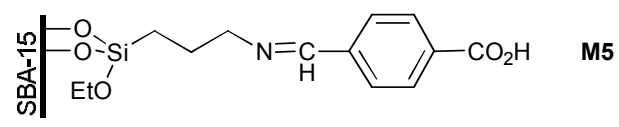<smiles>CC(SCCC[Si]12CC(CP)(CCO1)OC2(C)C)C(=O)O</smiles>

M6

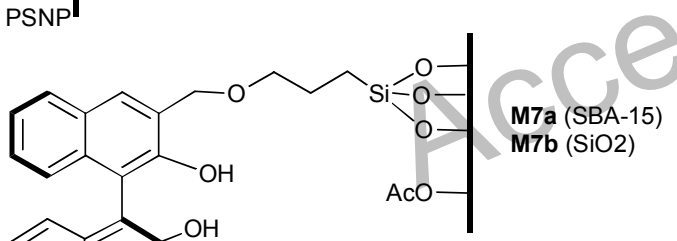<smiles>Oc1ccc2ccccc2c1</smiles>

Figure 3. Silica-supported acid organocatalysts

These sulfonic acid functionalized organosilicas have been applied as catalysts in esterification reactions of fatty acids with alcohols ${ }^{107}$ or polyols (Scheme 1). ${ }^{104,105,109}$ They provide selective monoesterification reactions of glycerol due to the strong hydrophilic interactions between the silica framework and the polyol, which are expected to favour a rapid desorption of the amphiphilic monoglyceride from the catalytic surface thus inhibiting the polymerization reactions. Improved selectivities with respect to homogeneous and common solid acid catalysts were also found in the formation of bisfurylalkanes by condensation of 2 -methylfuran and acetone and in the addition of maleic acid to dicyclopentadiene (Scheme 1). ${ }^{105}$, 109 Propylsulfonic acid functionalized SBA-15 M1c was also active for the one-pot synthesis of xanthenes and bis(indolyl)methanes from the reaction of substituted benzaldehydes with 2-naphthol or indole, respectively (Scheme 1). The use of this heterogeneous acid increases the yields by avoiding polymerization reactions occurring under homogeneous acidic catalysis. ${ }^{110}$ A plausible mechanism has been proposed in which the electrophilicity of the aldehyde is enhanced by interaction with the acidic sites on the catalyst surface, thus favouring the attack of the aromatic nucleophiles. 


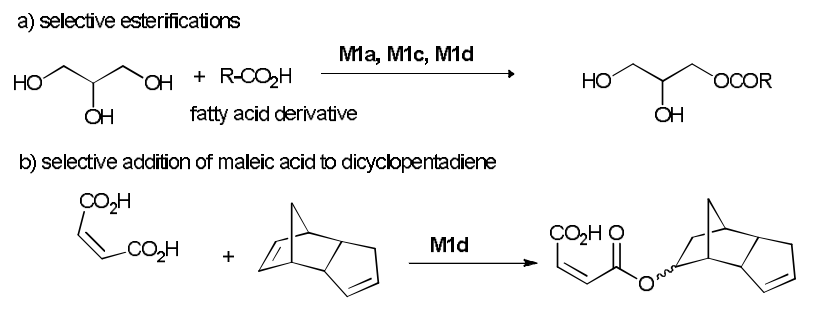

c) synhesis of bisfurylalkanes

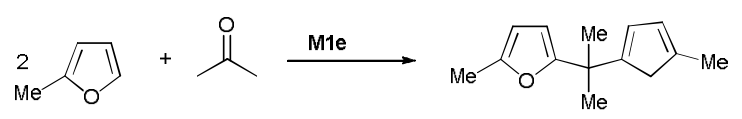

d) Synthesis of bisphend $\mathrm{A}$

e) synthesis of xanthenes and bis(indolyl)methanes<smiles>CC(C)Cc1ccc2ccc3c(c2c1)C(Br)c1c(ccc2ccccc12)O3</smiles>

f) selective synthesis of tetrasubstituted imictazoles

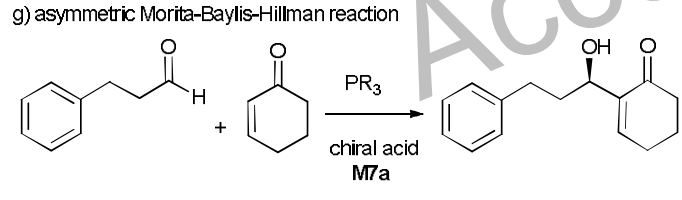

Scheme 1. Reactions catalyzed by silica-supported acids

Davis has prepared thiol/sulfonic acid-functionalized SBA-15 materials for cooperative catalysis by two approaches, one of them consisting on acidic surfactant-assisted co-condensation using both monomers, (3-mercaptopropyl)trimethoxysilane (MPTMS) and 2-(4-chlorosulphonylphenyl)-ethyl-trimethoxysilane in different molar ratios (M3) (Figure 3). ${ }^{108}$ In the other approach, a sultonederived organotrialkoxysilane was grafted on SBA-15 to give a versatile intermediate material for generating bifunctional catalysts with thiol/sulfonic acid pairing by sultone ring opening with thiol-containing nucleophiles (M4a-c) (Figure 3). ${ }^{102}$ These materials M3 and M4 have been investigated in the formation of bisphenol A by condensation of phenol and acetone (Scheme 1). By immobilizing the two functional groups on the same solid, both the reaction rate and regioselectivity are enhanced. A mechanism explaining the role of thiol group in the reaction has been suggested by the authors. They hypothesize that thiol further activates the carbonyl of acetone to nucleophilic attack by phenol via a charged sulfur intermediate. ${ }^{108}$ Moreover, the highest activity is reached when the two acid/thiol groups are as close as possible in the material. ${ }^{102}$

Bhaumik and coworkers have reported the post-synthesis modification of SBA-15 ${ }^{106,111}$ by introducing $-\mathrm{COOH}$ functionalities via Schiff-base condensation of 3-aminopropyl grafted SBA-15 with 4-formylbenzoic acid (M5) (Figure 3). This acid functionalized mesoporous material was used for the synthesis of xanthenes via condensation between aromatic aldehydes and 2-naphthol. However, the reaction with sulfonic-acid functionalized MCM-41 (M1b), with stronger acidic sites, proceeds more rapidly than with this carboxylic acid functionalized SBA-15 (M5). Recently, post-synthesis grafting of -COOH groups on porous silica nanoparticles (PSNP) has also been performed. ${ }^{112}$ Thus, M6 (Figure 3) was prepared by reacting the silanols of the PSNP with MPTMS and subsequent treatment with 2-bromopropionic acid. M6 promoted the chemoselective synthesis of tetrasubstituted imidazoles in water by a four-component reaction involving 1,2-diketone, aldehyde, an amine and ammonia (Scheme 1). A plausible mechanism has been proposed to explain the role of the supported acid and the selectivity for the tetrasubstituted product 
versus the trisubstituted imidazole. Although the carboxylic acid was essential for the condensation reaction, the authors state that the silanol groups of the silica surface also contribute by increasing the electrophilicity of the carbonyl carbon. The superiority of this material with respect to other solid acid catalysts has been established.

The Morita-Baylis-Hillman reaction of aldehydes with electron-deficient alkenes is promoted by nucleophilic amines and phosphines (Scheme 1). It has been demonstrated that the addition of chiral mild Brönsted acids of BINOL type to a phosphine promoter resulted in a significant increase of the reaction rate and a highly enantioselective process. A catalytic cycle has been proposed to explain these effects. ${ }^{113}$ Based on this result, Gao has synthesized by post-grafting method several chiral BINOL functionalized amorphous silica and SBA-15 materials for the asymmetric Morita-Baylis-Hillman reaction of 3-phenylpropanal and cyclohexenone, achieving modest enantioselectivities (see M7a-b for significant example of functionalization, M7a gave the best results) (Figure 3). ${ }^{114}$

\subsubsection{Basic Organosilicas.}

Many organic reactions take place under basic or nucleophilic catalysis, and much effort has been already devoted to the asymmetric versions of these reactions. The use of immobilized chiral amines for asymmetric induction will be treated in sections 3.2-3.4.

Thus, the aldol-type Knoevenagel condensation between active methylene compounds (malonates, cyanoacetates, malononitrile) and aldehydes or ketones to afford electron-deficient alkenes require weak basic catalysis (amines are usually employed) or baseacid pair catalysis (ie piperidine/acetic acid) (Scheme 2). The amine can act as a base to activate the pre-nucleophile by generating the corresponding enolate and/or as a nucleophile forming the imine or iminium salt of the carbonylic compound, enhancing its electrophilicity. Mixed aldol reactions involving aromatic aldehydes and alkylketones under basic catalysis give the aldol intermediates, which are dehydrated in most cases to afford the $\alpha, \beta$-unsaturated carbonyl compounds (Claisen-Schmidt aldol condensation), a dehydration step that is especially favorable because the resulting enone is conjugated with the aromatic ring (Scheme 2).
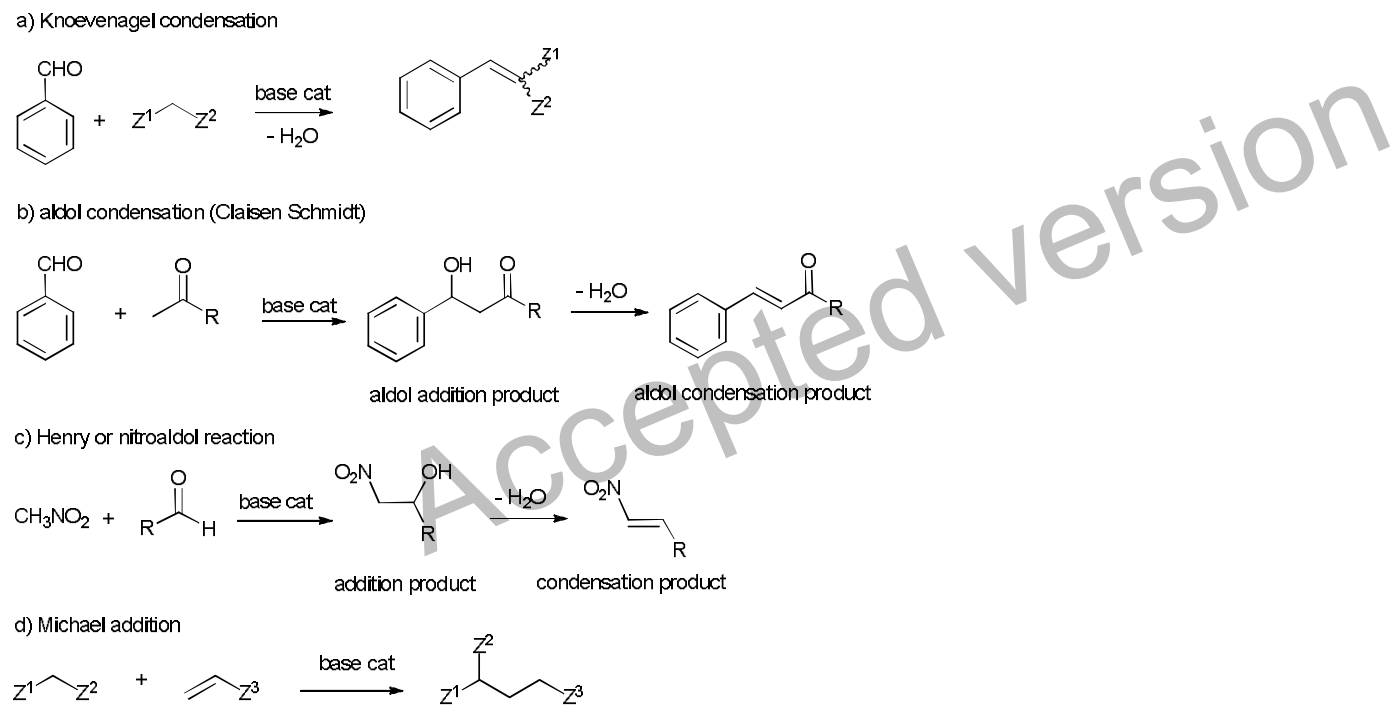

e) base-catalyzed nucleophilic epoxidation of enones and enals

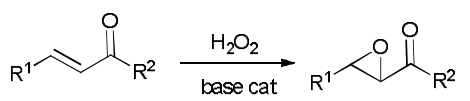

f) cycloaddition of $\mathrm{CO}_{2}$ to epoxides

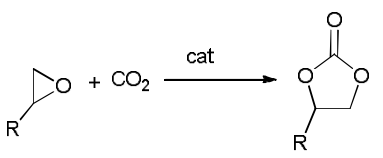

g) ring opening of glycidol with fatty acids

Scheme 2. Reactions under basic or nucleophilic catalysis

The nitro-aldol or Henry reaction is a classical carbon-carbon bond forming process in which a nitroalkane reacts with an aldehyde or ketone in the presence of a base to form $\beta$-nitroalcohols (Scheme 2). ${ }^{115}$ If dehydration takes place the corresponding conjugated 
nitroalkenes are obtained (Henry condensation). Sometimes a side reaction can occur to afford the 1,3-dinitroalkane by a Michael addition of the starting nitroalkane to the nitroalkene product. Nitroaldol reactions may be catalyzed or promoted by inorganic or organic bases (tertiary amines, guanidines), quaternary ammonium salts or Lewis-acid type activators for the carbonyl group.

Another base-catalyzed process leading to the formation of $\mathrm{C}-\mathrm{C}$ bonds is the Michael reaction, which involves the nucleophilic conjugate addition of an in-situ generated carbanion (enolate of a ketone, aldehyde or active methylene compound) to an $\alpha, \beta$ unsaturated carbonyl compound (Scheme 2). An analogous 1,4-addition process to Michael acceptors can be extended to other nucleophiles, such as amines (aza-Michael) or the conjugate base of hydrogen peroxide (base-catalyzed nucleophilic epoxidation of alkenones) (Scheme 2).

On the other hand, a reaction of industrial interest is the cycloaddition of $\mathrm{CO}_{2}$ to epoxides to produce cyclic carbonates, which constitute the raw materials for polycarbonates (Scheme 2). The homogeneous process operates under organic or inorganic halides, such as tetraalkylammonium bromides or potassium iodide. The mechanism include nucleophilic opening of the oxirane ring by the halide. The Lewis acid countercation favours the reaction by enhancing the electrophilicity of the epoxide. Thus, a solid catalyst with both acidic and basic/nucleophilic characteristics should be effective for this cycloaddition. The ring opening reaction of glycidol with fatty acids is the most convenient procedure for the selective preparation of monoglycerides, useful industrial products with emulsifying and lubricating properties (Scheme 2). The reaction takes place under basic (amines, metal alcoholates or other stronger bases) or nucleophilic catalysis (ammonium salts).

The immobilization of organic bases/nucleophiles in a silica matrix enables not only an easy work-up and recovery of the catalysts in all the above-mentioned processes, but the support also provides an interesting synergistic effect in some cases (Figure 4). Moreover, some reactions, such as aldol-type Claisen-Schmidt and Henry condensations, can benefit from acid-base cooperativity provided by silica-based catalysts containing both isolated acid and basic groups. The acid sites will provide activation of the carbonyl electrophile and the basic sites will deprotonate the pre-nucleophile.

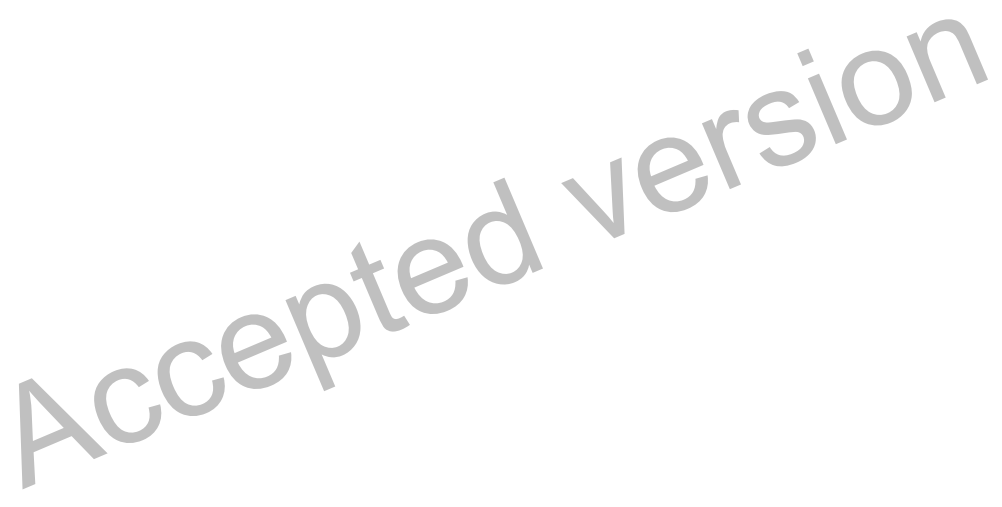




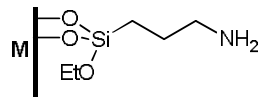

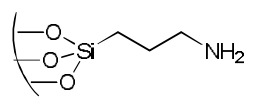
M8f (co-condensation, SBA-15 type material)
M8g (sol-gel co-condensation)
$\mathrm{M}=\mathrm{SiO}_{2}$ (M8a); MCM-41and MCM-48 (M8b, M8c), SBA-15 (M8d), MSN (M8e)
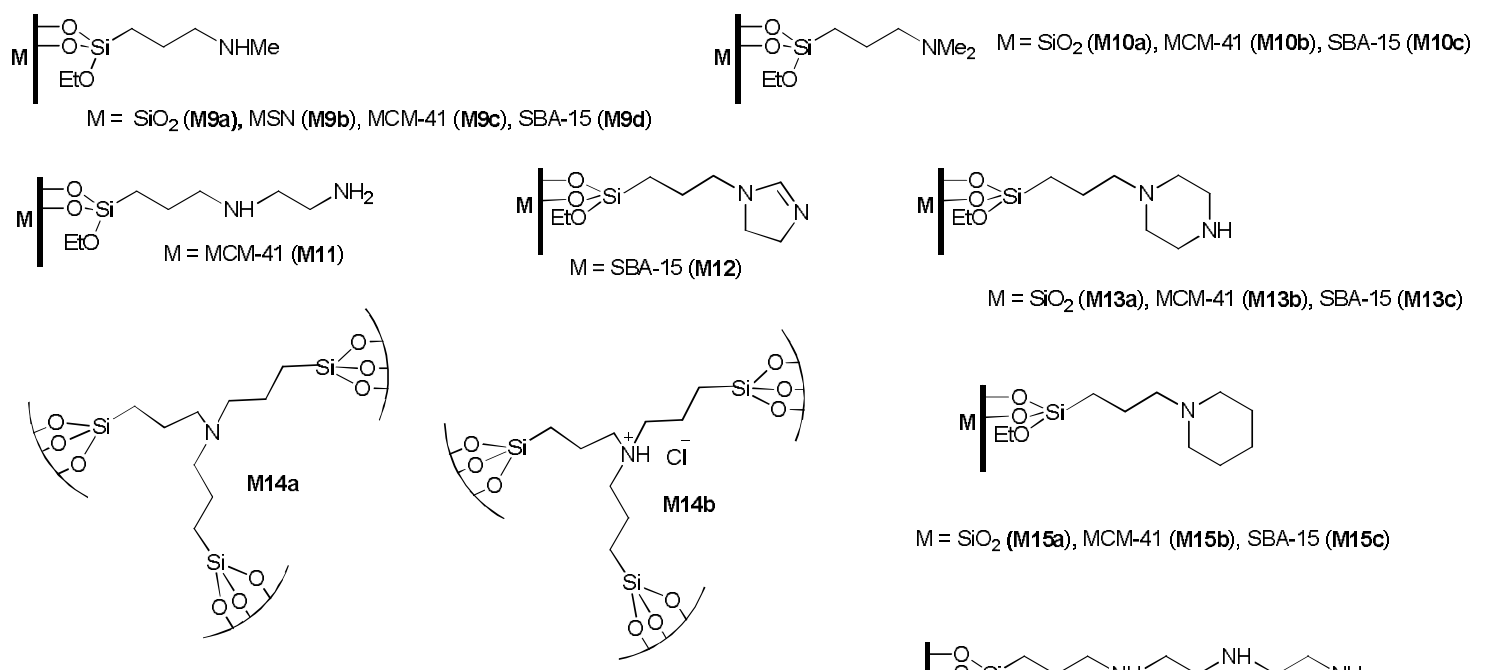

$M=\mathrm{SiO}_{2}(\mathrm{M} 13 \mathrm{a}), \mathrm{MCM}-41$ (M13b), SEA-15 (M13C)

竞

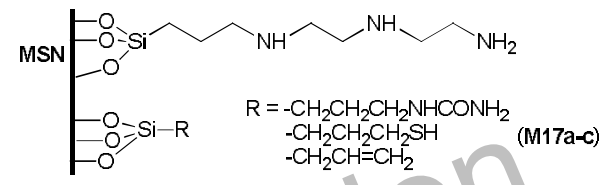

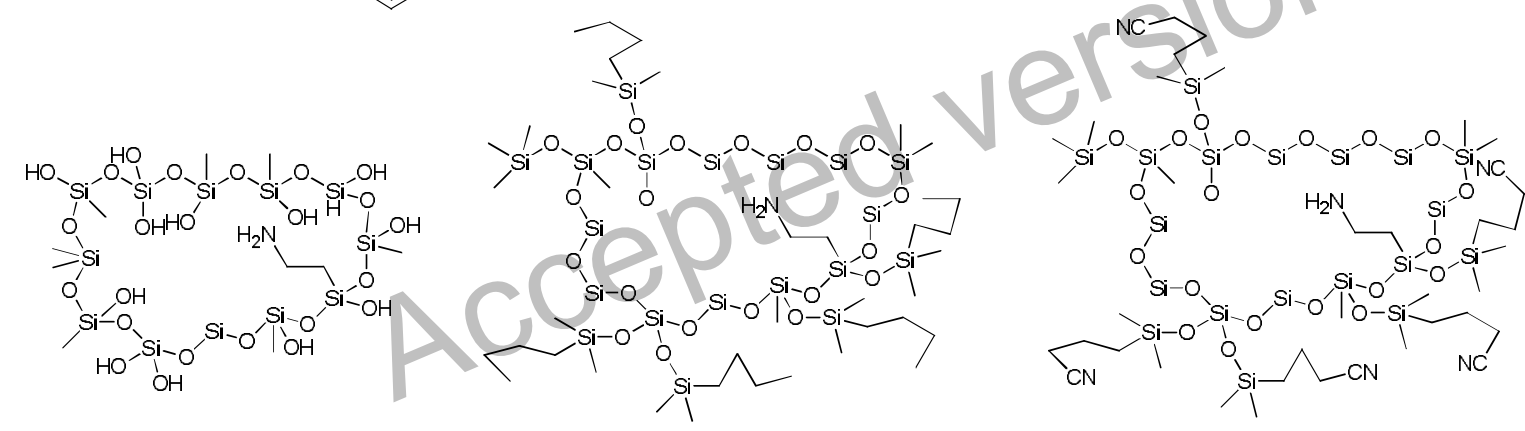

M18a

M18b

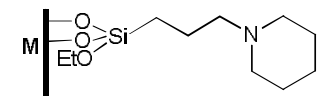

$\mathrm{M}=\mathrm{SiO}_{2}$ (M15a), MCM-41 (M15b), SBA-15 (M15c)

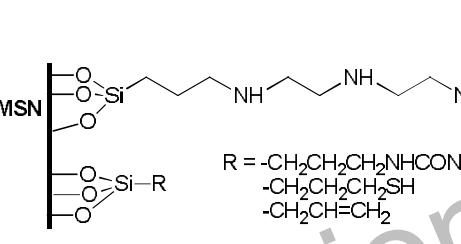


Thus, aminopropyl groups have been grafted on silica gel (M8a), ${ }^{93,116,117}$ on mesostructured MCM-type silicas (M8b, M8c), ${ }^{118,119}$ and on SBA-15 (M8d), ${ }^{94,120}$ whereas aminopropyl-functionalized mesoporous silica nanoparticles (M8e) ${ }^{121}$ and materials M8f $^{\mathbf{1 2 2}}$ and $\mathbf{M 8 g}{ }^{123}$ have also been obtained by co-condensation methods. Materials M8a-c and M8f have been used as supported catalysts for Knoevenagel condensation. Materials M8a, M8d and functionalized nanoparticles M8e promoted the aldol condensation between 4-nitrobenzaldehyde and acetone, and the authors studied the cooperative effect of the weakly acidic surface silanol groups and amine to explain the rate enhancement. ${ }^{94,117,120,121}$

A substrate inhibition was also observed in the aldol condensation with M8e that can be partially reduced by modifying the structure of the amine from primary (M8e) to secondary (M9b). ${ }^{121}$ In a step further, Jones prepared several silica-supported alkyl amines similar to M8d but with different length of the alkyl linker (from C1 to C5) attaching the amine to the silica surface, demonstrating that the linker length strongly affects the catalytic cooperativity in the aldol condensation. ${ }^{94}$ A related report on the cooperativity effects in the self-condensation of $n$-butanal has recently appeared, which involve silica-supported simple primary, secondary and tertiary amines (M8a, M9a, M10a). ${ }^{93}$ The xerogel M8g allowed the selective synthesis of $(E)$-nitrostyrenes from nitroalkanes and aromatic aldehydes by Henry condensation. ${ }^{123}$ Asefa has demonstrated an enhanced catalytic efficiency for the Henry condensation of an aminopropyl-derived MCM-41 material (M8b) which was prepared by post-grafting in a polar protic solvent (ethanol) at $78^{\circ} \mathrm{C}$ instead of using the classical grafting conditions (refluxing in toluene for a long reaction time). ${ }^{78}$ This effect was attributed to the spatially distributed and isolated organoamine and silanol groups present in the obtained material, which had a smaller number of organoamine moieties and more silanol groups than the more densely functionalized materials prepared under standard conditions. An extension of this study of cooperative catalysis in the nitroaldol condensation has been described by the same group through the synthesis of a series of organoamine-functionalized MCM-41 samples containing various densities of grafted linear monoamines, diamines and triamines and rigid substituted aromatic amines in different degrees of site isolation. ${ }^{124}$ This group also performed a similar study for aldol condensation with supported secondary amine M9c and other MCM-41 grafted amines. ${ }^{125}$ On the other hand, diamino-functionalised catalyst M11, prepared through anchoring of (3trimethoxysilylpropyl)ethylenediamine to MCM-41, has been reported for Knoevenagel and aldol condensations ${ }^{126}$ and also for Henry condensation, to afford selectively the nitroalkenes under mild conditions. ${ }^{127}$

Besides these simple amines, other basic compounds have also been heterogenized for catalytic purposes, such as dihydroimidazole functionalized SBA-15 (M12), which was obtained through co-condensation with N-(3-triethoxysilylpropyl)4,5-dihydroimidazole. ${ }^{122}$ In this case, acid-base cooperative catalysis involving weakly acidic silanol groups of the matrix has also been claimed. Commercial silica-immobilized piperazine M13a was used in aldol condensations of aromatic aldehydes with acetone and in the synthesis of coumarins by Knoevenagel reaction of diethyl malonate with salicylaldehyde followed by lactonization. ${ }^{128}$ Periodic mesoporous organosilicas (PMO) containing tertiary amine and ammonium substructures (M14a, M14b) have been found to act as recyclable organocatalysts in the Knoevenagel condensation, Henry reaction and ring opening of glycidol with lauric acid. ${ }^{70}$ Monoglyceride synthesis has also been performed by Brunel with MCM-41-functionalized silicas with primary and tertiary amino groups obtained by grafting (M8a and M15a). ${ }^{129}$ In this case, silylation of residual SiOH groups of the parent materials was found to improve the yields by avoiding the polymerization of the starting glycidol by these acidic groups. A Schiff base supported MCM-41 (M16) has recently been reported as an excellent recyclable catalyst for Knoevenagel condensations in water. ${ }^{130}$ It was prepared by reaction of APTES supported MCM-41 with 2-phenyl-2H-1,2,3-triazole-4carbaldehyde. In the tentative mechanism proposed by the authors the imine nitrogen atom acts as a base to deprotonate the malononitrile generating an iminium ion; after reaction of malononitrile enolate with the aldehyde, this iminium ion protonates the alkoxide intermediate, and the Schiff base is also involved in the subsequent dehydration.

It is worth to mention that the issue of selectivity in nitroaldol or Henry reaction catalyzed by silica-immobilized amines has been dealt by several authors. On one hand, Lin synthesized bifunctionalized mesoporous silica nanospheres containing a 3-[2-(2aminoethylamino)ethylamino]propyl group and three different secondary groups (ureidopropyl, mercaptopropyl and allyl) (M17ac) by co-condensation procedures. ${ }^{95}$ The results of competitive reactions between nitromethane and differently substituted aromatic aldehydes suggested that the hydrophobic secondary groups (mercaptopropyl and allyl) played a significant role in favoring the reaction with the more hydrophobic aldehydes as they penetrate preferentially into the mesopores. On the other hand, Katz has published an interesting study on acid-base bifunctional and dielectric outer-sphere effects in heterogeneous aminocatalysis for Henry, Knoevenagel and Michael reactions. ${ }^{131}$ He used a synthetic strategy based on bulk silica imprinting to prepare three materials M18a-c with different polarities and silanol contents. Co-condensation of (3-triethoxysilylpropyl)-tertbutylcarbamate with tetraethyl orthosilicate afforded a carbamate-containing hybrid silica which was thermally deprotected to generate a polar/acidic material M18a. By capping accessible silanol groups of the carbamate material with dimethyl butyl chlorosilane and cyanopropylchlorosilane and subsequent thermal deprotection, nonpolar/non acidic and polar/non acidic materials M18b and M18c were obtained, respectively. From the different selectivity found with these materials, he proposed that the Henry reaction may proceed via two mechanisms, namely, acid-base imine mechanism and ion-pair mechanism, each one giving rise to a different final product for this reaction. The first one involves the formation of an iminium ion from the aldehyde, the aminocatalyst and silanol groups, which would react as an enhanced electrophile towards the nitrocompound to give selectively the $\alpha, \beta$-unsaturated product. In the absence of outer-sphere acidity, an ion-pair mechanism is operating in which the aminocatalyst removes the proton of the nitrocompound to generate the enolate (ion-pair), which attacks the carbonyl group, the $\beta$-nitroalcohol being formed in this case. Shantz achieved high selectivity to the nitroalcohol addition product by grafting secondary and tertiary amines on the MCM-41 surface (M9c, M10b, M13b, M15b, M19), while the nitroalkene condensation product predominated for primary amines (M8b). Capping of surface silanol groups resulted in reduced activity of the materials, in a clear indication of their cooperative effect. ${ }^{132}$ Similar results had been described for the same reaction by Asefa, who proposed that while supported secondary amines M9c and M10b follow the ion-pair mechanism to yield $\beta$-nitroalcohols, primary amine functionalized material 
M8b preferentially follow imine mechanism to afford $\beta$-nitrostyrenes. ${ }^{133}$ In a step further, the same author has broadened the scope of the nitroaldol reaction for a variety of differently substituted benzaldehydes and he has shown an interesting substituentdependent selectivity. ${ }^{134}$ Thus, for the secondary amines M9c the outcome of the reaction was found to be dependent on the nature of the substituent of the aldehyde reactant. Whereas electron-donating substituents stabilize the imine intermediate and favor the formation of the condensation product, electron-withdrawing substituents facilitate the ion-pair mechanism, favoring the addition product. $^{134}$

Task-specific basic ionic liquids (TSILs) immobilized on MCM-41 and SBA-15 (M20a and M20b) have also been described for the Knoevenagel reaction in aqueous medium. ${ }^{135} \mathrm{~N}$-(3-aminopropyl), N(3)-(3-triethoxysilylpropyl)-4,5-dihydroimidazolium bromide hydrobromide was grafted onto the corresponding mesoporous silica and then the protonated amines were neutralized in the materials. Although the primary amino groups constitute the true catalytic species, the authors have found much better reusability in comparison with the amino-functionalized mesoporous silica lacking the dihydroimidazolium moiety. Moreover, the supported basic TSILs showed better catalytic performance as compared with a non-supported basic TSIL, which has been ascribed to the depressed reaction between the amine groups and the acidic hydrogen at C-2 of the dihydroimidazolium cation in the supported TSIL and to acid-basic cooperativity between the silanol groups of the support and amine groups. ${ }^{135}$

Post-synthetic modification of SBA-15 with thiols, followed by a thiol-ene click reaction using 2,4,6-triallyloxy-1,3,5-triazine has afforded M21, which catalyzed the one-pot three-component condensation of aromatic aldehydes, malononitrile and activated phenols for the synthesis of 2-amino-4H-chromenes. ${ }^{136}$ Non-covalently silica-supported 2,4,6-trichloro-1,3,5-triazine (Silica-TCT) (M22) catalyzes Hantzsch multicomponent preparation of 1,4-dihydropyridines from aromatic aldehydes, 1,3-dicarbonyl compounds and ammonium acetate. ${ }^{137}$ Material $\mathbf{M 2 3}$ has recently been obtained by immobilization of 1,4diazabicyclo[2.2.0] octane (DABCO) over SBA-15 via grafting procedures and it has been used for the synthesis of biologically active functionalized spirochromenes via three-component reaction of isatins, activated methylene reagents and 1,3-dicarbonyl compounds. $^{138}$

The heterogenized Brönsted base catalyst $\mathbf{M 2 4}$ has been obtained by Corma by anchoring tetraalkylammonium hydroxide on the surface of MCM-41. It was found active and selective for carrying out Knoevenagel and aldol condensation as well as Michael additions, and was applied for the selective synthesis of chromenes and coumarins. ${ }^{139}$

Silica-supported stronger and hindered amine bases such as 1,8-bis(dimethylaminonaphthalene) (DMAN) and 1,5,7triazabicyclo[4.4.0]dec-5-ene (TBD) (proton sponges) have also been described. Corma grafted DMAN onto amorphous silica and MCM-41 by using the monosilylated derivative 4-[(triethoxysilyl)propylaminocarbonylamino]-1,8-bis(dimethylamino)naphthalene $(\mathbf{M 2 5 a}, \mathbf{b})$ and the synergistic effect of the support by cooperative acid-base catalysis was also pointed out for the Knoevenagel condensation and Claisen-Schmidt synthesis of chalcones and flavanones. ${ }^{140}$ Guanidine bases were covalently tethered to MCM41 by Jacobs's group. ${ }^{141}$ They reacted the surface silanol groups with (3-trimethoxysilylpropoxy)methyloxirane and the resulting glycidylated MCM-41 was treated with excess of TBD to afford M26a. This heterogenized base was used as a catalyst for Knoevenagel condensations; Michael reactions and nucleophilic epoxidations of alkenones with $\mathrm{H}_{2} \mathrm{O}_{2}{ }^{141} \mathrm{The}$ same MCM-TBD material M26a was applied by Jaenicke as catalyst for the reaction of glycidol with lauric acid and the preparation of jasminaldehyde through the aldol condensation of heptaldehyde with benzaldehyde under continuous flow conditions. ${ }^{142}$ Sartori performed a continuous-flow two-step process by combining sequentially two column reactors, the first one packed with a silica gel-supported primary amine (M8a) to promote a nitroaldol condensation, and the second one consisting of a silica gel-supported TBD (M26b) to consequently catalyze the Michael addition of $\beta$-dicarbonyl compounds to the nitrostyrenes obtained in the previous step. ${ }^{143}$ Biguanide-functionalized $\mathrm{Fe}_{3} \mathrm{O}_{4} / \mathrm{SiO}_{2}$ nanoparticles (M27) with a core-shell structure were prepared through the covalent attachment of metformin to the chloropropylgrafted magnetic nanoparticles and they were evaluated in three-component processes, i.e. domino Knoevenagel condensation/Michael addition/cyclization reaction for the preparation of chromenes and tetrahydrobenzo[b]pyrans. ${ }^{144}$

\subsubsection{IONIC ORGANOSILICAS}

It is worth noting that also non-basic (dihydro)imidazolium-containing organosilicas have been reported as recyclable catalysts for the Knoevenagel reaction of aromatic aldehydes with malononitrile and ethyl cyanoacetate under neat conditions. Materials M28ab and M29a-b (Figure 5) bearing imidazolium and dihydroimidazolium salts in different dilutions were prepared using templatebased sol-gel methodologies. ${ }^{64}$ The experiments suggested a certain degree of cooperativity between the surface of the matrix and the active sites and underlined the crucial role of the (dihydro)imidazolium salt. In these cases no basic catalysis can be claimed. Speculations have been drawn from the relatively high acidity of the proton at the C-2 position of the heterocyclic ring, which could be on the origin of the catalysis through the activation of both the electrophile and the active methylene compound by hydrogen bond formation with the carbonyl group of the aldehyde and the cyano and/or ester group of the prenucleophile. Like in classical acid-catalyzed aldol-type reactions the process would take place through an "enol-type" intermediate. However, an alternative catalytic nucleophilic pathway involving halide anion cannot be discarded, ${ }^{145}$ as its nucleophilicity is enhanced due to the presence of soft countercation. Other examples for the same reaction include an imidazolium-functionalized SBA-15-type material M30a prepared by co-condensation with TEOS ${ }^{146}$ and a related material M30b obtained by co-condensation of the same monomer with TEOS under acidic conditions without template assistance (Figure 5). ${ }^{147}$ 

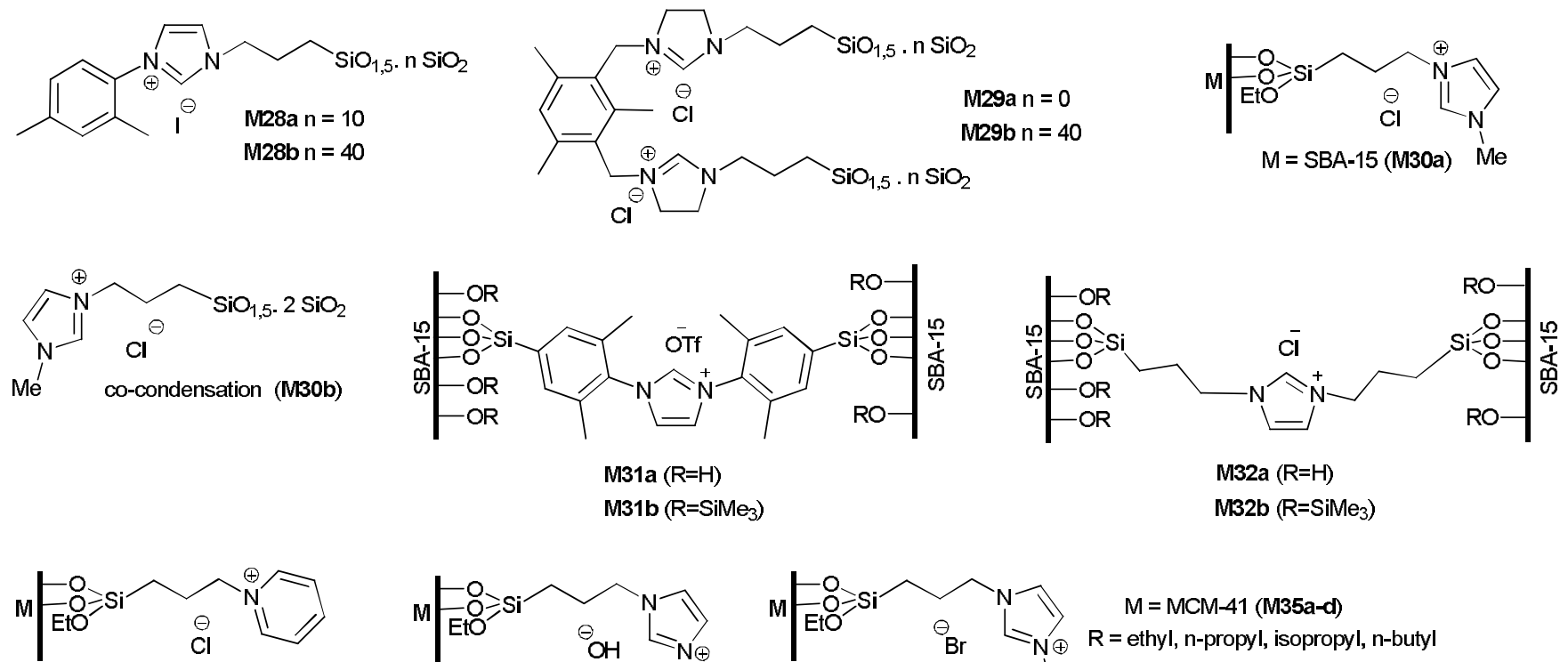

$M=S B A-15(M 33)$
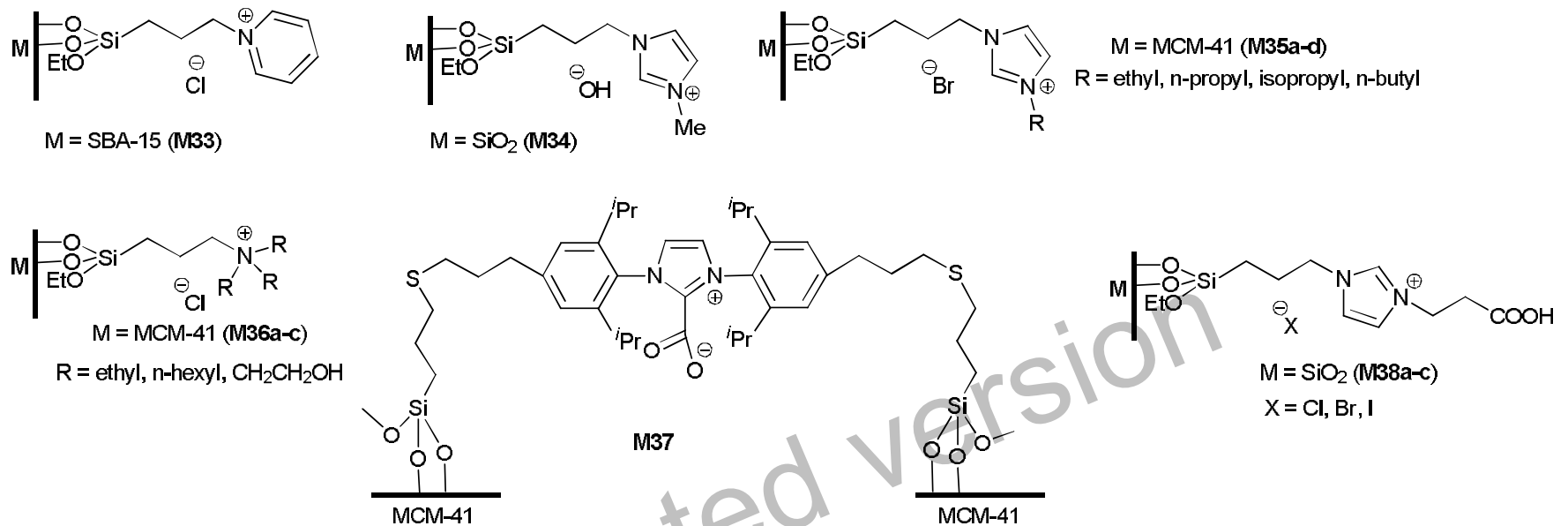

$\mathrm{R}=$ ethyl, n-hexyl, $\mathrm{CH}_{2} \mathrm{CH}_{2} \mathrm{OH}$

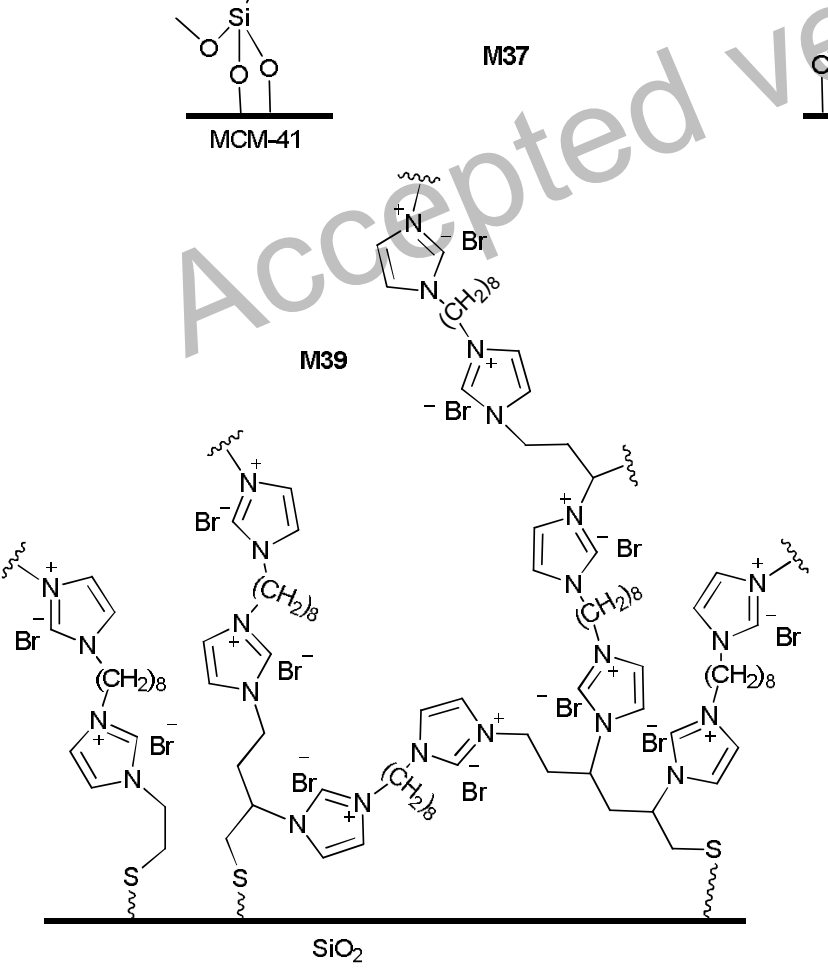

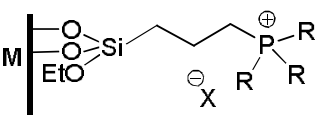

$\mathrm{M}=\mathrm{SiO}_{2}(\mathrm{M} 40 \mathrm{a}-\mathrm{d})$

$\mathrm{R}=$ ethyl, $\mathrm{X}=\mathrm{Cl}$

$\mathrm{R}=\mathrm{n}$-butyl, $\mathrm{X}=\mathrm{Cl}, \mathrm{Br}$, I

Figure 5. Ionic organosilicas as nucleophilic organocatalysts

Hesemann and Thomas reported the synthesis of SBA-type silica bearing imidazolium moieties (M31a-b and M32a-b) by postsynthesis grafting reactions using bis-silylated imidazolium precursors (Figure 5). ${ }^{92}$ These materials were found efficient and reusable heterogeneous organocatalysts for Henry reactions leading to $\beta$-nitroalcohols and for the cycloaddition of carbon dioxide to epichlorohydrin. In the case of Henry reaction a passivation of the materials was required for high catalytic activity.

Other ionic organosilicas have been described for the conversion of $\mathrm{CO}_{2}$ and epoxides into cyclic carbonates. Thus, M30a and M33 (Figure 5) bearing imidazolium and pyridinium moieties, respectively, tethered to the surface of SBA-15 by grafting 
procedures were used for the preparation of propylene carbonate from $\mathrm{CO}_{2}$ and propylene oxide. ${ }^{148}$ Additionally, M30a exhibited high catalytic activity for aza-Michael addition of amines to $\alpha, \beta$-unsaturated carbonyl compounds and the Biginelli reaction of aldehydes, ethyl acetoacetate and urea. ${ }^{148}$ A silica-grafted imidazolium hydroxide (M34) (Figure 5) ${ }^{149}$ and imidazolium functionalized MCM-41 type materials (M35a-d) (Figure 5) ${ }^{150}$ have also been reported for the cycloaddition of $\mathrm{CO}_{2}$ to epoxides. The materials M35a-d were synthesized via a template-directed co-condensation of TEOS with (3-chloropropyl)triethoxysilane, followed by reaction of the resulting mesostructured material with imidazole and subsequent alkylation with alkyl bromides. The same group applied a similar methodology to anchor quaternary ammonium salts to a mesostructured silica matrix (M36a-c) (Figure 5) for the cycloaddition of $\mathrm{CO}_{2}$ to allyl glycidyl ether. ${ }^{151} \mathrm{Lu}$ prepared a $\mathrm{CO}_{2}$ adduct of a $N$-heterocyclic carbene (NHC) functionalized MCM-41 (M37) (Figure 5) by reacting 1,3-bis-(4-allyl-2,6-diisopropylphenyl)imidazolium chloride with MPTMS, subsequent grafting of the resulting bis-silylated compound to MCM-41, deprotonation of the acidic proton of the imidazolium moiety with a strong base and trapping the formed carbene intermediate with $\mathrm{CO}_{2}{ }^{152}$ The reversible $\mathrm{CO}_{2}$ capture-release ability of this MCM-41-NHC was investigated by in situ diffuse reflectance infrared Fourier transform spectroscopy (DRIFTS). This material $\mathbf{M 3 7}$ proved to be an efficient recyclable heterogeneous catalyst for the regioselective cycloaddition of $\mathrm{CO}_{2}$ to epoxides and aziridines. The proposed mechanism involves nucleophilic attack of the carboxylate group of the zwitterionic moiety to the strained three-membered heterocyclic rings to generate a new zwitterionic species. Then the oxy or nitrogen anions formed in this first step perform an intramolecular nucleophilic attack to the carbonyl group, yielding the cyclic carbonates or oxazolidinones and the MCM-41-NHC intermediate, which quickly reacts with $\mathrm{CO}_{2}$ to regenerate the initial adduct M37. ${ }^{152}$ Imidazolium salts containing carboxyl acid moieties were grafted onto silica gel (M38a-c) (Figure 5) and tested as catalysts in the cycloaddition of $\mathrm{CO}_{2}$ to epoxides. ${ }^{153}$ In this case, the hydrogen bond donor carboxylic acid group was demonstrated to have a synergistic effect with halide anions, as it activates the epoxide ring towards the nucleophilic attack of the halide anion. Pescarmona has recently synthesized multilayered covalently supported ionic-liquid phase (mlc-SILP) materials (M39 as an example in Figure 5) by grafting bis-vinylimidazolium salts on thiol-functionalized silica gel via a click reaction under radical conditions, with concomitant cross-linking between the bis-vinylimidazolium units to form an oligomeric network. ${ }^{154}$ These materials were active as heterogeneous catalysts for the reaction of $\mathrm{CO}_{2}$ with various epoxides. The effect of the lengthening of the organic linker and the nature of the halide counterion has been studied, as the halide anion initiates the catalytic reaction by nucleophilic opening of the oxirane ring.

Also the guanidine-based catalyst MCM-41-TBD (M26a) (Figure 4) ${ }^{155}$ and phosphonium salts immobilized onto silica (M40a-d) (Figure 5) ${ }^{156}$ have been used in the cycloaddition reaction of $\mathrm{CO}_{2}$ to oxiranes. In the first case, the authors hypothesize that the hydroxyl group present on the material M26a would activate the epoxide ring, by hydrogen-bond formation, towards the nucleophilic attack of a zwitterionic species formed from $\mathrm{CO}_{2}$ and TBD basic moiety. In the second case, the activity of the heterogenized phosphonium salts is greatly enhanced with respect to that of the homogeneous catalysts, which is attributed to a synergistic effect of the silica matrix. Thus, the surface silanol groups would activate the epoxide ring towards the nucleophilic attack of the halide anion.

\subsubsection{BIFUNCTIONAL ORGANOSILICAS}

Mimicking the enzymatic catalysis, cooperative interactions of acidic and basic sites placed on the same catalytic system have also been investigated to perform some carbon-carbon bond-forming processes, such as aldol or nitroaldol reactions, by simultaneous dual activation of both the electrophile and the nucleophile. Moreover, some one-pot cascade reactions requiring acid and basic catalysis in a sequential manner can also be promoted with such type of catalysts (for instance a deacetalization followed by aldoltype reaction). As the acidic and basic components would interact in homogeneous systems leading to inactive salts, their immobilization in solid matrices has been envisaged to enable these groups to co-exist and function in the same reaction mixture. However, this is a challenging task as the positioning of these groups in the support should be precisely tuned to prevent the undesired complete acid-base neutralization and to optimize the cooperative effect.

Moreover, it should be taken into account that the spatially isolating requirements of the two groups would be not the same for sequential cascade reactions than for the cooperative acid-base reactions. Some acid-base bifunctional reusable heterogeneous catalysts (Figure 6) have been described by the group of Iwasawa in which the Brönsted acidic function is provided by the amorphous acidic silica-alumina (SA) support surface $\left(\mathrm{SiO}\left(\mathrm{H}^{+}\right) \mathrm{Al}\right)$ and the basic groups are grafted primary and tertiary amines (materials M41a and M42). ${ }^{157}$ Whereas primary supported amine M41a efficiently catalyzed the nitroaldol reaction of nitroalkanes with aldehydes (presumably through the formation of an imine intermediate), the immobilized tertiary amine base M42 promoted the Michael reaction of $\alpha$-substituted ethyl cyanoacetates with electron-deficient alkenes and the cyanoethoxycarbonylation of aldehydes and ketones with ethyl cyanoformate. IR studies revealed that the interaction between the immobilized $\mathrm{NEt}_{2}$ groups and the acidic sites on the SA surface were much weaker than the direct interaction between the free amines and the same acidic SA surface. Mechanistic proposals for all the reactions are given involving the dual activation of the donor and acceptor substrates on the SA surface. In a step further, this author has reported a heterogeneous combined tertiary and primary amine catalyst immobilized on acidic silica-alumina (M43) ${ }^{158}$ for the efficient and selective one-pot synthesis of 1,3 dinitroalkanes under very mild conditions. The transformation proceeds through a Henry condensation followed by a Michael addition of a second molecule of nitroalkane to the resulting nitroalkene intermediate. As the supported single amines and the corresponding amines in solution exhibited almost no significant activity in this reaction, the effect of this multifunctional catalyst M43 is clearly evidenced in the promotion of this one-pot reaction sequence. A cooperative reaction mechanism has been proposed. 

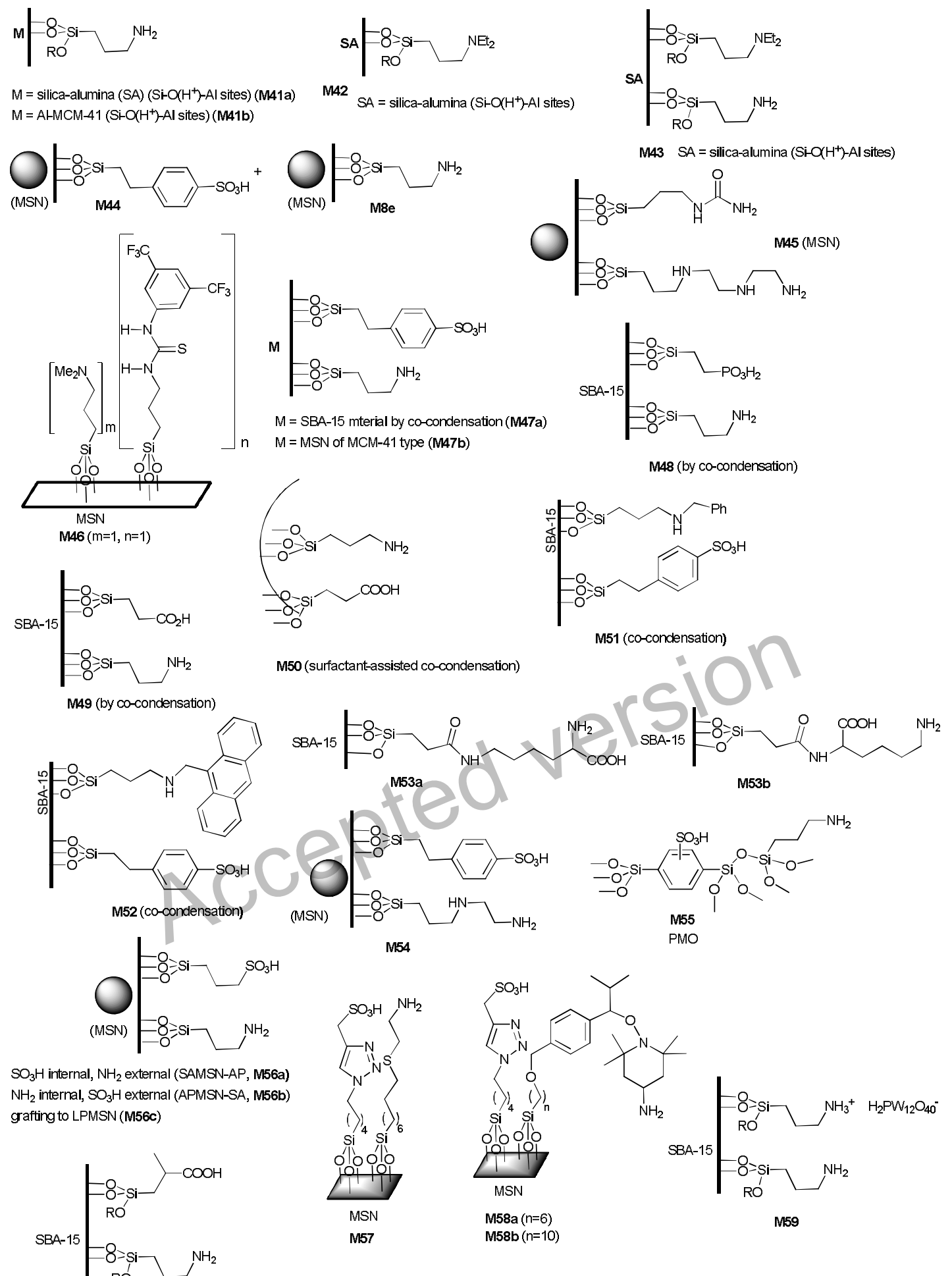

$\mathrm{SO}_{3} \mathrm{H}$ internal, $\mathrm{NH}_{2}$ external (SAMSN-AP, M56a) $\mathrm{NH}_{2}$ internal, $\mathrm{SO}_{3} \mathrm{H}$ external (AFMSN-SA, M56b) grafting to LPMSN (M56c)

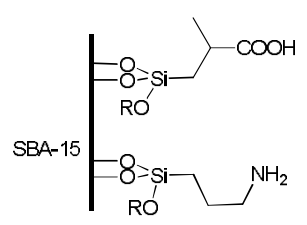

M60a(by grafting)

M60b (by co-condensation)

Figure 6. Silica-supported bifunctional organocatalysts containing acid and basic sites

The same group has found that the interaction between surface acidic sites and basic amine groups in M42 can be controlled by the pretreatment temperature of the SA before grafting. The amine-acid interactions, estimated by variable-contact-time-array measurements on solid state ${ }^{13} \mathrm{C}$ CP-MAS NMR spectroscopy, strongly affected the catalytic performances of the thermally treated materials for 1,4-addition reactions of nitroalkanes and thiols to various electron-deficient alkenes. ${ }^{159}$ Thiel has also reported amine-functionalized moderately acidic mesostructured alumino-silicates M41b, prepared by grafting APTMS) on Al-MCM-41 in 
refluxing ethanol, as efficient and reusable catalysts for the nitroaldol condensation between aromatic aldehydes and nitromethane. ${ }^{160}$

On the other hand, the compatibility and catalytic efficiency of physical mixtures of two materials based on mesoporous silica nanoparticles (MSN) containing confined bases (M8e) and acids (M44) inside the MCM-41 type porous channels has been demonstrated in a one-pot cascade process involving acid-catalyzed deprotection of 4-nitrobenzaldehyde dimethyl acetal followed by a base-catalyzed Henry condensation in nitromethane to generate the corresponding nitroalkene. ${ }^{161}$ Both materials have been synthesized via co-condensation of TEOS and the corresponding organosilane, (2-(4-chlorosulfonylphenyl)ethyltrimethoxysilane or APTMS, in the presence of cetyltrimethylammonium bromide (CTAB) as template under basic conditions.

However, besides these monofunctionalized acidic silica-alumina derivatives, several groups have focused on bifunctionalized silica-based materials incorporating both acid and basic groups for cooperative catalysis, taking care of the control of the relative concentrations and the proper spatial arrangements between the functional groups. Lin demonstrated that a general acid group such as ureidopropyl can activate carbonyl electrophiles, through double hydrogen bonding, in cooperation with a general base group

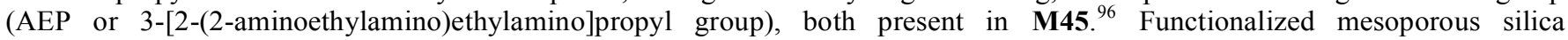
nanospheres (MSN) M45 were synthesized by a similar co-condensation procedure under basic conditions and with a cationic template, as described in the previous example of the same group, but with the sequential addition, in this case, of the two required organosilanes, 3-[2-(2-aminoethylamino)ethylamino]propyltrimethoxysilane and ureidopropyltrimethoxysilane. Then, M45 was successfully employed as a reusable catalyst for three model reactions with $p$-nitrobenzaldehyde as common electrophile, namely the aldol condensation with acetone leading to mixtures of aldol and alkene, the Henry condensation with nitromethane and the cyanosilylation reaction with trimethylsilyl cyanide. In these reactions, the secondary amines of the AEP group are responsible for the enamine formation with acetone (aldol reaction), the deprotonation of nitromethane (Henry reaction) and the generation of a potential nucleophile from trimethylsilyl cyanide through hypervalent silicate formation (cyanosilylation). ${ }^{96}$

Bifunctional MSN carrying tertiary amine and thiourea residues (M46) have also been reported by Benaglia. ${ }^{97}$ The recyclable catalyst M46, prepared by the co-condensation method, has been tested in the conjugate addition of acetylacetone to 2nitrostyrene. The tertiary amine deprotonates the donor nucleophile and the thiourea function activates the electrophile by double hydrogen bonding to the nitro group. The use of this catalyst has been extended to the addition of acetylacetone to $\mathrm{N}$-Cbzbenzaldimine.

Moreover, the dual-functionalized acid-base SBA-15 type material M47a was prepared by the usual template assisted cocondensation of TEOS with 2-(4-chlorosulfonylphenyl)ethyltrimethoxysilane and APTMS under acidic conditions. It was tested in the aldol reaction of $p$-nitrobenzaldehyde with acetone giving mixtures of the aldol and dehydration products, non polar aprotic solvents giving the best conversions. ${ }^{162}$ The acid and basic groups in the support would be in equilibrium between the free acid and base and the ion pair that results from neutralization, an equilibrium that would be more shifted to the free species in non polar aprotic solvents than in polar aprotic and polar protic solvents. The same group investigated this equilibrium between the active species and the inactive ion-pair by varying the pKa of the acid group. ${ }^{163}$ Thus, they compared the efficiencies of M47a with those of M48 and M49 SBA-15 co-condensation type materials for the same aldol reaction. They observed that the conversion increased significantly with decreasing acid strength (62\% for sulfonic acid/amine, $78 \%$ for phosphoric acid/amine, $100 \%$ for carboxylic acid/amine). Then, the aldehyde substrate scope for the best material M49 was explored. ${ }^{163}$

Aldol reactions between aromatic aldehydes and ketones were also studied by the group of Solin under catalysis by bi-functional mesoporous silica materials M50 containing both carboxylic and amino groups. ${ }^{164}$ Several mesoporous silicas M50 with highly ordered mesopores were synthesized via the cooperative self-assembly of surfactants (gemini cationic, anionic or mixtures of both), co-structure-directing agents (which are the precursors carboxyethylsilanetriol sodium salt and APTES) and TEOS as the silica source, following the procedure described by Che. ${ }^{165}$

The aldol reaction of $p$-nitrobenzaldehyde with acetone has again been used as model reaction by Kan and coworkers to study the effect of the steric hindrance in the control and prevention of the interaction between sulfonic acid and secondary amine moieties in bi-functional SBA-15 type materials M51 and M52, ${ }^{166}$ M52 showing a higher catalytic performance (94 vs $80 \%$ conversion). These materials were synthesized by a direct synthesis method from the corresponding silylated secondary amines and sulfonyl chloride. Later on, the same group has also chosen the aldol reaction to investigate the effect of the distance between acidic $\mathrm{COOH}$ sites and basic $\mathrm{NH}_{2}$ sites in a silica material on the catalytic cooperative activity. To this aim, they coupled different amine groups of conveniently protected lysine derivatives ( $\varepsilon$ - or $\alpha-\mathrm{NH}_{2}$ groups) with the activated carboxyl group of carboxyethyl-functionalized SBA-15 to generate the amides M53a and M53b after deprotection. They found that M53a (shorter acid-base distance) was more active than M53b (larger acid-base distance). ${ }^{167}$

Bifunctionalized MSN of MCM-41 type possessing sulfonic and amino groups (M47b and M54) have also been developed by Thiel via co-condensation method ${ }^{168}$ and evaluated in Henry condensation, one-pot deacetalization-nitroaldol condensation and one-pot deacetalization-aldol condensation. The authors emphasized the higher performance of bifunctionalized catalysts in Henry reaction with respect to monofunctionalized samples containing only primary amines and physical mixtures of acid and base heterogeneous catalysts. They demonstrated the cooperative effect between the amine groups and both $\mathrm{SO}_{3} \mathrm{H}$ and acidic silanol groups. The mechanism suggested for this reaction involves a dual activation of nucleophiles and electrophiles at the amine base sites and the neighboring acid sites. The organic acids and bases must be in close proximity for a catalytic enhancement. On the other hand, the one-pot cascade processes involve a tandem action of the bifunctionalized catalysts in two consecutive separate reactions: acid catalyzed deacetalization and base catalyzed aldol-type reaction, the presence of both groups in the materials being necessary for obtaining the tandem product. ${ }^{168}$

The same group has reported the successful cohabitation of two antagonistic functional groups in a periodic mesoporous organosilica $\mathbf{M 5 5}$ by locating the acidic $\mathrm{SO}_{3} \mathrm{H}$ groups in the hydrophobic framework walls and the basic $\mathrm{NH}_{2}$ groups directed into the channel pores of hydrophilic silica layers. ${ }^{169}$ M55 was synthesized by a sequence involving hydrolysis of 1 ,4bis(triethoxysilyl)benzene and APTMS in the presence of CTAB as a cationic surfactant, protection of the amino groups in the 
synthesized PMO- $\mathrm{NH}_{2}$ with di-tert-butyl dicarbonate, sulfonation of the aromatic ring by treatment with chlorosulfonic acid and final thermal deprotection of the amino groups. The accessibility of both groups in $\mathbf{M 5 5}$ was evaluated in the tandem process consisting in acid deprotection of benzaldehyde dimethyl acetal and subsequent base-catalyzed Henry condensation with nitromethane, achieving good conversions and recyclability of the material up to three runs.

Another approach to favor the coexistence of the acid $\mathrm{SO}_{3} \mathrm{H}$ groups and basic $\mathrm{NH}_{2}$ groups by site-separation within the same material has been developed by Lin by selectively attaching them on the external and internal surface of mesoporous silica nanoparticles (M56a, M56b). ${ }^{170}$ Material M56a (ASMSN-AP) was synthesized by co-condensation of TEOS and MPTMS in the presence of CTAB as template under basic conditions, post-synthesis grafting (without template removal) of APTMS onto the external surface, oxidation of mercapto groups to sulfonic acid and final template removal. Material M56b (APMSN-SA) was obtained by a similar procedure by changing the order of steps. Both immobilized bifunctional catalysts showed good activities and recyclabilities in the one-pot reaction sequence involving the hydrolysis of dimethyl acetal of $p$-nitrobenzaldehyde and subsequent Henry condensation with nitromethane. ${ }^{170}$

Silica nanoparticles with large mesopores have been functionalized with acid and basic groups by grafting procedures (M56c) and then used as cooperative heterogeneous catalysts for one-pot conversion of cellulose to 5-hydroxymethylfurfural. ${ }^{171}$

Eckert and Studer used thiol-ene reaction, $\mathrm{Cu}$-catalyzed alkyne-azide cycloaddition and a radical nitroxide exchange reaction as orthogonal processes to incorporate sulfonic acid and amino groups on the surface of mesoporous silica nanoparticles (MSN) containing orthogonally adressable functionalities. Following this approach, several materials were prepared and tested; among them M57, M58a and M58b were successfully applied to the Henry reaction of nitromethane with benzaldehyde to give trans- $\beta$ nitrostyrene. ${ }^{99}$ From this study, it was shown that the length of the linker between the inorganic host material and the two catalytically active organic functions has to be carefully adjusted to avoid acid/base quenching. Particles containing only the amino functionality showed lower activities, revealing the importance of cooperative catalysis.

Rothenberg has combined amine base functions and heteropolyacid functions by grafting (3-aminogropyl) groups on SBA-15 support and subsequent treatment with a methanolic solution of phosphotungstic acid. By controlling the ratio of immobilized heteropolyacids and aminopropyl tethers, only part of the amino groups were reacted to afford M59. ${ }^{172}$ This was found to be an efficient and robust bifunctional acid-base solid catalyst for one-pot cooperative catalysis (deacetalization-Knoevenagel condensation and deacetalization-Henry condensation).

Jones has recently investigated the impact of grafting and co-condensation synthesis methods on the cooperative catalytic properties of acid-base bifunctional SBA-15 type materials M60a and M60b for the aldol condensation of $p$-nitrobenzaldehyde with acetone. ${ }^{173}$

Interesting review articles covering also the topic of acid-base cooperativity on silica-based organocatalysts have been published. ${ }^{174-176}$

\subsection{Supported chiral amines for enamine activation}

The explosive growth of organocatalysis on the last 15 years has been due to the development and efficient application of a wide range of small chiral organic molecules that have led to the stereoselective synthesis of enantiomerically enriched compounds (asymmetric organocatalysis). One of the general mechanisms in asymmetric organocatalysis is the enamine activation for nucleophilic catalysis. It occurs when a chiral secondary amine (e.g. proline) interacts with a carbonyl substrate with $\alpha$-enolizable protons to form a nucleophilic enamine intermediate (the energy of the HOMO of the nucleophile is increased). Simultaneously, the catalyst activates the electrophile through hydrogen bond. This mechanism can operate in intermolecular direct aldol reactions between ketones (acetone, cyclohexanone, cyclopentanone, hydroxyacetone) and aromatic aldehydes.

\subsubsection{SUPPORTED PROLINES}

The accepted mechanism for the intermolecular proline-catalyzed direct asymmetric aldol reaction mimics that of class I aldolase enzymes and begins with the rate-limiting enamine formation (A) from the ketone donor, followed by the addition of this nucleophile to the carbonyl of the acceptor aldehyde, which is activated by the carboxylic acid of proline (B); then the resulting iminium ion $\mathrm{C}$ is hydrolyzed to give the aldol adduct and the regenerated organocatalyst (Scheme 3 ). ${ }^{10}$ Efforts have been devoted by different groups to silica-immobilization of L-proline derivatives as recyclable organocatalysts for direct aldol reaction (M61 to M73 in Figure 7). 


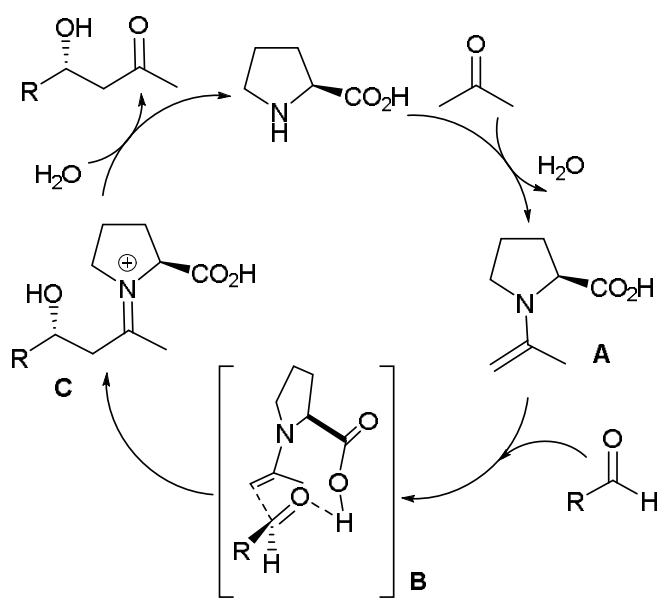

Scheme 3. Enamine activation pathway in the intermolecular proline-catalyzed asymmetric aldol reaction between a ketone and an aldehyde. 


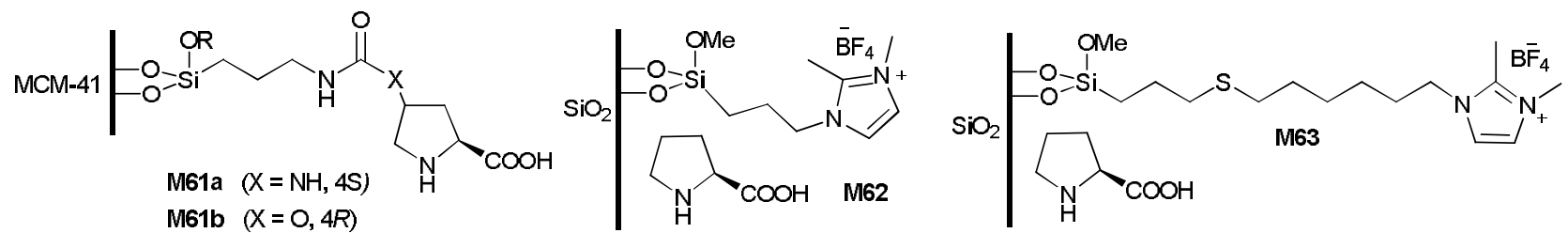

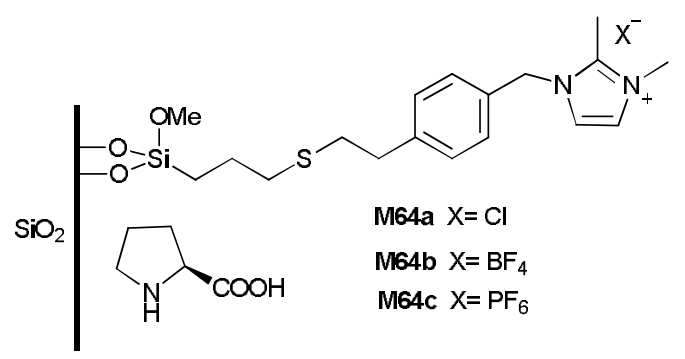<smiles>CCO[Si](CCCNC(=O)CCCC(=O)NC1CNC(C(=O)O)C1)(OC)OC(C)(C)C</smiles><smiles>[Y]CCCN1C=CN(CC)[Y]1CC</smiles><smiles></smiles>

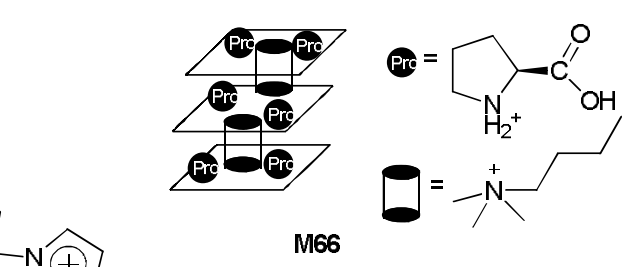<smiles>CCO[Si](CCCNC(=O)CCCC(=O)NC1CNC(C(=O)NC2CNC(C(=O)O)C2)C1)(OC(C)(C)C)OC(C)(C)C(C)(C)C(C)(C)C</smiles>
$\ominus$

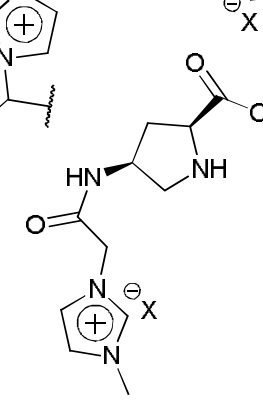

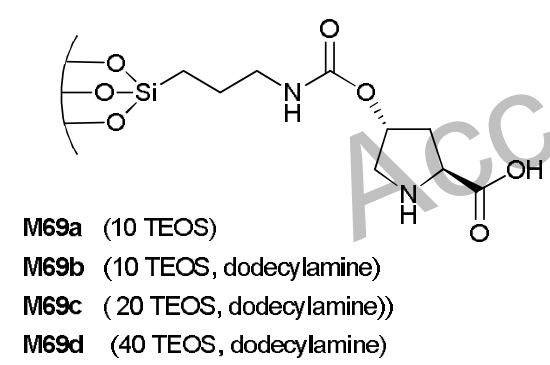

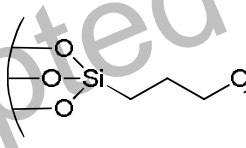

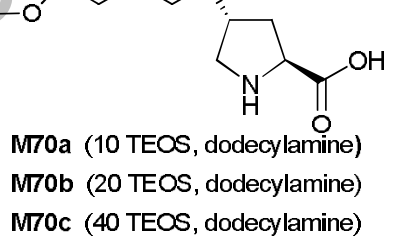<smiles>O=C(O)C1C[C@H](OCCCSCCC[Si]23CCC(C[SeH2+])(O2)O3)CN1</smiles>

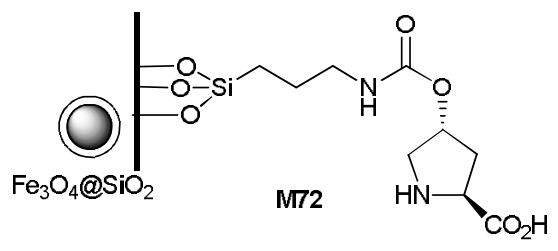

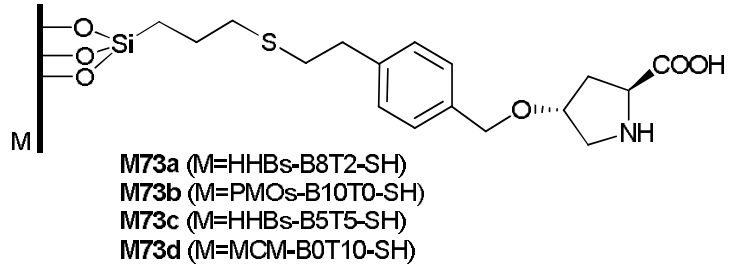

Figure 7. Silica-supported functionalized prolines for asymmetric direct aldol reaction via enamine pathway

In pioneering works, Fernández-Mayoralas heterogenized (S)-proline on mesoporous support MCM-41 by a grafting procedure to obtain M61 ${ }^{53}$ and M61b. ${ }^{177}$ In both cases, they started from protected $(2 S, 4 R)$-4-hydroxyproline to obtain the required silylated compounds. In the case of M61a the hydroxy group was replaced by an amino group by a sequence involving tosylation, nucleophilic substitution with sodium azide and reduction of the azide group by hydrogenation. The amino and hydroxyl groups of the protected prolines were reacted with (3-triethoxysilylpropyl)isocyanate to afford the desired silylated urea and carbamate derivatives, respectively, which were deprotected and grafted.

On the other hand, non-covalently anchored proline-based materials M62, M63 and M64a-c were prepared by Gruttadauria's group by adsorption of L-proline onto the surface of imidazolium-modified silica gels bearing three different linkers. ${ }^{178}$ The silica matrix for M62 was obtained by direct condensation between silica gel and 1-(3-trimethoxysilylpropyl)-2,3-dimethylimidazolium tetrafluoroborate. The supports for M63 and M64a-c were synthesized by thiol-ene coupling of 3-mercaptopropyl silica gel with the corresponding alkene-functionalized imidazolium salts. Later on, the same group prepared M65 following a similar 
methodology. In this case a cis-ion-tagged proline derivative with a robust amide linkage between the catalytic active site and the imidazolium tag was chosen for adsorption on multilayered covalently bonded supported ionic liquid phases (mlc-SILP). ${ }^{179}$ A layered clay material (montmorillonite) containing prolinium ions (M66) has also been prepared for enantioselective aldol reaction. ${ }^{180}$

Silica-supported proline M67 was synthesized from aminopropyl silica gel, which was first reacted with glutaric anhydride, then the carboxylic group was coupled with $N$-Boc-2(S)-carbomethoxy-4(S)-aminopyrrolidine and, finally, the orthogonal protecting groups removed. Proline-based peptides M68a-c were obtained by a similar procedure. ${ }^{181}$

Heterogenised silica-based organocatalysts M69a-d and M70a-c have been prepared by Moreau and Wong Chi Man via the solgel process from two silylated derivatives of L-proline, featuring either a carbamate or an ether linker. ${ }^{48}$ The silylated carbamate precursor was obtained as previously described. ${ }^{177}$ The precursor bearing the ether moiety was synthesized from $\mathrm{N}-\mathrm{Cbz}-$ trans-4allyloxy-L-proline, which was converted to its corresponding benzylic ester. Upon subsequent hydrosilylation reaction and removal of the benzylic and $\mathrm{Cbz}$ protecting groups by hydrogenolysis, the desired compound was achieved. Co-gelification of both monomers with variable amounts of TEOS was performed with and without dodecylamine as porogen, enabling the formation of materials with various organic loadings, pore sizes and surface areas. ${ }^{48}$

Covalently proline-functionalized silica gel M71 for continuous-flow aldol reaction in packed-bed microreactors has been described by Massi. It was prepared by the thermally or photochemically induced thiol-ene coupling of commercial 3mercaptopropyl silica gel with $N$-Boc-trans-4-allyloxy-L-proline. ${ }^{182}$

Trans-4-hydroxy-L-proline has also been successfully grafted onto core-shell $\mathrm{Fe}_{3} \mathrm{O}_{4} @ \mathrm{SiO}_{2}$ magnetic microspheres through a carbamate functionality (M72). A previously mentioned synthetic procedure was followed, namely reaction of protected 4hydroxyproline with the silylated isocyanate, deprotection and grafting. ${ }^{46}$

Recently, He has also used the thiol-ene coupling approach to anchor a derivative of L-proline to mercaptopropyl-functionalized mesoporous silicas (M73a-d). ${ }^{183}$ The parent mesostructured silicas have been obtained under aqueous basic conditions in the presence of cetyltrimethylammonium bromide. By adjusting the molar ratios of 1,4-bis(triethoxysilyl)benzene, tetraethyl orthosilicate and MPTMS, they achieved silica materials with alternating hydrophobic and hydrophilic blocks in the pore wall (M73a, M73c), with hydrophobic surface (M73b) or with hydrophilic surface (M73d). These heterogeneous catalysts have been applied to the asymmetric aldol reaction and also to a more challenging Knoevenagel-Michael cascade reaction. ${ }^{183}$

\subsubsection{SUPPORTED PROLINE DERIVATIVES}

To expand the scope of enamine catalysis in homogeneous systems, a series of modifications of the structure of natural aminoacid L-proline have been accomplished by different research groups, who aimed mainly at improving the solubility and/or enhancing the acidity of the stereodirecting group. The design has focused on the introduction of tunable hydrogen-bonding donor groups to improve the dual activation ability while preserving the molecular scaffold created by nature as a central design element. To this aim different prolinamides, prolinthioamides, prolintetrazoles and prolinsulfonamides have been developed for reactions in homogenous medium.

Figure 8 gathers the organosilicas based on proline mimics which have been applied to asymmetric aldol reaction, mainly prolinamides (M74-M80, M83, M84), although supported prolinsulfonamide M81 and pyrrolidinyl tetrazole M82 have also been recently reported.

Following a similar methodology as previously described for M64a-c, the tripeptide H-Pro-Pro-Asp- $\mathrm{NH}_{2}$ has been adsorbed on the surface of modified silica gels functionalized with a monolayer of covalently attached 1,2-dimethylimidazolium chloride, tetrafluoroborate or tetrafluorophosphate $\left(\right.$ M74a-c) ${ }^{178}$

In the other reports of Figure 8 the organocatalytic moiety has been covalently attached to several silica supports through different linkers and by different approaches. Wang obtained M75 by direct coupling of Fmoc-L-proline with 3-aminopropyl functionalized silica gel and subsequent deprotection. Repeating the same procedures proline-based peptides M76a-c could be prepared. ${ }^{181}$

Several silicas with SBA-15 mesostructure functionalized with the L-prolinamide group (M77a-c) were synthesized by Yang's group by co-condensation of silicon precursors (a mixture of TEOS and $\mathrm{Na}_{2} \mathrm{SiO}_{3}$ ) with L-prolinamide modified organosilane in an $\mathrm{AcOH} / \mathrm{NaOAc}$ buffer using block copolymer P123 as template. Material M77d with foam mesostructure was obtained under analogous conditions but with pure TEOS as silicon precursor. ${ }^{184}$ For comparison, the same silylated prolinamide derivative was also grafted onto SBA-15 and MCM-41 (M77h, M77i) ${ }^{184}$ Later on, the same group prepared L-prolinamide functionalized hollow nanospheres with different surface properties M77e-g. ${ }^{185}$ M77e was obtained by co-condensation of the organosilane with TEOS in aqueous $\mathrm{K}_{2} \mathrm{SO}_{4}$ using F127 $\left(\mathrm{EO}_{106} \mathrm{PO}_{70} \mathrm{EO}_{106}\right)$ as template. For M77f a similar procedure was used, but with 1,2bis(trimethoxysilyl)ethane as silicon precursor in aqueous NaOAc. The surface of M77f was modified by reaction with trimethoxymethylsilane in refluxing toluene to afford $\mathbf{M 7 7 g} .{ }^{185}$ The silylated bifunctional L-prolinamide monomer required for the preparation of materials M77 was synthesized by DCC mediated coupling of N-[4-(trimethoxysilyl)benzyl]-(1R, 2R)diaminocyclohexane with N-Boc-L-proline. Removal of Boc group was performed after the synthesis of the materials ${ }^{184}$

We have reported some organocatalytic materials for asymmetric aldol reaction based on prolinamide scaffolds (M78, M79a-d). Thus, non-porous bridged silsesquioxane M78 was obtained from a bis-silylated aminoindane-derived prolinamide by sol-gel methodology in the absence of TEOS with a fluoride salt (TBAF) as catalyst. The required monomer was synthesized from NCbz-4-trans-hydroxy-L-proline and $(1 S, 2 R)$-cis-1-amino-2-indanol. After amide formation, both hydroxyl groups were reacted with (3-isocyanatopropyl)triethoxysilane to afford the bis-carbamate and the Cbz protecting group was removed by catalytic hydride transfer $(\mathrm{Pd} / \mathrm{C}$, cyclohexene $){ }^{51}$ A similar procedure enabled the synthesis of the monosilylated aminoindane-derived prolinamide required for materials M79a-c. ${ }^{52}$ Whereas M79a-b were prepared by sol-gel co-condensation of the organosilane with different amounts of TEOS (5 and 19 equivalents, respectively) under nucleophilic catalysis (TBAF), M79c was obtained by template-assisted hydrolytic polycondensation of the monomer with TEOS (24 equivalents) under acidic conditions and with the neutral surfactant P123 as structure-directing agent. Despite using the typical conditions for SBA-15 type materials, it was not 
possible in this case to obtain such a structured porosity, most probably due to the bulky organic part of the precursor. Finally, M79d was achieved by grafting on a SBA-15 type mesostructured silica. ${ }^{52}$

Following a similar methodology as previously described for M71, Massi and Cavazzini have recently prepared silica gelimmobilized proline mimetics, namely prolinamide $\mathbf{M 8 0}$, prolinsulfonamide $\mathbf{M 8 1}$ and pyrrolidinyl tetrazole $\mathbf{M 8 2}^{\mathbf{1 8 6}}$ with the aim to perform aldol reactions under continuous-flow conditions in packed-bed microreactors. The required precursors for thiol-ene coupling to 3-mercaptopropyl silica gel were obtained from N-protected $(2 S, 4 R)$-4-allyloxyproline by standard methods. Transformation of carboxyl group to a tetrazole moiety was achieved by conversion to the primary amide, subsequent dehydration promoted by cyanuric chloride to obtain the nitrile and cycloaddition with sodium azide.

Silica-gel supported binam-derived prolinamide $\mathbf{M 8 3}$ has been prepared by a sol-gel co-condensation procedure under ammonium fluoride catalysis. First, a photoinduced thiol-ene coupling strategy has been used to synthesize the required monosilylated precursor from the styrylsulfonyl binam derivative. This compound was obtained by reacting 4-vinylbenzenesulfonyl chloride with $\left(R_{a}\right)$-1,1 '-binaphtyl-2,2'-diamine, subsequent coupling with N-Boc-D-proline followed by deprotection with trifluoroacetic acid. ${ }^{187}$ A direct synthesis has been undertaken to obtain the aldolisation catalyst M84 based on the tetrapeptide sequence Pro-Pro-AspLys. The triethoxysilylated peptide was achieved by reaction of the terminal amino group of lysine residue with (3isocyanatopropyl)trimethoxysilane. The material has been prepared by hydrolytic co-condensation of this monomer with TEOS under acidic conditions in the presence of P123 as structure-directing agent. ${ }^{188}$ 


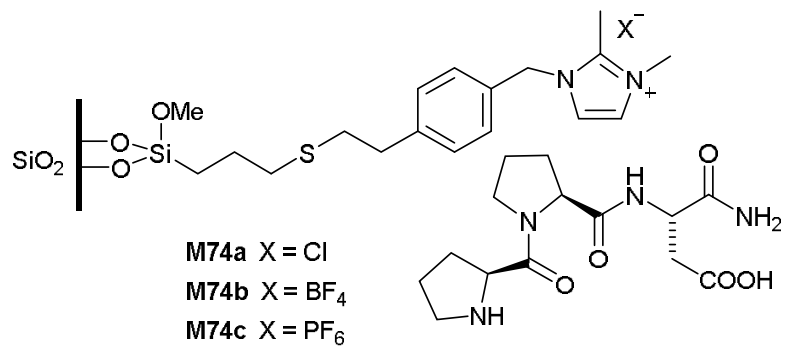

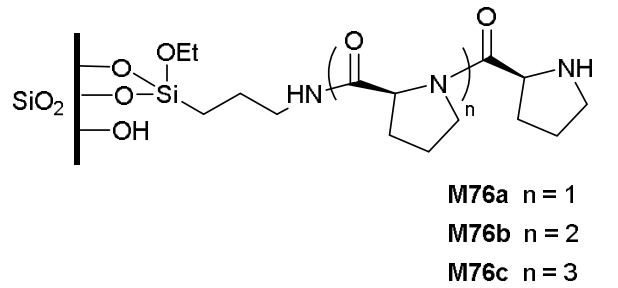

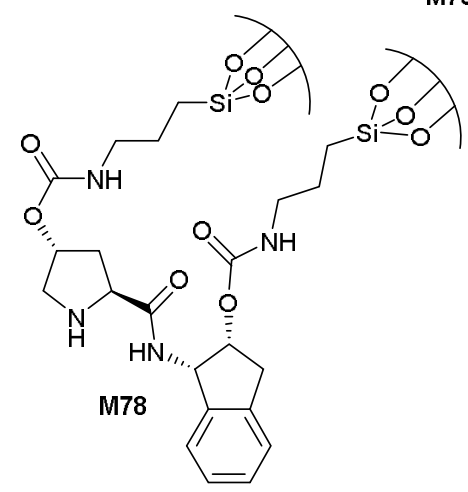

$\operatorname{M76c} n=3$<smiles>O=C(N[C@@H]1CCCC[C@H]1NCc1ccccc1)[C@H]1CCCN1</smiles>

M77a (SBA-15-10)

M77b (SBA-15-20)

M77c (SBA-15-30)

M77d (FOAM-10)

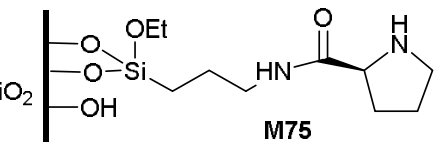<smiles>CCCCCC[Si]OC=[Si]CCC</smiles><smiles>CC12CCC(O1)[Si](CCCC=O)O2</smiles><smiles>CCCNC1=CCCC1</smiles>

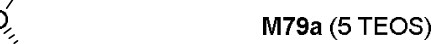
O M79b (19 TEOS) M79c (24 TEOS) 80<smiles>C[C@@H]1CN[C@H](C(N)=O)C1</smiles><smiles>CCO[Si]1(C)OCC2CO[Si](CCc3ccc(S(=O)(=O)Nc4ccc5ccccc5c4-c4c(NC(=O)[C@@H]5CCCN5)ccc5ccccc45)cc3)(O2)O1</smiles><smiles>CC1O[Si]2(CCCSCCCO)OC1(CO)CC2(O)O</smiles>

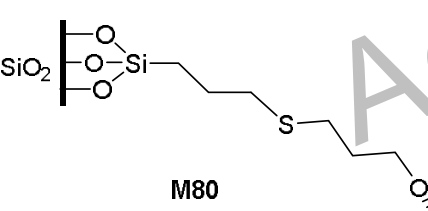<smiles>CC1(C)O[Si]2(CCCSCCCO)OC1(C)O[C@H]2O</smiles>

M81<smiles>O=C(NS(=O)(=O)c1ccccc1[N+](=O)[O-])C1CCCN1</smiles>

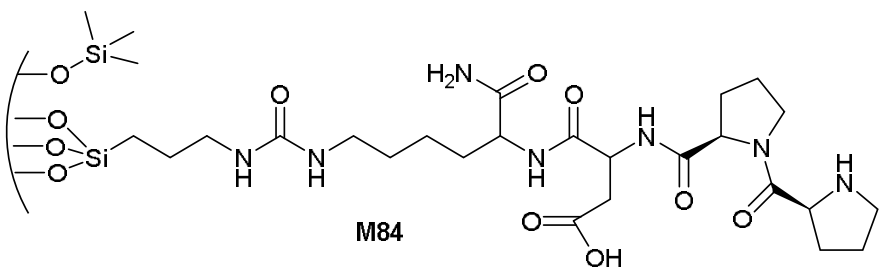

Figure 8. Silica-supported proline mimics for asymmetric direct aldol reaction via enamine pathway

An enamine pathway is also followed for the aldol reaction in the case of non-covalently anchored silica-supported chiral amines M85a-b ${ }^{189}$ and $\mathbf{M 8 6}^{\mathbf{1 8 2}}$ (figure 9). Solid chiral catalyst M85a has been obtained through acid-base interaction of the chiral diamine and $\mathrm{SO}_{3} \mathrm{H}$-containing hollow nanospheres. For this purpose, thiol-hollow nanospheres were synthesized from 1,2bis(trimethoxysilyl)ethane and MPTMS in NaOAc aqueous solutions, with F127 as micelle template. Subsequent oxidation by $\mathrm{H}_{2} \mathrm{O}_{2}$ afforded the acid-containing supporting material. ${ }^{189}$ In a similar way, M85b was prepared from a $\mathrm{SO}_{3} \mathrm{H}_{-}-\mathrm{mesoporous-}$ ethanesilica. Material M86 was readily obtained in two steps from commercial 3-mercaptopropyl silica gel by a sequence 
involving oxidation and further treatment of the resulting $\mathrm{SO}_{3} \mathrm{H}$-silica with (S)-1-(2-pyrrolidinylmethyl)pyrrolidine in acetonitrile at room temperature. ${ }^{182}$

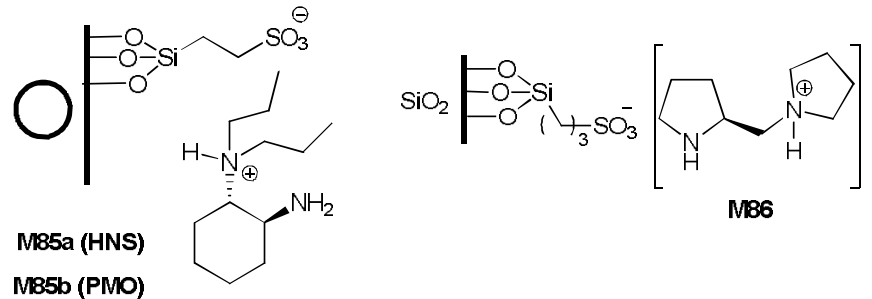

Figure 9. Non-covalently anchored silica-supported chiral amines for direct aldol reaction via enamine pathway

Small chiral amines may also catalyze the asymmetric conjugate addition of ketones and aldehydes containing $\alpha$-enolizable protons to Michael acceptors, such as $\alpha, \beta$-unsaturated ketones and conjugated nitroalkenes, by transforming the carbonyl group of the donor into an enamine intermediate. The mechanism through an enamine pathway is outlined in Scheme $4 .{ }^{190}$ By reversible reaction between the chiral amine catalyst $\mathrm{A}$ and the carbonyl donor $\mathrm{B}$ an iminium ion $\mathrm{C}$ is generated, which can be more easily deprotonated to form the enamine nucleophilic intermediate $\mathrm{D}$. This carbanion equivalent reacts with the electron deficient olefin $\mathrm{E}$ in order to create the new $\mathrm{C}-\mathrm{C}$ bond in a stereoselective manner. The subsequent hydrolysis of the $\alpha$-modified iminium ion $\mathrm{F}$ formed affords the Michael adduct $\mathrm{G}$ and restores the aminocatalyst $\mathrm{A}$. As the amino catalyst could be trapped by the electrophilic alkene, the reversibility of this trapping is crucial for the occurrence of the desired Michael addition. The diastereo- and enantioselectivity rely on electronic or steric interactions in the transition state leading to F, depending on the nature of the stereodirecting group in the aminocatalyst. Thus, electronic interactions would be rationalized by hydrogen bonding in L-proline, tetrazole or thiourea catalysts, but steric shielding would be involved in the facial selectivity when bulky groups are present in the chiral aminocatalyst.

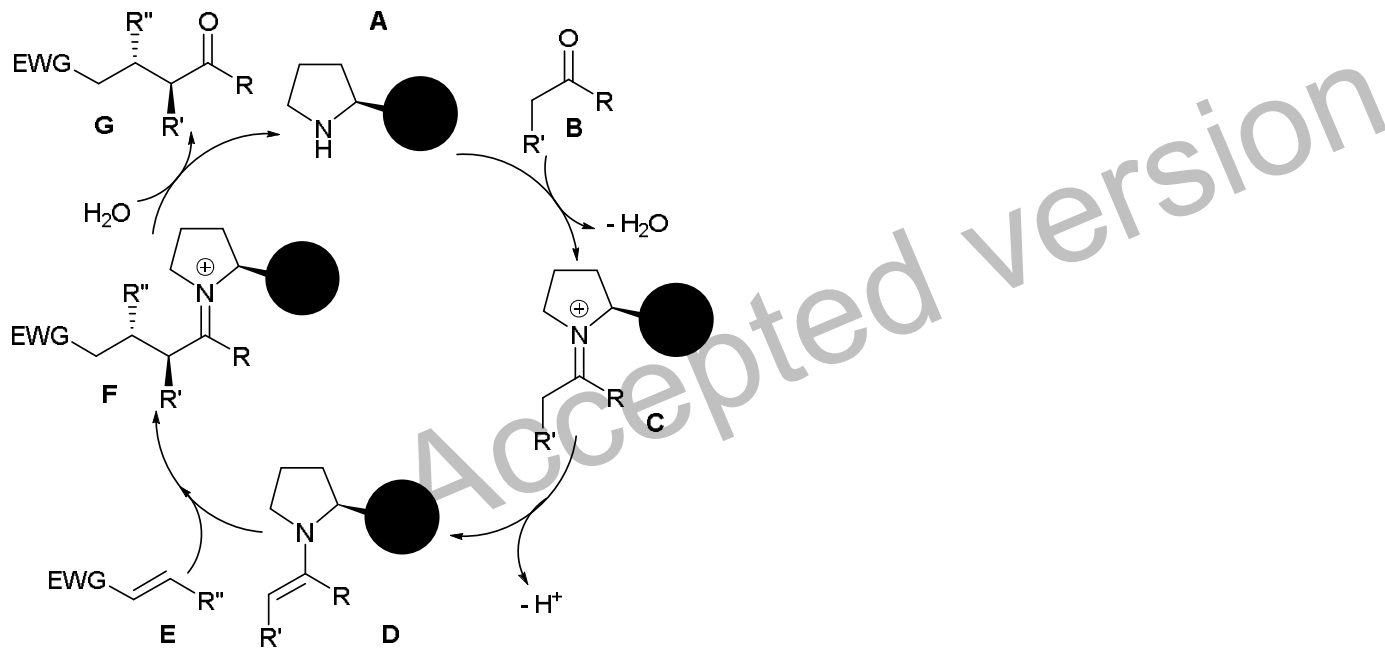

Scheme 4. Enamine activation pathway in the intermolecular asymmetric conjugate addition of $\alpha$-enolizable carbonyl compounds and Michael acceptors.

Some silica-supported organocatalysts (M87-M96) for asymmetric Michael addition following the enamine pathway have been described in the literature and they are summarized in Figure 10. 

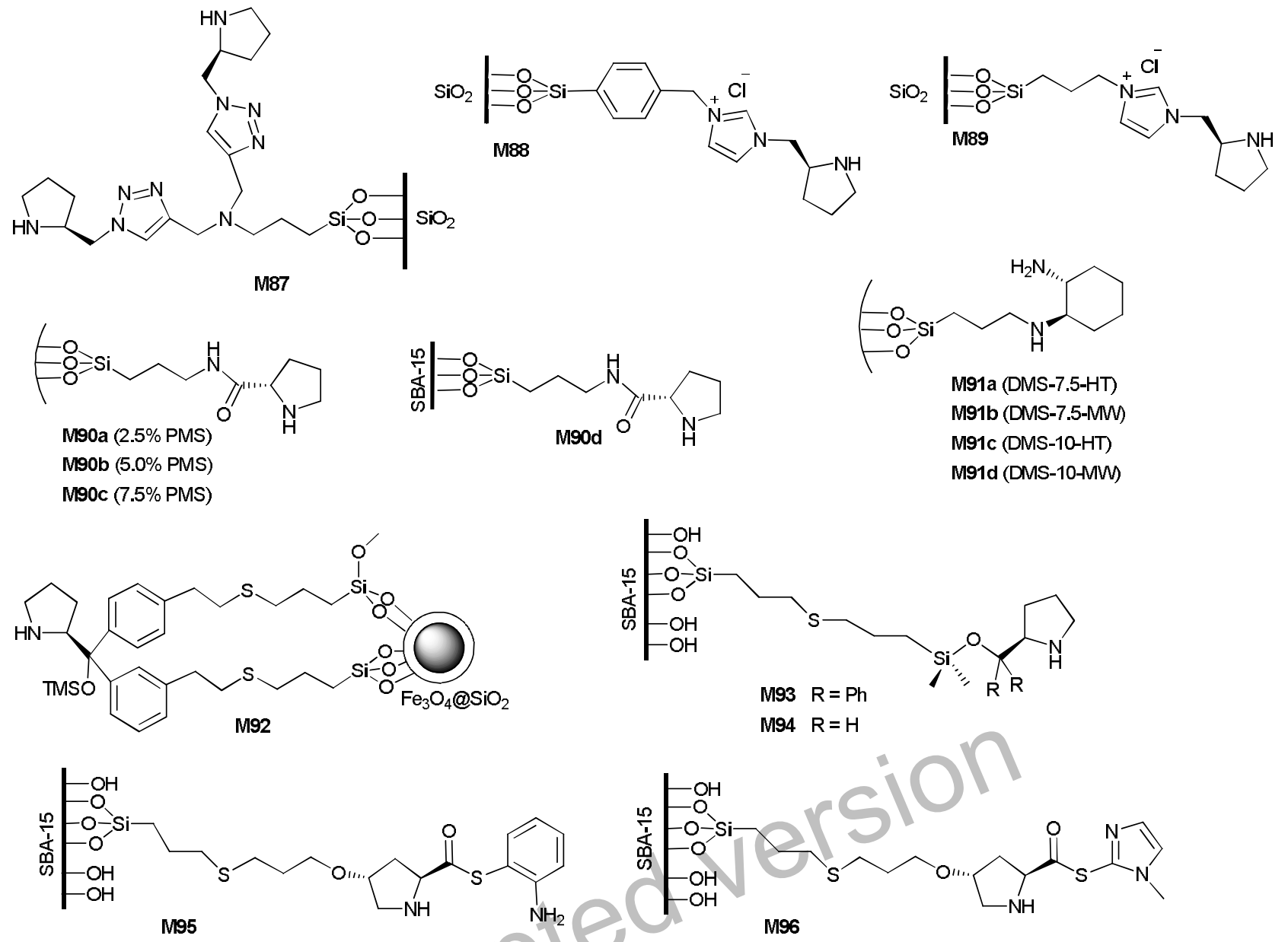

Figure 10. Silica-supported organocatalysts for asymmetric Michael addition via enamine pathway

Silica-supported pyrrolidine-triazole M87 was developed for the Michael addition of ketones to nitroalkenes. A 1,2,3-triazole ring plays a dual role of grafting the chiral pyrrolidine onto the silica surface and of providing a structural element complementary to the pyrrolidine. The triazole moiety was constructed via a $\mathrm{Cu}(\mathrm{I})$-catalyzed azide-alkyne cycloaddition (CuAAC). N-Boc-(S)proline was transformed into the corresponding azide derivative in three steps. The dialkyne coupling partner was obtained by treatment of 3-aminopropyl functionalized silica gel with propargyl bromide under basic conditions. Deprotection with TFA was performed on the material after the click reaction. 191

The asymmetric Michael addition of ketones to nitrostyrenes was also successfully achieved by the use of silica-immobilized pyrrolidines M88 and M89 presenting an imidazolium moiety in the linker, which were obtained by a post-functionalization approach. The synthesis involved treatment of activated silica gel with trichloro-(4-chloromethyl)phenylsilane and (3chloropropyl)triethoxysilane in refluxing toluene. The resulting materials were reacted with $N$-Boc- $(S)-1-($ pyrrolidin-2-ylmethyl)$1 \mathrm{H}$-imidazole, readily available from N-Boc-L-proline in three steps, to obtain $\mathbf{M 8 8}$ and M89, respectively. ${ }^{\text {.9 }}$

L-Proline functionalized plugged hexagonal templated silicas M90a-c were prepared by direct microwave synthesis under acidic conditions using Pluronic P123 as template, sodium metasilicate nonahydrate as silica source and controlled amounts of the prolinamide precursor, $(S)-N$-(3-(triethoxysilyl)propyl)pyrrolidine-2-carboxamide. For comparison, M90d was also prepared by post-grafting onto conventional SBA-15. M90a-d have been tested in the asymmetric Michael addition of diethyl malonate to cyclohexenone and in the asymmetric epoxidation of cinnamaldehyde with hydrogen peroxide ${ }^{50,193}$ The suggested mechanism for this epoxidation reaction involves the formation of an enamine intermediate. Following a similar methodology the same group prepared plugged trans-(1R,2R)-diaminocyclohexane functionalized mesoporous silicas M91a-d for asymmetric 1,4-addition reactions, by varying the amount of organosilane and the heating method (microwave for M91a,c or hydrothermal for M91b,d). ${ }^{194}$ A superparamagnetic nanoparticle-supported $(S)$-diarylprolinol silyl ether $\mathbf{M 9 2}$ has been found a very convenient recyclable catalyst for Michael addition. A thiol-ene coupling between MPTMS and (S)-2-(((trimethylsilyl)oxy)bis-(4vinylphenyl)methyl)pyrrolidine (available from L-proline by a four steps sequence), enabled the formation of the bis-silylated prolinol precursor which was covalently attached to the surface of $\mathrm{Fe}_{3} \mathrm{O}_{4} @ \mathrm{SiO}_{2} .{ }^{195}$

Efficient and enantioselective Henry-Michael one-pot reaction has been achieved on heterogeneous catalysts M93-M96 as a result of the synergistic action of inherent achiral silanol groups as acidic sites and chiral proline-derived amines as basic sites. ${ }^{196}$ Again, a thiol-ene reaction has been used to immobilize the chiral amines on SBA-15-SH material, which was synthesized from a mixture 
of TEOS and MPTMS (4:1) under acidic conditions in the presence of P123. The alkene partners required for M93 and M94 were obtained by treatment of allylchlorodimethylsilane with $(S)$-diphenylprolinol and $(S)$-prolinol, respectively. Protection of the amine by Boc group was performed before the coupling and a final deprotection step on the solid materials was achieved with TFA. On the other hand, the alkene precursors for M95 and M96 have been prepared from $N$-Boc-trans-4-hydroxy-L-proline in two steps, namely O-allylation and thioester formation. ${ }^{196}$

Also the materials M73a-d (Figure 7), M78 and M82 (Figure 8) have been tested in Michael additions.

\subsection{Supported Cinchona derivatives for the formation of chiral ion-pairs}

Over the past few years a considerable number of publications has arisen dealing with chiral Brönsted bases as catalytic promoters of asymmetric transformations involving the reaction between a relatively acidic pronucleophile and an electrophile. The mechanistic pathway generally adopted for a carbon pronucleophile is depicted in Scheme $5 .{ }^{197}$ In the key step, a pro-nucleophile unit loses one proton to render a new species with enhanced nucleophilicity, which forms a chiral ion-pair with the protonated form of the base. Thus, ion pairing arises as the principal interaction between a substrate and a Brönsted base catalyst, which will be responsible for the stereo-induction. Various nitrogen-containing compounds have been used as chiral Brönsted bases, such as tertiary amines, guanidines, amidines and imidazoles. Alkaloids of the Cinchona family constitute a straightforward source of enantiopure base catalysts. To enhance both the activity and the asymmetric induction, ambifunctional catalysts have been designed, which combine the Brönsted basic site with another hydrogen-bonding site. Thus, Cinchona derivatives containing additional urea or thiourea functionalities can anchor both nucleophilic and electrophilic components in the transition state. In that way, concurrent activation of both substrates is achieved and a higher degree of stereochemical order in the transition state is obtained.

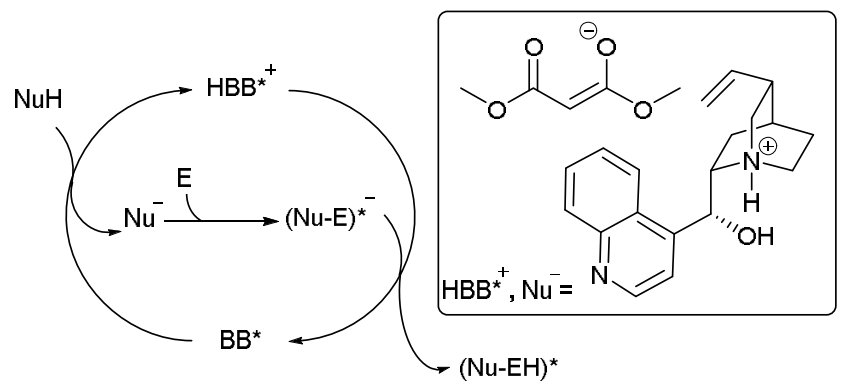

Scheme 5. Brönsted base catalytic activation pathway in a carbon pronucleophile-electrophile coupling reaction (exemplified by the cinchonidine-malonate pair). An asterisk denotes chirality.

Following the successful results in homogeneous catalysis with this type of compounds, some authors have recently developed silica-based heterogeneous versions of Cinchona derivatives for conjugate additions (Figure 11; M97-M103). 


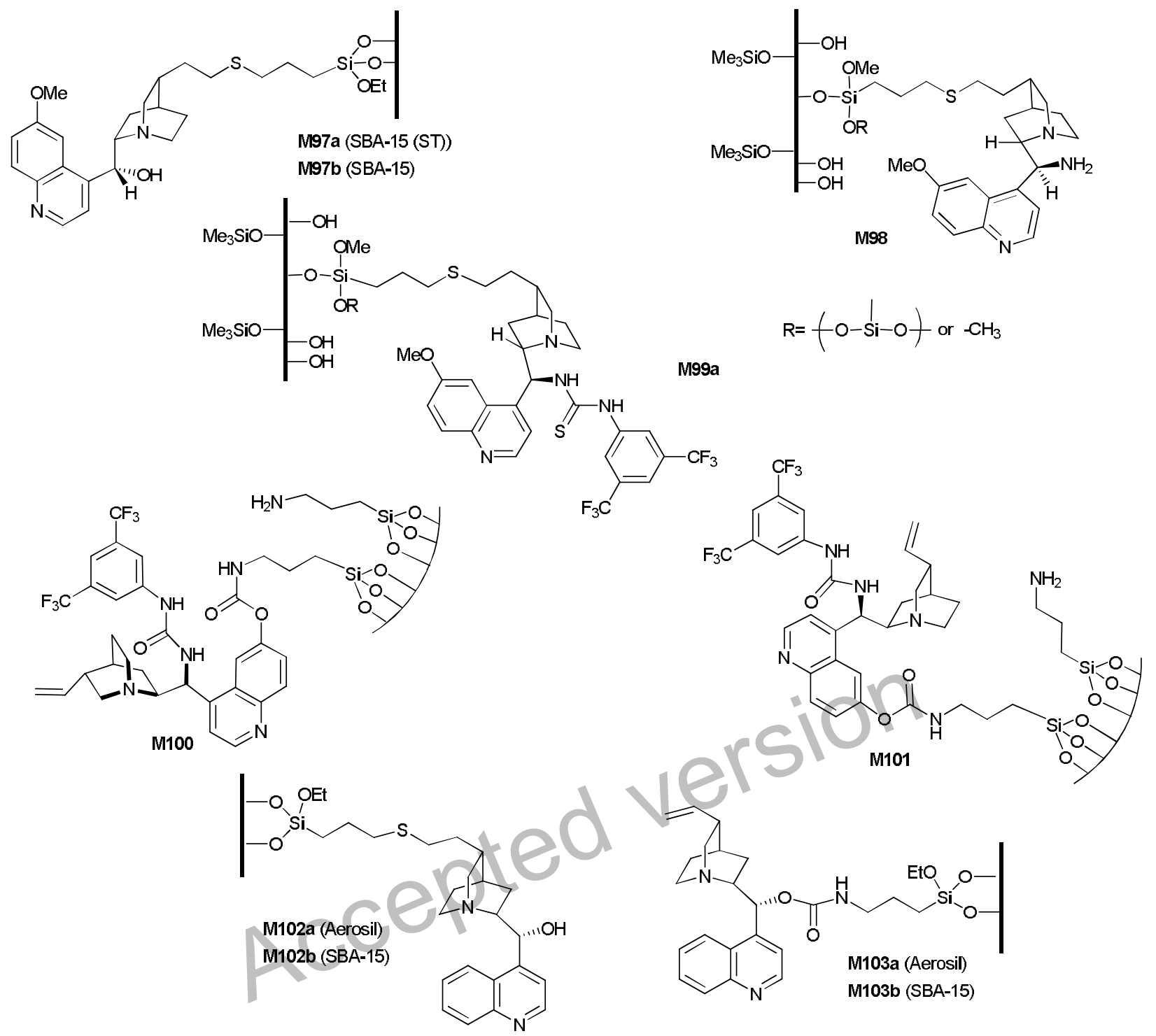

Figure 11. Silica-supported Cinchona derivatives for asymmetric conjugate additions via formation of a chiral ion-pair

Heterogeneous catalysts of quinine supported on mesoporous SBA-15 of short mesochannels (M97a) and conventional mesoporous SBA-15 (M97b) were applied for asymmetric Michael addition of malonitrile to chalcones. The parent silicas functionalized with mercapto groups were prepared by a co-condensation approach and then they were reacted with natural quinine under the thiol-ene click conditions. ${ }^{198}$

The immobilization of 9-amino(9-deoxy)epi-quinine and 9-thiourea epi-quinine at the interior surfaces of mesoporous supports (M98 and M99a, respectively) has been achieved by a step-by-step covalent linking approach, which involves capping of the exterior silanol groups of the as-synthesized MCM-41 or SBA-15, removal of surfactant, grafting of mercaptopropyl linkers and thiol-ene coupling with the corresponding amine. Chiral 9-amino(9-deoxy)epi-quinine was synthesized from natural quinine. Further reaction with 3,5-bis(trifluoromethyl)phenyl isothiocyanate afforded the 9-thiourea epi-quinine. By modulating the pore size of the mesoporous host the enantioselectivity in the Michael addition has been improved. ${ }^{90}$

Corma has described an asymmetric multicomponent reaction of aldehydes, nitromethane and malonates catalyzed by a chiral mesoporous organosilica incorporating a urea-based cinchona derivative and propylamine groups (M100). In this case a different approach has been used to covalently attach the organocatalyst to the support. 9-Urea-(9-deoxy)epi-6-hydroxycinchonidine, prepared from quinine in three steps, has been reacted with (3-isocyanatopropyl)triethoxysilane. The sol-gel co-condensation of the resulting silylated carbamate with TEOS catalyzed by $\mathrm{NH}_{4} \mathrm{~F}$ afforded $\mathbf{M 1 0 0}$. The primary amine sites are derived from partial degradation of the carbamate function and would catalyze the Henry reaction. The bifunctional cinchona-based moiety would be responsible for the subsequent enantioselective Michael addition. ${ }^{199}$ The same group has recently reported the preparation of M101 following a similar methodology by using quinidine as starting compound. The material proved efficient in promoting the asymmetric Henry-Michael domino process to yield some valuable intermediates which have been transformed to GABAanalogues in enantioenriched form. ${ }^{176}$ 
Cinchonidine molecules tethered to silica surfaces (Aerosil or SBA-15) by a grafting method have been found to catalyze the addition of $p$-tert-butylbenzenethiol to 2-cyclohexenone. Two approaches have been envisaged for the derivatization of the chiral base, one where (3-mercaptopropyl)triethoxysilane has been used to create a mercapto linkage through the vinyl moiety of the cinchonidine (M102a,b), and a second where a carbamate link is made by reacting (3-isocyanatopropyl)triethoxysilane with the $\mathrm{OH}$ group of cinchonidine (M103a,b). The effect of the surface of solid and the tether approach on the catalytic performance has been studied. ${ }^{91}$

Silica-immobilized Cinchona bases as heterogeneous chiral organocatalysts for other reactions have also been reported (Figure 12, M99b, M104-M107). Thus, 9-thiourea epi-quinine supported on SBA-15 (M99b) was applied to the asymmetric Friedel-Crafts reaction of indoles with imines. The synthesis of the material was carried out by thiol-ene reaction between the vinyl moiety of 9thiourea epi-quinine and mercaptopropyl-modified SBA-15. ${ }^{200}$ An analogous approach was followed by Han to obtain silica-gel supported bis-cinchona alkaloids M104-M107 from 1,4-bis(quinidinyl)anthraquinone or 1,4-bis(quininyl)anthraquinone. They were explored for the asymmetric desymmetrization of meso-cyclic anhydrides with alcoholysis. The rigidity of the organocatalyst was found to be an important parameter for the enantioselectivity, M104 giving the best results. ${ }^{201}$ 


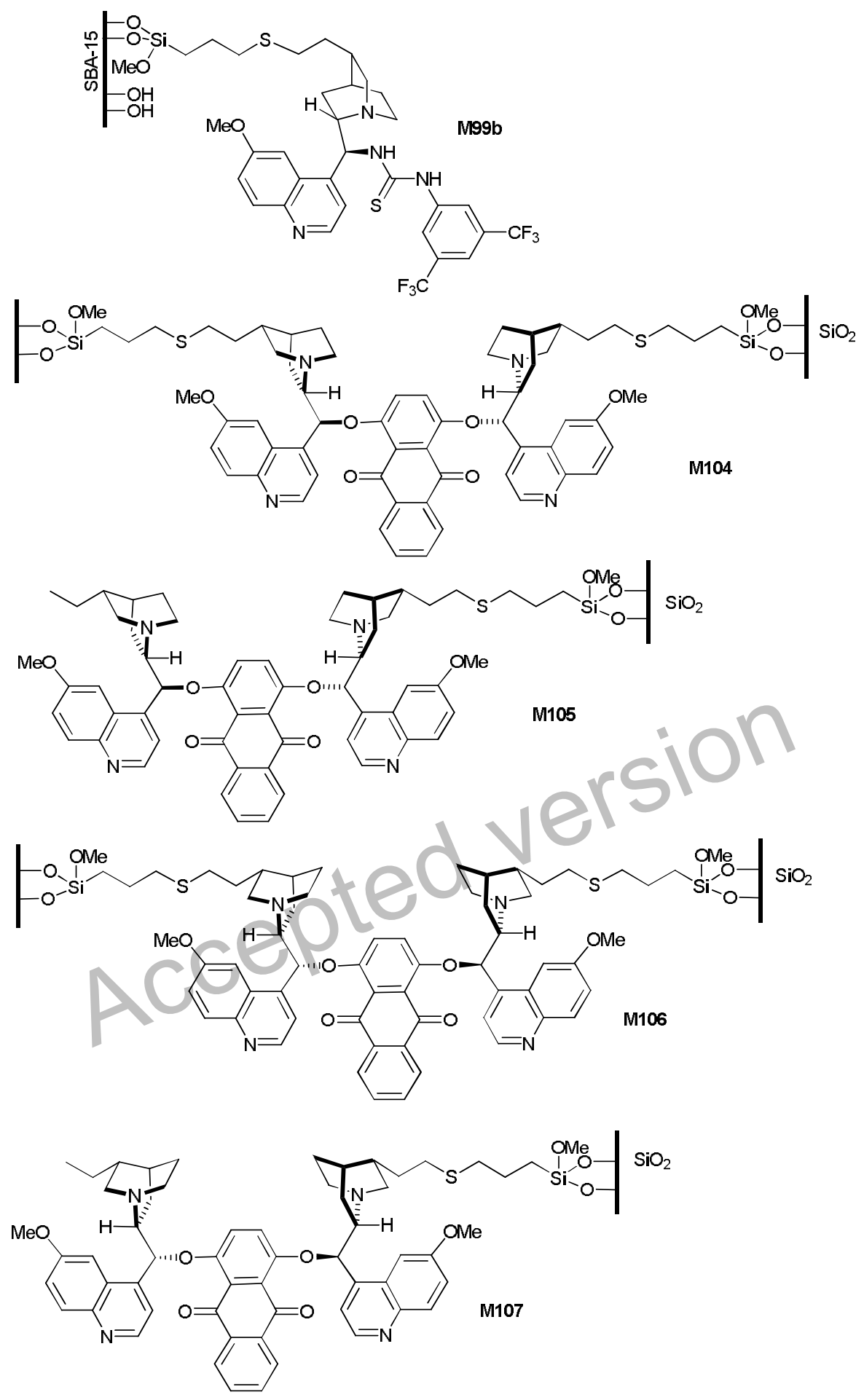

Figure 12. Silica-supported Cinchona derivatives for other asymmetric processes via formation of a chiral ion-pair

\subsection{Supported chiral imidazolidinones for iminium activation}

The iminium activation pathway involves the formation of an iminium ion between an $\alpha, \beta$-unsaturated aldehyde (a dienophile in Diels-Alder cycloaddition) and a secondary amine organocatalyst, leading to enhanced electrophilicity of the acceptor substrate (the LUMO of the electrophile/dienophile is lowered). Scheme 6 summarizes the catalytic cycle for the Diels-Alder reaction. ${ }^{202}$ 


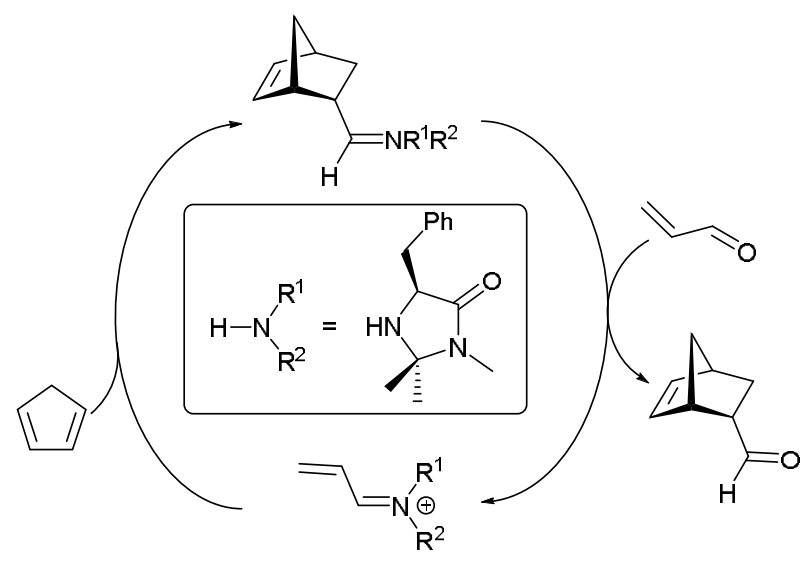

Scheme 6. Iminium activation pathway in Diels-Alder reaction catalyzed by MacMillan imidazolidinones.

As the most used chiral organocatalysts following this mechanism are the chiral imidazolidinones developed by MacMillan (Scheme 6), some groups have reported the immobilization of this type of compounds on silica supports for their use as heterogeneous recyclable chiral organocatalysts for Diels-Alder reactions between cyclic or acyclic dienes and $\alpha, \beta$-unsaturated aldehydes (Figure 13; M108-M115).<smiles>CC1CCO[Si]2(CCCN3C(=O)[C@@H](Cc4ccccc4)N[C@@]3(C)O)OCC1O2</smiles><smiles>[R]OCC(C)O[Si](C)(C)CCCCOc1ccc(C[C@@H]2NC(C)(C)N(C)C2=O)cc1</smiles>

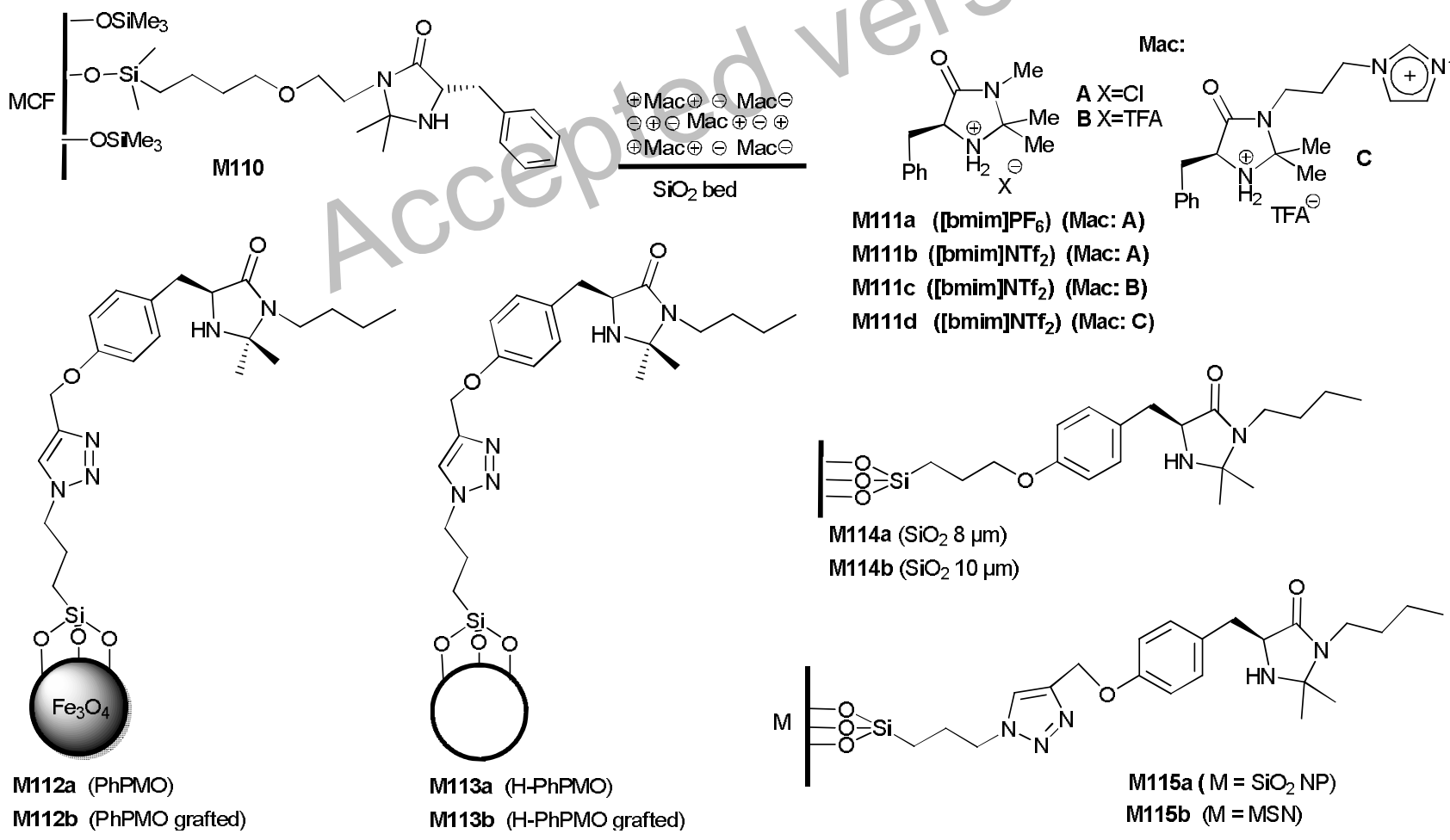

Figure 13. Silica-supported MacMillan imidazolidinones for Diels-Alder reaction via an iminium activation pathway

Silica gel-supported chiral imidazolidinone M108 was achieved through coupling of $N$-Fmoc-protected (S)-phenylalanine with $n$ propylamine-functionalized silica gel via the acid chloride, deprotection and final cyclization of the silica-bound $\alpha$-amino amide with $50 \%$ acetone in DMF. ${ }^{203}$ 
Siliceous mesocellular foam (MCF) has also been used as support of this type of chiral catalysts. Thus, M109a,b, and M110 showed good catalytic performance and recyclability in both Diels-Alder cycloaddition and Friedel-Crafts alkylation. ${ }^{61}$ The characteristics of the linkages, such as length and flexibility, are different in the two types of materials. The required derivatizedimidazolidinone for obtaining M109 was prepared from $(S)$-tyrosine methyl ester hydrochloride by reaction with methylamine and then acetone. The phenolic group was alkylated with allyl(4-bromobutyl)dimethylsilane. The resulting compound was anchored onto the surface of MCF and pre-capped MCF supports to afford M109a and M109b, respectively. On the other hand, for the synthesis of M110, $(S)$-phenylalanine methyl ester hydrochloride was reacted with ethanolamine and then acetone to generate an imidazolidinone with the ethylene hydroxyl group bound to the amide nitrogen, which enabled the anchoring onto the support as for M109. ${ }^{61}$

Hagiwara has immobilized several MacMillan's imidazolidinones as supported ionic liquid catalysts (Mac-SILC) in the pores of silica gel (M111a-d). ${ }^{204}$

Functionalization of solid periodic mesoporous organosilica (PMO) spheres and hollow-PMO spheres with MacMillan catalyst has been achieved by the group of Wang (M112 and M113, respectively). ${ }^{205}$ Two synthetic strategies were followed. One of them involved an hydrolytic co-condensation of 1,4-bis(triethoxysilyl)benzene and (3-azidopropyl)trimethoxysilane in aqueous NaOH in the presence of cetyltrimethylammonium bromide, employing $\alpha-\mathrm{Fe}_{2} \mathrm{O}_{3}$ nanoparticles as a hard template. Hollow azidefunctionalized spheres were obtained after extraction of surfactant and acid etching. Post-modification through click reaction with an alkyne-derivative of a MacMillan imidazolidinone afforded M113a. Full PMO spheres M112a have been obtained by an analogous pathway in which the acid etching step has been omitted. The second strategy involved the grafting of a monosilylated click derivative of the MacMillan imidazolidinone onto non-functionalized dense and hollow PMO spheres to afford M112b and M113b, respectively. ${ }^{205}$

Continuous-flow organocatalyzed Diels-Alder reactions have been carried out on a home-made HPLC column packed with silicasupported salts of chiral imidazolidinones (M114a,b). ${ }^{206}$ A properly modified MacMillan-type catalyst was obtained starting from $(S)$-tyrosine methyl ester in four steps consisting in $N$-butyl amide formation, followed by treatment with acetone, $N$-alkylation of the imidazolidinone formed ring with allyl bromide and platinum-catalyzed hydrosilylation of the alkene with trimethoxysilane. The resulting derivative was grafted to commercially available silicas by standard procedures. Recently, the same group has also employed a triazole-linkage to support an alkyne-imidazolidinone moiety to both azide-functionalized silica and mesoporous silica nanoparticles via click chemistry (CuAAC) $(\mathbf{M 1 1 5 a , b}){ }^{207}$

\section{Main results in asymmetric catalysis}

In this section the main achievements for asymmetric processes involving the previously mentioned silica-supported chiral organocatalysts are detailed. However, some non asymmetric reactions with achiral organocatalysts are also included in the miscellaneous section 4.6 .

\subsection{Direct asymmetric aldol reaction}

The aldol reaction is one of the most useful organic transformations leading to the formation of new $\mathrm{C}-\mathrm{C}$ bonds with the creation of one or more stereogenic centres. The enamine pathway followed by chiral silica-supported recyclable functionalized prolines and proline mimics has enabled the direct synthesis of aldol products in a diastereo- and enantioselective manner (see figures 7,8 and 9 for the organocatalysts). Although in some cases other aromatic aldehydes and other ketones have been tested, the activities of the organosilicas have been mostly evaluated via two typically used benchmarks for direct asymmetric aldolisations, namely the reactions of $p$-nitrobenzaldehyde with cyclohexanone and with acetone. As the diverse silica-supported catalysts have been used with different substrates under varying conditions (amount of catalyst, presence or absence of co-catalyst, solvent, temperature), the comparison of their performances only in terms of type of matrix or type of organic-containing moiety becomes difficult. For comparative purposes, we have chosen to present some significant results for these two benchmark reactions in Tables 1 and 2 , respectively, which will give the reader on overview of the efficiencies (TON/TOF) and selectivities $(d r$, ee) achieved in these particular reactions under the reported conditions for the different catalysts.

Table 1 Asymmetric direct aldol reaction between cyclohexanone and $p$-nitrobenzaldehyde

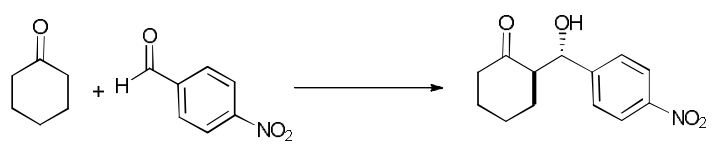




\begin{tabular}{|c|c|c|c|c|c|c|c|c|c|c|c|}
\hline \multirow[t]{2}{*}{ Entry } & \multirow[t]{2}{*}{ Cat. } & \multirow[t]{2}{*}{ Co-cat } & \multirow{2}{*}{$\begin{array}{c}\mathrm{mol}^{\mathrm{a}} \\
\mathrm{cat}^{\mathrm{a}}\end{array}$} & \multirow[t]{2}{*}{ Solvent/T/t } & \multirow{2}{*}{$\begin{array}{l}\text { Yield } \\
(\%)\end{array}$} & \multirow{2}{*}{$\begin{array}{c}\mathrm{dr} \\
(\text { anti:syn) }\end{array}$} & \multicolumn{2}{|c|}{ ee } & \multirow{2}{*}{ Recycling } & \multirow[t]{2}{*}{ TON } & \multirow{2}{*}{$\begin{array}{l}\text { TOF } \\
\left(\mathrm{h}^{-1}\right)\end{array}$} \\
\hline & & & & & & & anti & syn & & & \\
\hline 1 & M65 $^{179}$ & - & 5.0 & $\mathrm{H}_{2} \mathrm{O} / \mathrm{r}$.t $/ 2.5 \mathrm{~h}$ & 99 & $94: 6$ & 98 & - & 15 & 19.8 & 7.92 \\
\hline 2 & M66 ${ }^{180}$ & $\begin{array}{c}{\left[\mathrm{tmba}^{\mathrm{N}} \mathrm{NTf}_{2}(1\right.} \\
\text { equiv })\end{array}$ & 30 & THF/r.t./16 h & 78 & $63: 37$ & 88 & $-\mathrm{b}$ & - & 2.6 & 0.16 \\
\hline 3 & M71 $^{182}$ & - & 10 & Toluene/ r.t./24 h & 67 & $4: 1$ & 78 & 2 & - & 6.7 & 0.28 \\
\hline 4 & $M 72^{46}$ & - & 20 & EtOH/r.t/48 h & 92 & $85 / 15$ & 80 & $27^{\mathrm{c}}$ & 5 & 4 & 0.08 \\
\hline 5 & M73a ${ }^{183}$ & - & 6.7 & Brine $/ 25^{\circ} \mathrm{C} / 24 \mathrm{~h}$ & $>99$ & 90: 10 & 96 & 84 & $>3$ & 15.1 & 0.63 \\
\hline 6 & $\mathbf{M} 73 b^{183}$ & - & 8.2 & Brine $/ 25^{\circ} \mathrm{C} / 24 \mathrm{~h}$ & $>99$ & $86: 14$ & 72 & 39 & $>3$ & 12.0 & 0.50 \\
\hline 7 & $M 73 c^{183}$ & - & 5.9 & Brine $/ 25^{\circ} \mathrm{C} / 24 \mathrm{~h}$ & 31 & 91:9 & 84 & 41 & 3 & 3.7 & 0.15 \\
\hline 8 & $\mathbf{M 7 3 d}^{183}$ & - & 5.5 & Brine $/ 25^{\circ} \mathrm{C} / 24 \mathrm{~h}$ & 24 & $77: 23$ & 33 & 17 & 3 & 5.0 & 0.20 \\
\hline 9 & M77 $\mathbf{a}^{184}$ & $\begin{array}{c}\mathrm{HOAc}(60 \\
\mathrm{mol} \%)\end{array}$ & 60 & $\mathrm{CHCl}_{3} /-25^{\circ} \mathrm{C} / 4 \mathrm{~d}$ & 87 & $89: 11$ & 90 & 12 & - & 1.45 & 0.02 \\
\hline 10 & M77b ${ }^{184}$ & $\begin{array}{c}\text { HOAc (60 } \\
\text { mol } \%)\end{array}$ & 60 & $\mathrm{CHCl}_{3} /-25^{\circ} \mathrm{C} / 4 \mathrm{~d}$ & 86 & $70: 30$ & 91 & 42 & - & 1.43 & 0.01 \\
\hline 11 & M77c ${ }^{184}$ & $\begin{array}{c}\mathrm{HOAc}(60 \\
\mathrm{mol} \%)\end{array}$ & 60 & $\mathrm{CHCl}_{3} /-25^{\circ} \mathrm{C} / 4 \mathrm{~d}$ & 89 & $70: 30$ & 87 & 42 & - & 1.48 & 0.02 \\
\hline 12 & $M 77 e^{184}$ & $\begin{array}{c}\operatorname{HOAc}(60 \\
\text { mol } \%)\end{array}$ & 60 & $\mathrm{CH}_{2} \mathrm{Cl}_{2} /-25^{\circ} \mathrm{C} / 4 \mathrm{~d}$ & 87 & $85 / 15$ & 96 & 39 & $4^{c}$ & 0.65 & $6.7 \cdot 10^{-3}$ \\
\hline 13 & M77 d ${ }^{184}$ & $\begin{array}{c}\mathrm{HOAc}(60 \\
\mathrm{mol} \%)\end{array}$ & 60 & $\mathrm{CHCl}_{3} /-25^{\circ} \mathrm{C} / 4 \mathrm{~d}$ & 85 & $87: 13$ & 75 & 24 & - & 1.25 & 0.01 \\
\hline 14 & $\mathbf{M} 77 \mathrm{e}^{185}$ & $\begin{array}{c}\text { HOAc (20 } \\
\text { mol } \%)\end{array}$ & 20 & $\mathrm{H}_{2} \mathrm{O} / 15^{\circ} \mathrm{C} / 17 \mathrm{~h}$ & 39 & $71: 29$ & 95 & 18 & - & 1.95 & 0.11 \\
\hline 15 & $\mathbf{M} 77 \mathbf{f}^{185}$ & $\begin{array}{c}\text { HOAc (20 } \\
\text { mol } \%)\end{array}$ & 20 & $\mathrm{H}_{2} \mathrm{O} / 15^{\circ} \mathrm{C} / 17 \mathrm{~h}$ & 73 & $79: 21$ & 95 & 25 & - & 3.65 & 0.21 \\
\hline 16 & $M 77 g^{185}$ & $\begin{array}{c}\text { HOAc (20 } \\
\text { mol } \%)\end{array}$ & 20 & $\mathrm{H}_{2} \mathrm{O} / 15^{\circ} \mathrm{C} / 17 \mathrm{~h}$ & 96 & $85: 15$ & 96 & & 7 & 4.8 & 0.28 \\
\hline 17 & $\mathbf{M} 77 \mathbf{h}^{184}$ & HOAc & 60 & $\mathrm{CHCl}_{3} /-25^{\circ} \mathrm{C} / 4 \mathrm{~d}$ & 83 & $79: 21$ & 88 & 59 & - & 1.38 & 0.01 \\
\hline 18 & M77 $\mathbf{i}^{184}$ & HOAc & 60 & $\mathrm{CHCl}_{3} /-25^{\circ} \mathrm{C} / 4 \mathrm{~d}$ & 85 & $80: 20$ & 88 & 16 & - & 1.41 & 0.01 \\
\hline 19 & $\mathbf{M} 78^{51}$ & - & 16 & $\mathrm{H}_{2} \mathrm{O} / 22^{\circ} \mathrm{C} / 6 \mathrm{~h}^{\mathrm{d}}$ & 97 & $82 / 18$ & 74 & - & 5 & 4.63 & 0.77 \\
\hline 20 & M79a $^{52}$ & - & 10 & $\mathrm{H}_{2} \mathrm{O} /$ r.t. $/ 24 \mathrm{~h}$ & 88 & $86 / 14$ & 86 & - & 5 & 8.8 & 0.37 \\
\hline 21 & $\mathbf{M 7 9 b}^{52}$ & - & 10 & $\mathrm{H}_{2} \mathrm{O} /$ r.t. $/ 7 \mathrm{~h}^{\mathrm{d}}$ & $70^{e}$ & $81 / 19$ & 88 & - & 5 & 7 & 1 \\
\hline 22 & $M 79 c^{52}$ & - & 10 & $\mathrm{H}_{2} \mathrm{O} /$ r.t. $/ 1 \mathrm{~d}^{\mathrm{d}}$ & 97 & $82 / 18$ & 88 & - & 3 & 9.7 & 0.4 \\
\hline 23 & M79d $d^{52}$ & - & 10 & $\mathrm{H}_{2} \mathrm{O} /$ r.t. $/ 8 \mathrm{~h}^{\mathrm{d}}$ & $75^{e}$ & $83 / 17$ & 80 & - & 5 & 7.5 & 0.94 \\
\hline 24 & M80 $^{186}$ & & 10 & Toluene/r.t/24 h & 45 & $4: 1$ & 23 & - & - & 4.5 & 0.19 \\
\hline 25 & M81 $^{186}$ & & 10 & Toluene/r.t/24 h & 58 & $3: 1$ & 30 & - & - & 5.8 & 0.24 \\
\hline 26 & M82 $^{186}$ & & 10 & Toluene/r.t/24 h & $>95$ & $3: 1$ & 82 & - & - & 9.5 & 0.39 \\
\hline 27 & $\mathbf{M 8 3}^{187}$ & $\begin{array}{c}\mathrm{PhCO}_{2} \mathrm{H}(5 \\
\mathrm{mol} \%)\end{array}$ & 10 & neat $^{\mathrm{f}} / 25^{\circ} \mathrm{C} / 6 \mathrm{~h}$ & 88 & $93 / 7$ & 92 & & $9^{g}$ & 8.8 & 1.5 \\
\hline 28 & M85a $^{189}$ & - & 10 & $\mathrm{H}_{2} \mathrm{O} /$ r.t. $/ 12 \mathrm{~h}$ & 91 & $91 / 9$ & 96 & - & $4^{\mathrm{h}}$ & 2.6 & 1.3 \\
\hline 29 & M85b $^{189}$ & - & 10 & neat/r.t. $/ 12 \mathrm{~h}$ & 91 & $88 / 12$ & 92 & - & - & 1.6 & 0.8 \\
\hline 30 & M86 $^{182}$ & - & 10 & Toluene/ r.t./24 h & $>95$ & $2: 1$ & 55 & 2 & - & 9.5 & 0.39 \\
\hline 31 & $\mathbf{M}_{71}{ }^{182}$ & & & Toluene $/ 25^{\circ} \mathrm{C}$ & $88^{\mathrm{i}}$ & $5: 1$ & 76 & & $\begin{array}{l}\text { Continuous } \\
\text { flow mode }\end{array}$ & & $0.64^{\mathrm{j}}$ \\
\hline 32 & M82 $^{186}$ & & & Toluene $/ 50^{\circ} \mathrm{C}$ & $95^{\mathrm{i}}$ & $2: 1$ & 80 & & $\begin{array}{l}\text { Continuous } \\
\text { flow mode }\end{array}$ & & $0.26^{\mathrm{j}}$ \\
\hline 33 & M86 $^{182}$ & & & Toluene $/ 25^{\circ} \mathrm{C}$ & $50^{\mathrm{i}}$ & $2: 1$ & 40 & & $\begin{array}{l}\text { Continuous } \\
\text { flow mode }\end{array}$ & & \\
\hline
\end{tabular}

${ }^{a}$ Proline derivative loading. ${ }^{b}$ Non described. ${ }^{\mathrm{c}}$ After 4 cycles both dr anti/syn and ee values decreased. ${ }^{\mathrm{d}}$ Longer reaction time required for complete conversion was observed upon recycling. ${ }^{\mathrm{e}}$ Better values were obtained upon recycling. ${ }^{\mathrm{f}}$ Reaction performed with 12 equiv of water. ${ }^{\mathrm{g}} \mathrm{A}$ small decrease of the yield was observed after the fifth cycle. ${ }^{\mathrm{h}}$ Each cycle gave similar dr anti/syn and ee values but a decreasing.conversion was observed. ${ }^{\mathrm{i}}$ Conversion by ${ }^{1} \mathrm{H}$ NMR analysis of the eluate after $2 \mathrm{~h}$ reaction time. ${ }^{\mathrm{j}}$ Productivity measured in (mmol product) $\mathrm{h}^{-1}$ $(\mathrm{mmol} \text { catalyst })^{-1}$

He and co-workers ${ }^{183}$ (Table 1, entries 5-8) have found that the nature of the surface of the silica-supported prolinederived catalysts has a significant influence on the catalytic performance, M73a (hydrophobic and hydrophilic alternating surface) affording better yield, diastereo- and enantioselectivity than M73b (hydrophobic surface). However, a rise of the hydrophilic blocks $(\mathbf{M 7 3 c})$ or a hydrophilic surface (M73d) reduces the catalytic activity. They found that the recycled catalysts have preserved the long-range ordered mesoporous structures and the periodic structure.

Yang has reported ${ }^{184}$ that prolinamide-derived ordered mesoporous silicas prepared by co-condensation (M73a-c) (Table 1, entries 9-12) exhibit similar activity and enantioselectivity than materials obtained by grafting methods (M73h-i) (Table 1, entries 17-18). The lower enantioselectivity of a foam-like mesostructure (M77d) (Table 1, entry 13) was attributed to the disordered pore structure. The use of an acid co-catalyst was found essential in this case for good performances. The low TON values of these catalytic materials (high catalyst loading of $60 \mathrm{~mol} \%$ ) 
must be due, at least in part, to the reaction conditions, as the same author ${ }^{185}$ described, later on, related prolinamide-functionalized silica hollow nanospheres M77f-g (Table 1, entries 17-18) exhibiting higher TON/TOF values by working in water. Moreover, nanospheres with a more hydrophobic surface (M77g) showed higher activity than those with a hydrophilic surface (M77f). Both He and Yang rationalize their results in terms of formation of an oil-water interface, which play a critical role in the acceleration of the reaction in aqueous media.

A further improvement of the TON values for this reaction in water could be achieved by the use of supported aminoindane-prolinamides $\mathbf{M 7 8}^{51}$ and M79a-d ${ }^{52}$ (Table 1, entries 19-23), which, in addition, did not require the presence of a co-catalyst. Despite its non-porous nature, M78 exhibited performances similar to those found for related homogeneous organocatalysts. Better enantioselectivities than the homogeneous analogues were observed for supported catalysts M79 derived from a monosilylated monomer. Interestingly, an increase of the porosity (M79b) or an ordered structure of the matrix (M79d) enhanced the reaction rate but did not significantly affect the selectivity. Longer reaction times required for complete conversion upon recycling materials M79 could be ascribed to some loss of catalyst. Some leaching of the organocatalyst after nine cycles has been confirmed by Nájera ${ }^{187}$ in the case of supported binam-prolinamide $\mathbf{M 8 3}$ in the presence of a small amount of water (Table 1, entry 27).

Pyrrolidinyl tetrazole M82 showed superior activity and selectivity for this aldol reaction than prolinamide M80 and prolinesulfonamide M81 under the same conditions (compare entries 24-26 in Table 1). ${ }^{186}$ Undoubtedly, the differences should be attributed to the organocatalytic motif, the higher acidity of the tetrazole moiety enhancing the hydrogen-bonding with the electrophile ( $\mathrm{pKa}$ in DMSO of 11,26 for proline tetrazole versus 23,81 for prolinamide). ${ }^{208}$

Table 2 Asymmetric direct aldol reaction between acetone and $p$-nitrobenzaldehyde

\begin{tabular}{|c|c|c|c|c|c|c|c|c|c|c|}
\hline Entry & Cat & Co-cat & $\mathrm{mol} \%$ cat & Solvent/T/t & Conv [\%] & $\begin{array}{r}\text { Yiel } \\
(\%)\end{array}$ & ee & $\operatorname{Re}$ & TON & $\begin{array}{l}\text { TOF } \\
\left(\mathrm{h}^{-1}\right)\end{array}$ \\
\hline 1 & $\mathrm{M62}^{178}$ & - & 30 & Acetone/r.t./24 h & & 99 & $70^{a}$ & $5^{b}$ & 3.3 & 0.14 \\
\hline 2 & $\mathbf{M 6 3}^{178}$ & - & 30 & Acetone/r.t. $/ 24 \mathrm{~h}$ & & 93 & $70^{\mathrm{a}}$ & $5^{\mathrm{b}}$ & 3.1 & 0.13 \\
\hline 3 & $\mathbf{M 6 4 a}^{178}$ & - & 30 & Acetone/r.t. $/ 24 \mathrm{~h}$ & & 98 & $71^{a}$ & $4^{\mathrm{b}}$ & 3.27 & 0.14 \\
\hline 4 & $M 64 b^{178}$ & - & 30 & Acetone/r.t. $/ 24 \mathrm{~h}$ & & 96 & $73^{\mathrm{a}}$ & 9 & 3.2 & 0.13 \\
\hline 5 & M64 $\mathbf{c}^{178}$ & - & 30 & Acetone/r.t./24 h & & 99 & $68^{\mathrm{a}}$ & - & 3.3 & 0.14 \\
\hline 6 & M66 ${ }^{180}$ & [tmba]NTf $f_{2}$ & 30 & THE/r.t./16 h & & 82 & $81^{\mathrm{a}}$ & 10 & 2.7 & 0.17 \\
\hline 7 & M6 $7^{181}$ & - & 5 & DMSO/r.t/48 h & & 70 & 78 & - & 14 & 0.29 \\
\hline 8 & M68 $a^{181}$ & - & 5 & DMSO/r.t/48 h & & 82 & $96^{\mathrm{a}}$ & 5 & 16.4 & 0.34 \\
\hline 9 & $\mathbf{M 6 8 b ^ { 1 8 1 }}$ & - & 5 & DMSO/r.t/48 h & & 71 & $91^{\mathrm{a}}$ & - & 14.2 & 0.29 \\
\hline 10 & M68 $\mathrm{c}^{181}$ & - & 5 & DMSO/r.t/48 h & & 70 & $90^{\mathrm{a}}$ & - & 14 & 0.29 \\
\hline 11 & M69 $a^{48}$ & - & 30 & $\mathrm{DMSO} / 25^{\circ} \mathrm{C} / 1 \mathrm{~d}$ & 100 & - & 20 & & 3.33 & 0.14 \\
\hline 12 & M69 $\mathbf{b}^{48}$ & - & 30 & $\mathrm{DMSO} / 25^{\circ} \mathrm{C} / 1 \mathrm{~d}$ & 100 & - & 25 & & 3.33 & 0.14 \\
\hline 13 & M69 $\mathrm{c}^{48}$ & - & 30 & $\mathrm{DMSO} / 25^{\circ} \mathrm{C} / 1 \mathrm{~d}$ & 100 & - & 36 & $2^{\mathrm{c}}$ & 3.33 & 0.14 \\
\hline 14 & M69 $\mathrm{d}^{48}$ & - & 30 & $\mathrm{DMSO} / 25^{\circ} \mathrm{C} / 1 \mathrm{~d}$ & 100 & - & 38 & $2^{\mathrm{b}}$ & 3.33 & 0.14 \\
\hline 15 & M70 $\mathbf{a}^{48}$ & - & 30 & $\mathrm{DMSO} / 25^{\circ} \mathrm{C} / 5 \mathrm{~d}$ & 64 & - & 27 & & 2.13 & 0.02 \\
\hline 16 & $\mathbf{M 7 0 b ^ { 4 8 }}$ & - & 30 & $\mathrm{DMSO} / 25^{\circ} \mathrm{C} / 5 \mathrm{~d}$ & 51 & - & 37 & $2^{\mathrm{b}}$ & 1.7 & 0.01 \\
\hline 17 & M70 $c^{48}$ & - & 30 & $\mathrm{DMSO} / 25^{\circ} \mathrm{C} / 5 \mathrm{~d}$ & 32 & - & 35 & & 1.07 & 0.01 \\
\hline 18 & M74a ${ }^{178}$ & - & 5 & Acetone $/ 25^{\circ} \mathrm{C} / 4 \mathrm{~h}$ & & 99 & $80^{\mathrm{d}}$ & $4^{\mathrm{b}}$ & 19.8 & 4.95 \\
\hline 19 & $\mathbf{M} 74 \mathbf{b}^{178}$ & - & 5 & Acetone $/ 25^{\circ} \mathrm{C} / 4 \mathrm{~h}$ & & 99 & $74^{d}$ & $4^{\mathrm{b}}$ & 19.8 & 4.95 \\
\hline 20 & $\mathbf{M} 74 \mathbf{c}^{178}$ & - & 5 & Acetone $/ 25^{\circ} \mathrm{C} / 4 \mathrm{~h}$ & & 99 & $78^{\mathrm{d}}$ & $4^{e}$ & 19.8 & 4.95 \\
\hline 21 & $\mathbf{M} 75^{181}$ & - & 5 & DMSO/r.t/48 h & & 45 & $35^{\mathrm{a}}$ & - & 9 & 0.19 \\
\hline 22 & M76a ${ }^{181}$ & - & 5 & DMSO/r.t/48 h & & 53 & $48^{\mathrm{a}}$ & - & 10.6 & 0.22 \\
\hline 23 & $\mathbf{M} 76 b^{181}$ & - & 5 & DMSO/r.t/48 h & & 45 & $43^{\mathrm{a}}$ & - & 9 & 0.19 \\
\hline 24 & M76c ${ }^{181}$ & - & 5 & DMSO/r.t/48 h & & 47 & $45^{\mathrm{a}}$ & - & 9.4 & 0.20 \\
\hline 25 & M84 $4^{188}$ & NMM (2 mol\%) & 2 & DMSO/r.t./48 h & & 60 & 74 & $>5$ & 30 & 0.63 \\
\hline
\end{tabular}

${ }^{\mathrm{d}}$ Determined by chiral HPLC, $S$ configuration. ${ }^{e}$ After 4 cycles both yields and ee values decreased.

The reaction of $p$-nitrobenzaldehyde with acetone has been carried out mostly in an excess of this reagent as solvent or in a common polar solvent for aldol reaction such as DMSO (Table 2). Gruttadauria has used several ionic-liquid 
modified silica gels to adsorb L-proline (M62, M63, M64a-c) (Table 2, entries 1-5) ${ }^{178}$ Three different linkers were employed to attach the imidazolium moiety to the silica surface, the reuse of the materials being dependent on the nature of the linker. The best recyclability was observed for M64b. Thus, using the linker of M64, materials M74ac with an adsorbed proline-based tripeptide were prepared and tested (Table 2, entries 18-20), ${ }^{177}$ providing better activities and enantioselectivities than M64a-c under the same conditions. Higher TON values and selectivities were achieved by proline based peptides covalently attached to silica in DMSO (M68a-c, Table 2, entries 8-10). ${ }^{181}$ The most efficient was M68a which was used for five consecutive trials. The same author, ${ }^{181}$ has found that prolinederived peptides M76a-c lacking the carboxyl group (Table 1, entries 22-24) are less efficient and selective than M68a-c. Silica-supported prolines prepared by sol-gel co-gelification with TEOS and bearing carbamate (M69a-d) or ether linkages (M70a-c) have also been tested in DMSO (table 2, entries 11-17), ${ }^{48}$ achieving low or moderate enantioselectivities. The systems bearing ether linkages displayed much slower kinetics. The low enantioselectivity was rationalized considering the competition of the acidic silanols with the $\mathrm{COOH}$ proline moieties for the positioning of the aldehyde. The better selectivity observed for materials M68 in comparison with M69 and M70 can be ascribed to the different nature and length of the linker and the catalytic organic motif.

As shown before in Tables 1 and 2, in many cases relatively low amounts of supported organocatalysts have been employed in the absence of an acid co-catalyst, contrarily to the usual requirements under homogeneous conditions, with the added advantage of an easy separation and recycling of the catalyst. It is worth to remark the use of green conditions (water, ethanol, brine or neat) (entries 1, 4, 5-8, 14-16, 19-23, 27-29 in Table 1) and temperatures not exceeding $25^{\circ} \mathrm{C}$. However, the reaction of hydroxyacetone with different aromatic and aliphatic aldehydes to afford $\alpha, \beta$-dihydroxyketones was best performed under the assistance of heat or microwaves under catalysis of recyclable (3 runs) proline M61a (Scheme 7). ${ }^{53}$ The same author has used M61a and M61b for the reaction of 2,2-dimethyl1,3-dioxan-5-one with several achiral and chiral aldehydes, furnishing useful intermediates for the synthesis of azasugars (Scheme 8). ${ }^{177}$ Interestingly, supported prolinamides M78, ${ }^{51}$ M79a,b, $\mathbf{d}^{52}$ and ent-M83a ${ }^{187}$ allowed the challenging intramolecular aldol reaction of a triketone to give the Wieland-Miescher ketone under green conditions (water or neat) (Table 3).<smiles>[R]C(=O)[CH+]CC(C)=O</smiles>

$\mathrm{R}=\mathrm{Ph}$ DMSO, $90{ }^{\circ} \mathrm{C}, 24 \mathrm{~h} ; 55 \%$ yield, dr (anti:syn) $=1: 1.4,70 \% \mathrm{ee}$ $\mathrm{R}=\mathrm{Ph} \mathrm{DMSO}, \mathrm{MW}, 30 \mathrm{~min} ; 70 \%$ yield, dr (anti:syn) $=1: 1.4,80 \%$ ee $\mathrm{R}=$ isopropyl DMSO, $\mathrm{rt}, 24 \mathrm{~h} ; 45 \%$ yield, dr (anti:syn) $>20: 1,>99 \% \mathrm{ee}$ $\mathrm{R}=$ isopropyl DMSO, MW, 10 min; 60\% yield, dr (anti:syn) $>20: 1,>99 \%$ ee

Scheme 7. Aldol reactions with hydroxyketone

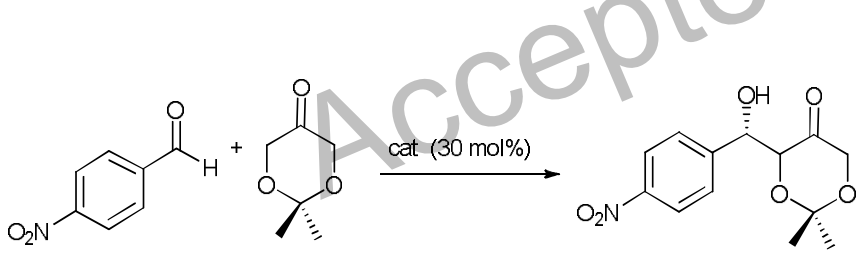

M61a, formamide, $\mathrm{rt}, 13 \mathrm{~h} ; 96 \% \mathrm{corr}, \operatorname{dr}($ anti:syn) $=2: 1,67 \%$ ee ( $2 \mathrm{runs})$ M61b, formamide, it, $48 \mathrm{~h}, 88 \% \mathrm{conv}$, dr (anti:syn) $=2: 1,46 \%$ ee

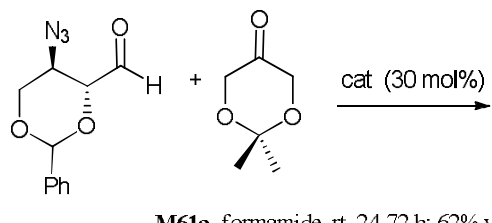<smiles>CC1(C)OCC(=O)C(C(O)[C@H]2OC(c3ccccc3)OCC2N)O1</smiles>

M61a, formamide, rt, $24-72 \mathrm{~h} ; 62 \%$ yield dr (anti:syn) $=5: 1$

Scheme 8. Aldol reactions with 2,2-dimethyl-1,3-dioxan-5-one

Table 3 Asymmetric intramolecular aldol reaction

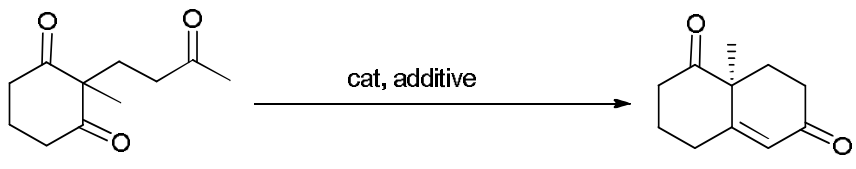

\begin{tabular}{|c|c|c|c|c|c|c|c|c|c|}
\hline Entry & Cat & Co-cat & $\mathrm{mol} \% \mathrm{cat}$ & Solvent/T/t & $\begin{array}{c}\text { Yield } \\
(\%)\end{array}$ & ee & Recycling & TON & $\begin{array}{l}\text { TOF } \\
\left(\mathrm{h}^{-1}\right)\end{array}$ \\
\hline 1 & M78 ${ }^{51}$ & $p-\mathrm{NO}_{2} \mathrm{C}_{6} \mathrm{H}_{4} \mathrm{COOH}(10 \mathrm{~mol} \%)$ & 16 & $\mathrm{H}_{2} \mathrm{O} /$ r.t. $/ 1 \mathrm{~d}^{\mathrm{a}}$ & $74^{b}$ & 43 & $5^{\mathrm{c}}$ & 4.6 & 0.19 \\
\hline 2 & $M 79 a^{52}$ & $p-\mathrm{NO}_{2} \mathrm{C}_{6} \mathrm{H}_{4} \mathrm{COOH}(10 \mathrm{~mol} \%)$ & 10 & $\mathrm{H}_{2} \mathrm{O} /$ r.t. $/ 2 \mathrm{~d}^{\mathrm{a}}$ & $61^{\mathrm{b}}$ & 44 & 5 & 6.1 & 0.13 \\
\hline 3 & $M 79 b^{52}$ & $p-\mathrm{NO}_{2} \mathrm{C}_{6} \mathrm{H}_{4} \mathrm{COOH}(10 \mathrm{~mol} \%)$ & 10 & $\mathrm{H}_{2} \mathrm{O} /$ r.t. $/ 2 \mathrm{~d}^{\mathrm{a}}$ & $60^{\mathrm{b}}$ & 42 & 5 & 6 & 0.13 \\
\hline 4 & M79d $d^{52}$ & $p-\mathrm{NO}_{2} \mathrm{C}_{6} \mathrm{H}_{4} \mathrm{COOH}(10 \mathrm{~mol} \%)$ & 10 & $\mathrm{H}_{2} \mathrm{O} / \mathrm{r}$.t. $/ 2 \mathrm{~d}^{\mathrm{a}}$ & $82^{b}$ & 48 & $5^{c}$ & 8.2 & 0.17 \\
\hline
\end{tabular}




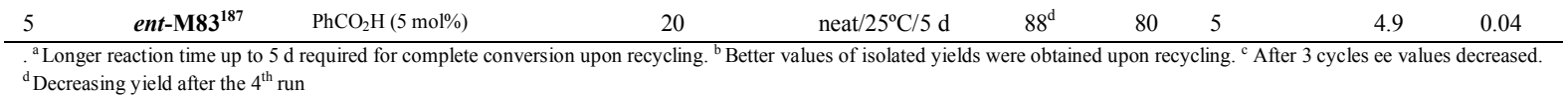

Furthermore, $\mathbf{M 8 3}$ was applied in the kinetic resolution of a racemic keto ester by an intramolecular aldol reaction (Scheme 9). ${ }^{187}$

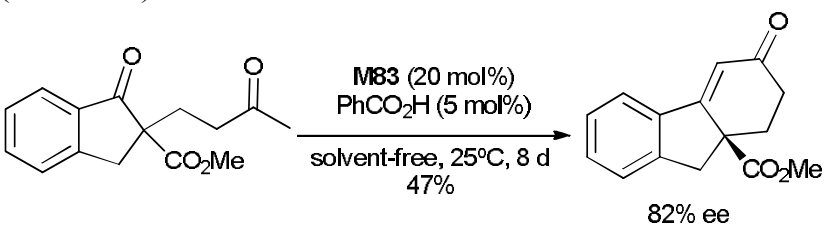

Scheme 9. Intramolecular aldol reaction of a racemic $\beta$-keto ester

Concerning the effect of solvent, several solvents of different nature have been used for asymmetric aldol reactions with silica-supported organocatalysts, as shown in tables 1-3, going from apolar and hydrophobic (such as toluene) to polar ones (such as DMSO). In proline-catalyzed aldol reactions, the highly polar transition states are stabilized by polar solvents, resulting in faster reactions. On the other hand, the beneficial effect of a small amount of water (oil-water interface), both in the efficiency and the stereoselectivity, has also been observed in both homogeneous and heterogeneous conditions. ${ }^{177,183,185,187,189}$ This allowed the successful use of apolar hydrophobic solvents and neat conditions by adding some equivalents of water in both cases. However, as mentioned before, the hydrophilic or hydrophobic nature of the support has also been found to have some influence on the yield and selectivity in different media. ${ }^{183}$ Concerning the reusability of the heterogeneous organocatalyst, Massi has found that apolar solvents (toluene, diisopropyl ether) allow better recycling than polar solvents $\left(\mathrm{CH}_{3} \mathrm{CN}\right)$, decreasing the degradation or leaching of the organic moiety, especially for non-covalently bound supported organocatalysts. ${ }^{182,186}$

\subsection{Asymmetric Michael reaction and conjugate additions}

The asymmetric conjugate addition of carbon nucleophiles to electron-deficient olefins using chiral organocatalysts is another important method for the formation of carbon-carbon bonds in a diastereo- and/or enantioselective manner. Two types of mechanisms can be found in the literature with silica-heterogenized chiral bases. On one hand, an enamine pathway employing secondary amines derived from proline or primary amines obtained from trans-1,2-diaminocyclohexane (materials of Figure 10). The second one is a general base mechanism by chiral ionpair formation followed by tertiary amines of the Cinchona family (materials of Figure 11). The most used donor prenucleophiles are malonates, malononitrile, nitroalkanes, and $\alpha$-enolizable aldehydes and ketones. As acceptor substrates, nitrostyrenes and cyclic or acyclic $\alpha, \beta$-unsaturated ketones (cyclohexenone, chalcone) have been tested. As previously mentioned for the aldol reaction, comparison of efficiencies and selectivities for different organocatalysts can only be conveniently established when the same reaction conditions and substrates are involved. The addition of aldehydes to nitroalkenes in water has been performed with diarylprolinol trimethylsilyl ether $\mathbf{M 9 2}$ affording products in moderate to good yields (up to 96\%) with good enantioselectivities (up to 90\% ee) and diastereoselectivities (up to 99:1). The catalyst was easily separated by an external magnet (Scheme 10). ${ }^{195}$

Cyclic and acyclic ketones have also been reacted with nitroalkenes under catalysis by supported prolinamide M78, ${ }^{51}$ 5-(pyrrolidin-2-yl)tetrazole M82, ${ }^{186}$ and pyrrolidines $\mathbf{M 8 7},{ }^{191} \mathbf{M 8 8}$ and $\mathbf{M 8 9} .{ }^{192}$ An acid co-catalyst was required for good conversions in the addition of 3-pentanone and butanone to nitrostyrene with M78 in water, obtaining the syn diastereoisomer as the major product with moderate enantioselectivities (Scheme 11) ${ }^{51}$ Table 4 summarizes some comparative results for the 1,4 addition of cyclohexanone to nitrostyrene. Whereas Cavazzini and Massi ${ }^{186}$ have chosen for proline tetrazole $\mathbf{M 8 2}$ a solvent of low-polarity, such as diisopropyl ether, due to enhanced selectivity over polar DMSO (Table 4, entry 1), much better efficiencies, diastereo- and enantioselectivities for this reaction were achieved under neat conditions by silica-supported pyrrolidines M87-M89 (Table 4, entries 2-4) after testing a variety of solvents of different polarity. ${ }^{191},{ }^{192}$ In this case, both the reactions conditions and the organic moiety of the supported catalyst play an important role on the catalytic results.

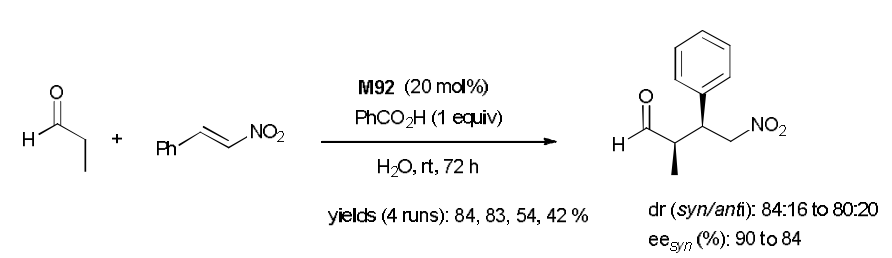

Scheme 10. Asymmetric Michael addition of $n$-propanal to trans- $\beta$-nitrostyrene

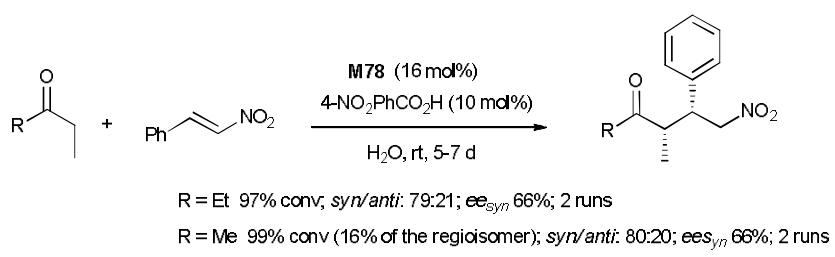


Scheme 11 Asymmetric Michael addition of 3-pentanone and butanone to trans- $\beta$-nitrostyrene

Table 4 Asymmetric Michael addition of cyclohexanone to trans- $\beta$-nitrostyrene

\begin{tabular}{|c|c|c|c|c|c|c|c|c|c|}
\hline Entry & Cat & $\mathrm{mol} \%$ & Solvent/T/t & $\begin{array}{c}\text { Yield } \\
(\%)\end{array}$ & $\begin{array}{c}d r \\
\text { syn/anti }\end{array}$ & $e e(\%)$ & Recycling & TON & $\begin{array}{l}\text { TOF } \\
\left(\mathrm{h}^{-1}\right)\end{array}$ \\
\hline 1 & M82 $^{186}$ & 30 & $(\mathrm{iPr})_{2} \mathrm{O} / \mathrm{r}$.t. $/ 24 \mathrm{~h}$ & 80 & $15 / 1$ & 55 & - & 2.7 & - \\
\hline 2 & M87 ${ }^{191}$ & 10 & neat $/ \mathrm{r} . \mathrm{t} / 72 \mathrm{~h}$ & 97 & $96 / 4$ & 91 & 4 & 9.7 & 0.13 \\
\hline 3 & M88 $^{192}$ & 10 & neat/r.t./36 h & 91 & $98 / 2$ & 98 & 6 & 9.1 & 0.25 \\
\hline 4 & M89 $^{192}$ & 10 & neat/r.t. $/ 36 \mathrm{~h}$ & 87 & $98 / 2$ & 98 & - & 8.7 & 0.24 \\
\hline
\end{tabular}

Silica-supported quinines M97a,b have been evaluated for the Michael addition of malononitrile to chalcones. Both the activity and the enantioselectivity were enhanced by using the short mesochannels SBA-15 support compared with the conventional analogue (Scheme 12). ${ }^{198}$

Trans-1,2-diaminocyclohexane mesoporous silicas M91a-d, ${ }^{194}$ and heterogenized 9-amino(9-deoxy)epiquinine $\mathbf{M 9 8}$ and 9-thiourea epiquinine ${ }^{90}$ have been applied as catalysts for asymmetric Michael addition of nitroalkanes to chalcones (Table 5), using in this case an apolar solvent such as toluene. In the case of M91a-d, short channels and plugs in the pore structure offered chiral enhancement in the addition. Visible improvement in the activity and enantioselectivity has been achieved by introducing thiourea moiety in the Cinchona derivative (compare M98 and M99a) and dependence of the selectivity on the pore size of mesoporous host has been explored.

$$
\begin{aligned}
& \mathrm{NC} \sim \mathrm{CN}+\mathrm{Ph}_{\mathrm{Ph}} \underset{\text { toluene, r.t. } 5 \mathrm{~d}}{\mathrm{Cat}(10 \mathrm{~mol} \%)} \\
& \text { M97a } 72 \% \text { yield, } 62 \% \text { e; } 3 \text { runs } \\
& \text { M97b } 38 \% \text { yield, } 44 \% € e
\end{aligned}
$$

Scheme 12 Asymmetric Michael addition of malononitrile to chalcone

Table 5 Asymmetric Michael addition of nitromethane to chalcone

\begin{tabular}{llllllllll} 
& & & & & & \\
\hline
\end{tabular}

Chiral enhancement in the diethyl malonate conjugate addition to cyclohex-2-en-1-one has also been observed in Lproline derived materials possessing short channels and plugs in the pore structure (compare M90a-c and M90d in Scheme 13). ${ }^{50,193}$

Zaera has also described the conjugate addition of p-tert-butylbenzenethiol to 2-cyclohexen-1-one catalyzed by cinchonidines M102a,b and M103a,b. ${ }^{91}$ Although full conversions were achieved after one day in benzene at room temperature with the supported catalysts, a loss of enantioselectivity was observed upon tethering, which was attributed to the interference of the surface of the solid on the catalytic performance. 


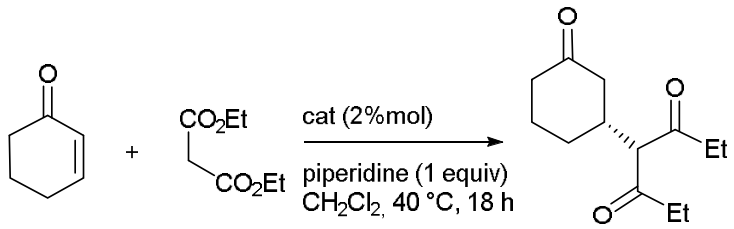

M90a, conv $49 \%$, ee $64 \%$ (2 runs)

M90b, conv $57 \%$, ee $68 \%$ (2 runs)

M90c, conv $61 \%$, ee $70 \%$ (2 runs)

Scheme 13 Asymmetric Michael addition of diethyl malonate to cyclohexenone

Although a variety of solvents have been reported for diverse Michael additions, as seen from the examples mentioned in this section, some authors concluded, after a solvent screening, that water ${ }^{195}$ (Scheme 10) or neat conditions ${ }^{191,192}$ (entries 2, 3 and 4 in Table 4) were the best options taking into account activity, selectivity and environmental concerns.

\subsection{Asymmetric multicomponent reactions}

Knoevenagel-Michael cascade reaction of isatin, malononitrile and acetone has been recently found as an effective approach to produce enantiomerically enriched 3,3'-disubstituted oxindoles under catalysis by proline-supported M73a-d (Scheme 14). ${ }^{183}$

Asymmetric Henry-Michael one-pot reaction involving benzaldehyde, nitromethane and cyclohexanone has been achieved with proline-derived catalysts M93-M96 with moderate diastereoselectivities and good enantioselectivities (Scheme 15). ${ }^{196}$

Similar asymmetric multicomponent Henry-Michael reactions between aromatic or heteroaromatic aldehydes, nitromethane and malonates have been accomplished by Corma et al by using supported Cinchona derivatives M100 and M101 (Scheme 16). ${ }^{199,} 209$

A three-component synthesis of spiroindolones in water has been reported under catalysis by a reusable silicasupported L-proline M116, although the process was not stereoselective. A model condensation reaction of isatin, barbituric acid and malononitrile is represented in Scheme 17. The process would involve a Knoevenagel condensation followed by Michael addition and further cyclization. ${ }^{210}$

A convenient method for the synthesis of cyclohexenones has recently been developed using a L-proline immobilized silica gel organocatalyst by a continuous-flow approach. The reaction of acetone with aliphatic, aromatic or heteroaromatic aldehydes takes place by initial aldol condensation followed by a Michael addition and subsequent Robinson cyclization. However the process is not enantioselective. ${ }^{211}$

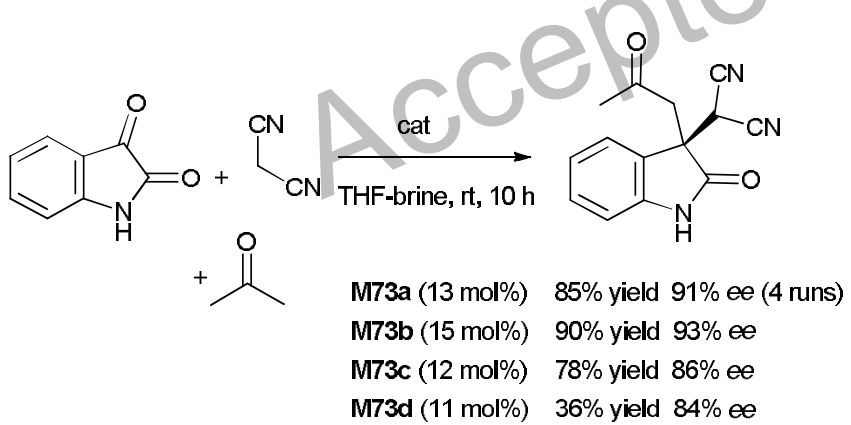

Scheme 14 Asymmetric Knoevenagel-Michael cascade reaction of isatin, malononitrile and acetone

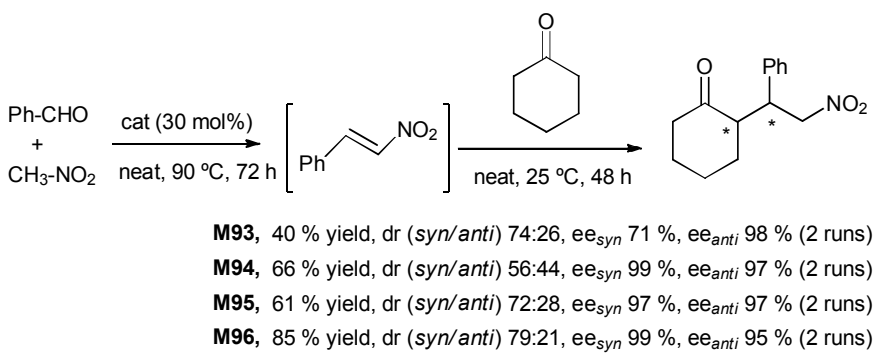

Scheme 15 Asymmetric Henry-Michael one-pot reaction between benzaldehyde, nitromethane and cyclohexanone 


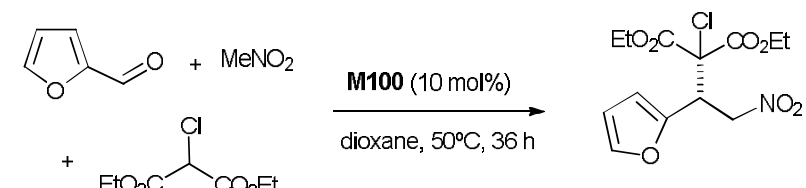

4 runs, yields: $90,93,85,54 \%$, er $93: 7,91: 9,93: 7,92: 8$<smiles>COC(C)=O</smiles>

$\underset{\text { o-xylene, } 70^{\circ} \mathrm{C}, 18 \mathrm{~h}}{\stackrel{\text { M101 }(10 \mathrm{~mol} \%)}{\longrightarrow}}$<smiles>CC(=O)C(C(C)=O)[C@H](C[N+](=O)[O-])c1ccccc1</smiles>

$76 \%$ yield, er $85: 15$

Scheme 16 Asymmetric multicomponent Henry-Michael reactions between aromatic aldehydes, nitromethane and malonates

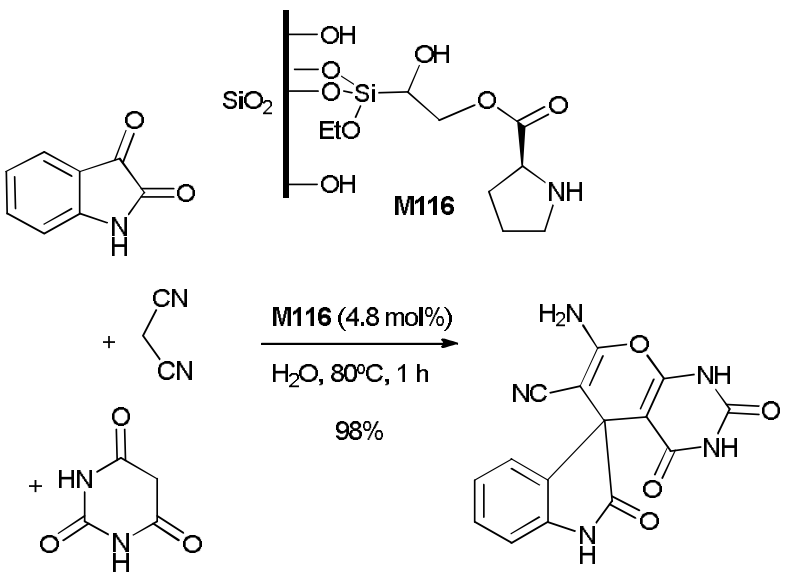

Scheme 17 Three-component synthesis of a spiroindolone

\subsection{Asymmetric Diels-Alder cycloadditions}

Asymmetric Diels-Alder reactions with several diene and dienophiles have been achieved with silica-supported imidazolidinones via an iminium activation pathway (M108-M115 in Figure 13).

Some comparative results for the reaction between cyclopentadiene and cinnamaldehyde under batch conditions are summarized in Table 6. By immobilizing the enantiomerically pure organocatalysts in different types of supports (silica, MCF, SILC, PMO nanospheres, MSN) low exo-endo diastereoselectivities and moderate to good enantioselectivities for both the endo and exo adducts were obtained under mild conditions. In most cases an acid co-catalyst was added. Water or mixtures of water with other polar solvents (alcohols, acetonitrile, THF) have been mainly used. Partial capping of the MCF silanols in materials M109 improved the enantioselectivity (compare entries 3 and 4 with entry 2 in Table 6). The more hydrophobic $t$-amyl alcohol was found to be the best choice, among different alcohols tested, in order to prevent the leaching of MacMillan catalyst in M111a-c (entries 5,6 and 7 in Table 6), where there is no covalent anchoring to the support. The importance of the counter anion in the recycling has also been observed. ${ }^{204}$ Other dienophiles have also been explored with M111b and the low endo selectivity was attributed to inherent steric crowding of the imidazolidinone moiety. ${ }^{204}$ It is worth noting that hollow structured PMO spheres exhibit higher catalytic activity than solid PMO spheres (compare M113a and M112a in entries 11 and 9 of Table 6) and catalysts prepared by co-condensation process and click chemistry modification are more active than those synthesized by a grafting method (compare M113a and M113b in entries 11 and 12 of Table 6). ${ }^{205}$ Benaglia and Puglisi have also performed this reaction with functionalized silica nanoparticles M114a,b and M115b under continuous-flow conditions in a homemade reactor, achieving higher TON values than in batch process. Moreover, by regeneration of the organocatalytic column, the life of the reactor has been prolonged for more than $300 \mathrm{~h}^{206,207}$

Table 6 Enantioselective Diels-Alder cycloaddition between cyclopentadiene and cinnamaldehyde

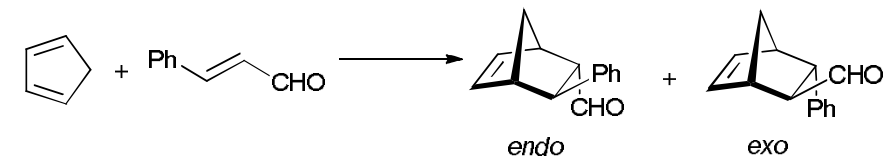

\begin{tabular}{|c|c|c|c|c|c|c|c|c|c|c|c|}
\hline \multirow[t]{2}{*}{ Entry } & \multirow[t]{2}{*}{ Cat } & \multirow[t]{2}{*}{$\mathrm{mol} \%$} & \multirow[t]{2}{*}{ Co-cat } & \multirow[t]{2}{*}{ Solvent/T/t } & \multirow[t]{2}{*}{ Yield (\%) } & \multirow[t]{2}{*}{ endo:exo } & \multicolumn{2}{|c|}{$e e(\%)$} & \multirow[t]{2}{*}{ TON } & \multirow[t]{2}{*}{ TOF } & \multirow[t]{2}{*}{ Recycling } \\
\hline & & & & & & & endo & exo & & & \\
\hline 1 & M108 $^{203}$ & 3.3 & $\mathrm{HCl}$ & $\mathrm{CH}_{3} \mathrm{CN}-\mathrm{H}_{2} \mathrm{O} /$ r.t. $/ 64 \mathrm{~h}$ & 33 & $1 / 1.1$ & 90 & 90 & 10 & 0.16 & \\
\hline 2 & M109a $a^{61}$ & 5 & TFA & THF- $\mathrm{H}_{2} \mathrm{O} /$ r.t. $/ 30 \mathrm{~h}$ & 93 & $1 / 1.3$ & 74 & 73 & 18.6 & 0.62 & $2^{\mathrm{a}}$ \\
\hline
\end{tabular}




\begin{tabular}{|c|c|c|c|c|c|c|c|c|c|c|c|}
\hline 3 & M109b ${ }^{61}$ & 5 & TFA & THF $-\mathrm{H}_{2} \mathrm{O} /$ r.t. $/ 30 \mathrm{~h}$ & 93 & $1 / 1.3$ & 87 & 83 & 18.6 & 0.62 & $2^{\mathrm{a}}$ \\
\hline 4 & $\mathrm{M}_{110}{ }^{61}$ & 5 & TFA & THF $-\mathrm{H}_{2} \mathrm{O} /$ r.t. $/ 30 \mathrm{~h}$ & 95 & $1 / 1.3$ & 85 & 83 & 19 & 0.63 & $2^{\mathrm{a}}$ \\
\hline 5 & M111a $^{204}$ & 10 & & $95 \% \mathrm{EtOH} /$ r.t. $/ 27 \mathrm{~h}$ & 73 & $1 / 1.1$ & 95 & 90 & 7.3 & 0.27 & 2 \\
\hline 6 & M111b ${ }^{204}$ & 10 & & $t$-amylOH /r.t. $22 \mathrm{~h}$ & 69 & $1 / 1.2$ & 87 & 81 & 6.9 & 0.31 & 6 \\
\hline 7 & M111c ${ }^{204}$ & 10 & & $t$-amylOH /r.t./22 h & 74 & $1 / 1.2$ & 92 & 80 & 7.4 & 0.34 & - \\
\hline 8 & M111d 204 & 10 & & $t$-amylOH /r.t./24 h & 52 & $1 / 1.3$ & 71 & 64 & 5.2 & 0.22 & - \\
\hline 9 & M112a ${ }^{205}$ & 20 & TFA (20 mol $\%)$ & $\mathrm{H}_{2} \mathrm{O} / \mathrm{r} . \mathrm{t} / 12 \mathrm{~h}$ & 84 & $1 / 1.1$ & 79 & 78 & 3.95 & 0.33 & - \\
\hline 10 & M112b $^{205}$ & 20 & TFA (20 mol $\%)$ & $\mathrm{H}_{2} \mathrm{O} / \mathrm{r} . \mathrm{t} / 12 \mathrm{~h}$ & 80 & $1 / 1.1$ & 59 & 62 & 4 & 0.33 & - \\
\hline 11 & M113a ${ }^{205}$ & 20 & TFA (20 mol $\%)$ & $\mathrm{H}_{2} \mathrm{O} / \mathrm{r} . \mathrm{t} / 12 \mathrm{~h}$ & 98 & $1 / 1.1$ & 81 & 81 & 4.05 & 0.34 & $8^{\mathrm{a}}$ \\
\hline 12 & M113b $^{205}$ & 20 & TFA $(20 \mathrm{~mol} \%)$ & $\mathrm{H}_{2} \mathrm{O} / \mathrm{r} . \mathrm{t} / 12 \mathrm{~h}$ & 86 & $1 / 1.2$ & 63 & 62 & 4.3 & 0.36 & - \\
\hline 13 & M114a $\mathbf{a}^{207}$ & 30 & $\mathrm{HBF}_{4}$ & $\mathrm{CH}_{3} \mathrm{CN}-\mathrm{H}_{2} \mathrm{O}(95: 5) / 25^{\circ} \mathrm{C} / 48 \mathrm{~h}$ & 75 & $53 / 47$ & 75 & 76 & 2.5 & 0.05 & - \\
\hline 14 & M114a $\mathbf{a}^{207}$ & 30 & TFA & $\mathrm{CH}_{3} \mathrm{CN}-\mathrm{H}_{2} \mathrm{O}(95: 5) / 25^{\circ} \mathrm{C} / 48 \mathrm{~h}$ & 69 & $51 / 49$ & 80 & 82 & 2.3 & 0.05 & - \\
\hline 15 & M114b $^{207}$ & 30 & $\mathrm{HBF}_{4}$ & $\mathrm{CH}_{3} \mathrm{CN}-\mathrm{H}_{2} \mathrm{O}(95: 5) / 25^{\circ} \mathrm{C} / 48 \mathrm{~h}$ & 78 & $52 / 48$ & 78 & 77 & 2.6 & 0.05 & $2^{\mathrm{b}}$ \\
\hline 16 & M114b ${ }^{207}$ & 30 & TFA & $\mathrm{CH}_{3} \mathrm{CN}-\mathrm{H}_{2} \mathrm{O}(95: 5) / 25^{\circ} \mathrm{C} / 48 \mathrm{~h}$ & 66 & $53 / 47$ & 83 & 86 & 2.2 & 0.05 & $2^{\mathrm{b}}$ \\
\hline 17 & M115b ${ }^{207}$ & 30 & $\mathrm{HBF}_{4}$ & $\mathrm{CH}_{3} \mathrm{CN}-\mathrm{H}_{2} \mathrm{O}(95: 5) / 25^{\circ} \mathrm{C} / 48 \mathrm{~h}$ & 75 & $54 / 46$ & 91 & 89 & 2.5 & 0.05 & - \\
\hline 18 & M115b $^{207}$ & 30 & TFA & $\mathrm{CH}_{3} \mathrm{CN}-\mathrm{H}_{2} \mathrm{O} / 25^{\circ} \mathrm{C} / 48 \mathrm{~h}$ & 52 & $55 / 45$ & 87 & 97 & 1.73 & 0.04 & - \\
\hline
\end{tabular}

Good activity and high diastereo- and enantioselectivities have been obtained in the cycloaddition reactions of acrolein with 2-methylbutadiene and cyclohexadiene with $\mathbf{M 1 0 8}^{\mathbf{2 0 3}}$ and $\mathbf{M 1 1 1 b}^{204}$ (Scheme 18).

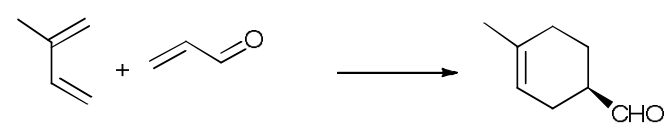

M108 (20 mol\%), $\mathrm{CH}_{3} \mathrm{CN}-\mathrm{HCl}_{\mathrm{aq}}$, r.t., $24 \mathrm{~h} ; 79 \%$ yield, endo $90 \%$ ee

M111b (10 mol\%), t-amylOH, r.t, 26 h; $80 \%$ yield, endo $93 \% œ$
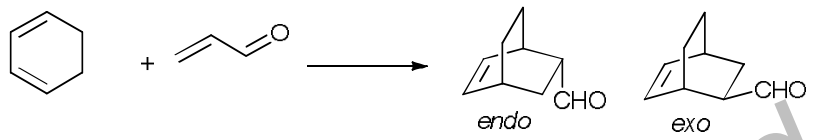

M108 (20 mol\%), $\mathrm{CH}_{3} \mathrm{CN}-\mathrm{HCl}_{\mathrm{aq}}$, r.t., $24 \mathrm{~h} ; 83 \%$ yield; endo/exo 14:1; endo $90 \% £$

M111b (10 mol\%), t-amylOH, r.t., 48 h; $80 \%$ yield; endo/exo 18:1; endo $80 \%$ ee

Scheme 18 Asymmetric Diels-Alder cyeloadditions

\subsection{Other asymmetric reactions with organosilicas derived from proline, Cinchona alkaloids or MacMillan imidazolidinones}

Supported proline $\mathbf{M 7 1}$ catalyzed the $\alpha$-amination of isovaleraldehyde with dibenzyl azodicarboxylate under continuous-flow conditions ${ }^{182}$ and pyrrolidinyl tetrazole $\mathbf{M 8 2}$ was tested in model Mannich and $\alpha$-amination reactions in batch mode with cyclohexanone as donor substrate ${ }^{186}$ (Scheme 19). Binam-prolinamide M83 has been found a good recyclable catalyst for the Friedlander condensation between cyclohexanone derivatives and 2aminoaromatic aldehydes under solvent-free conditions (Scheme 20). ${ }^{212}$

Silica-immobilized bis-cinchona alkaloids M104-M107 were explored for the desymmetrization of meso-cyclic anhydrides with alcoholysis, achieving high enantioselectivitiy and recyclability (Scheme 21). ${ }^{201}$ Supported 9thiourea epi-quinine M99b exhibited enhanced enantioselectivity in the asymmetric Friedel-Crafts reaction of indoles with imines as a result of the immobilization inside the nano-sized channels of the SBA-15 (Scheme 22). ${ }^{200}$ Heterogenized imidazolidinones M109a,b and M110 have also been successfully applied for the enantioselective Friedel-Craft alkylation of $N$-methylpyrrole with trans-cinnamaldehyde (Scheme 23) ${ }^{61}$ For comparative purposes with heterogeneous metal-containing catalysts, we should mention that asymmetric Friedel-Crafts alkylation of indoles with nitroalkenes has been performed with catalytic systems prepared by mixing copper(II) salts, a chiral ligand and different supports $\left(\mathrm{SiO}_{2}, \mathrm{Al}_{2} \mathrm{O}_{3}\right.$, molecular sieves, zeolites) with TON values ranging from 6 to 12 depending on the support. ${ }^{213}$ Corma has also reported enantioselective Friedel-Crafts hydroxyalkylation of 1,3dimethoxybenzene using silica-supported chiral copper(II) bisoxazoline (TON: 7-8). ${ }^{214}$ Thus, organocatalysts used in the reactions of schemes 22 and 23 present better or similar performances (TON: 77 and 7.2 ) than more conventional metal-containing catalysts. 


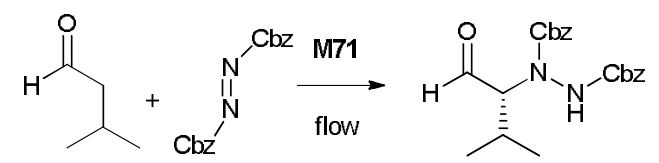

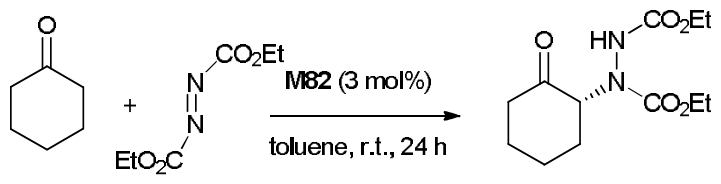

$72 \%$ yield, $\infty 71 \%$

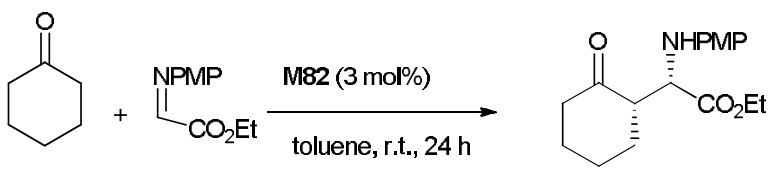

$>95 \%$ yield, $d r$ syn/anti > 19:1, $\infty_{\text {syn }} 95 \%$

Scheme 19 Asymmetric Mannich and $\alpha$-amination reactions

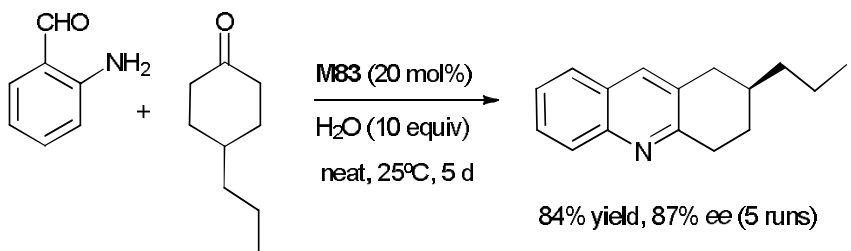

Scheme 20 Asymmetric Friedlander condensation

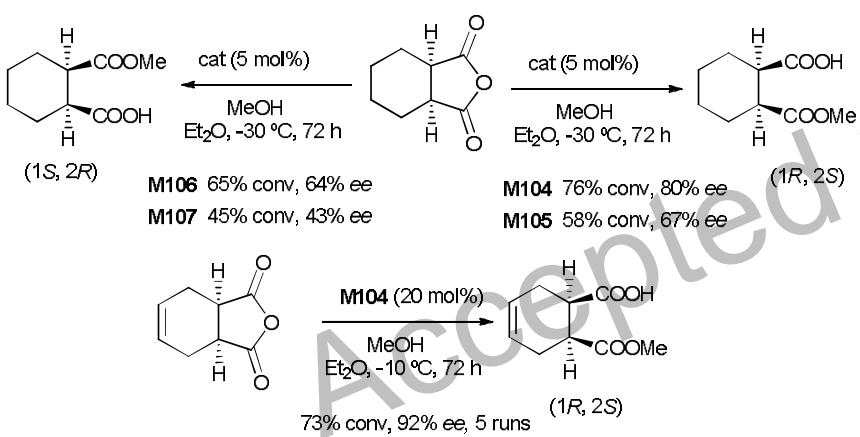

Scheme 21 Desymmetrization of meso-cyclic anhydrides

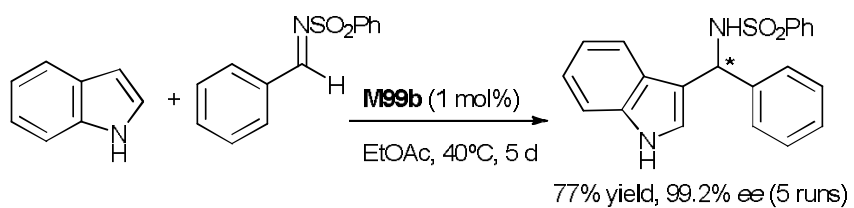

Scheme 22 Asymmetric Friedel-Crafts reaction of indoles with imines

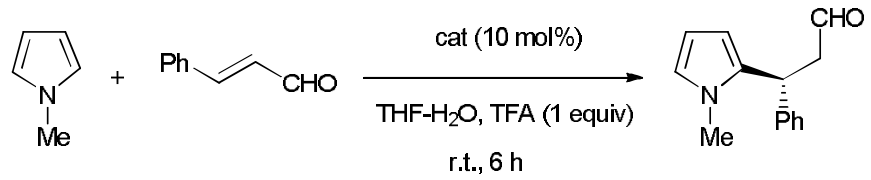

M109a $72 \%$ yield, $67 \% \Subset$; M109b $71 \%$ yield, $68 \%$ e; M110 $72 \%$ yield, $74 \%$ ee

Scheme 23 Asymmetric Friedel-Crafts alkylation of $N$-methylpyrrole with cinnamaldehyde

\subsection{Miscellaneous}

\subsubsection{ACID ANd B ASE-Catalyzed Diels-Alder CYCloadditions}

Urea- and thiourea-functionalized mesoporous silica nanoparticles M117a-d have been used as Lewis acid catalysts for carbonyl activation in the Diels-Alder reactions between cyclopentadiene and several $\alpha, \beta$-unsaturated aldehydes (Scheme 24). They exhibited a superior catalytic activity than their homogeneous analogues, the reactivity 
enhancement being attributed to the surface hydrogen bonding between the urea/thiourea moieties and silanol groups and to the site isolation effect induced by heterogenization. The recycling of M117b has been successfully achieved up to 10 runs in the reaction between cyclopentadiene and methyl vinyl ketone. ${ }^{215}$

On the other hand, proazaphosphatranes (Verkade's superbases) immobilized onto SBA-15 by post-synthetic grafting (M118a-c) have also been evaluated as recyclable organocatalysts in the Diels-Alder reactions of anthrone and 3-hydroxy-2-pyrone with dienophiles (Scheme 25). High activities and endo/exo selectivities have been found, and M118c was reused up to 3 cycles without loss of activity. ${ }^{54}$

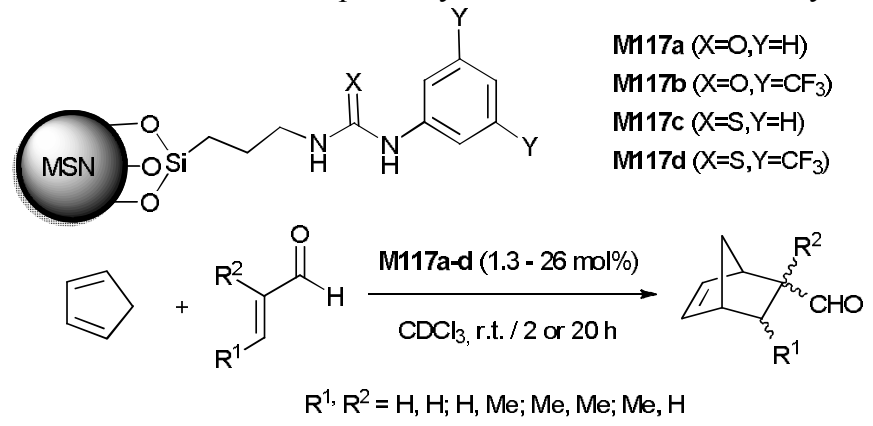

Scheme 24 Diels-Alder cycloadditions with urea/thiourea-functionalized MSN

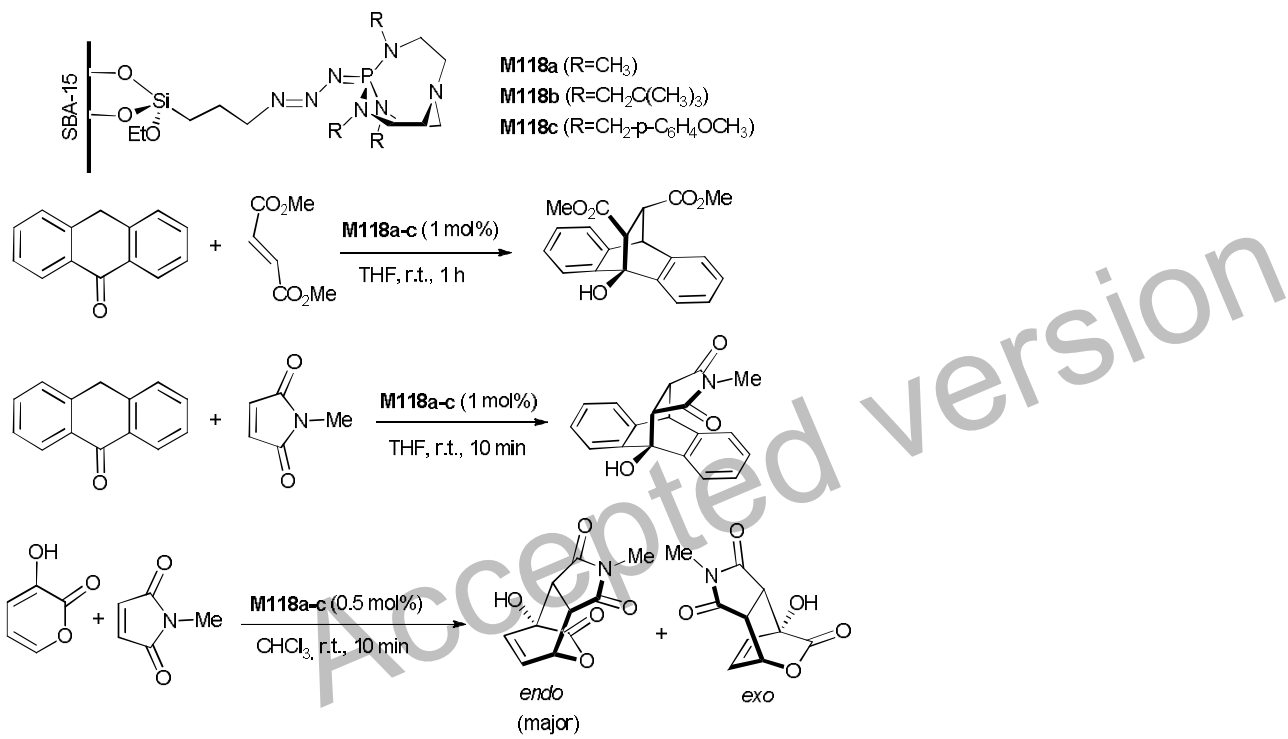

Scheme 25 Diels-Alder cycloadditions with supported bases

\subsubsection{NUCLEOPHILIC CROSS-CONJUGATE ADDITION}

A reusable proline-modified SBA-15 M119 promoted the intermolecular conjugate addition between nitroalkenes and enones (Scheme 26). ${ }^{216}$ The proposed mechanism involves secondary amine nucleophilic addition to the nitroalkene followed by sequential enone-conjugate addition. However, low diastereoselectivity was achieved due to rapid epimerization on the nitro position and negligible enantiomeric excesses were observed.
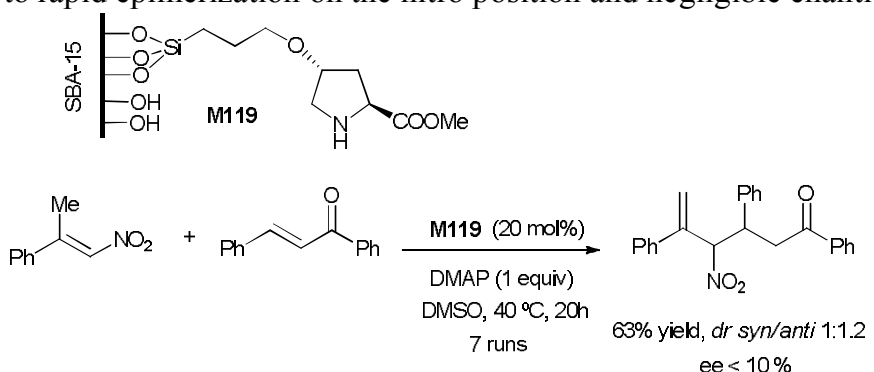

Scheme 26 Nucleophilic cross-conjugate addition

\subsubsection{SILICA-SUPPORTED ORGANOCATALYSTS FOR OXIDATION REACTIONS}

Karimi has reported a green, transition-metal-free SBA-15-supported TEMPO catalyst M120 as highly efficient and selective for the aerobic oxidation of a wide range of alcohols, including secondary and even sterically hindered ones, substrates that were reluctant to oxidation with previous heterogeneous systems involving TEMPO/O $\mathrm{O}_{2}$ in combination with transition metals (Scheme 27). ${ }^{217}$ This recyclable heterogeneous organocatalyst (14 consecutive 
runs) turned out to be very sustainable and neither the organic group nor the nanometer-scale voids and channels of the SBA-15 support were significantly affected by multiple uses.

Proline-derived organosilicas M90a-d have been tested in the asymmetric epoxidation of cynnamaldehyde with hydrogen peroxide with moderate enantiomeric excesses. ${ }^{193}$ The suggested mechanism for this reaction involves the formation of an enamine intermediate.

Enantiomerically pure iminium cations adsorbed in Al-MCM-41 M121 and M122 have been described as effective catalysts for the asymmetric epoxidation of alkenes in the presence of tetraphenylphosphonium monoperoxosulphate (TPPP) as oxidant (Scheme 28). The process would involve the formation of a chiral oxaziridinium intermediate capable of transferring an oxygen atom directly to the prochiral substrate. ${ }^{218}$ The catalysts were found reusable, but although enantiomeric excesses remained constant, the conversions decreased upon recycling. These supported organocatalysts, however, give lower conversions at higher reaction times that more conventional polymer-bound Mn-salens. ${ }^{219}$

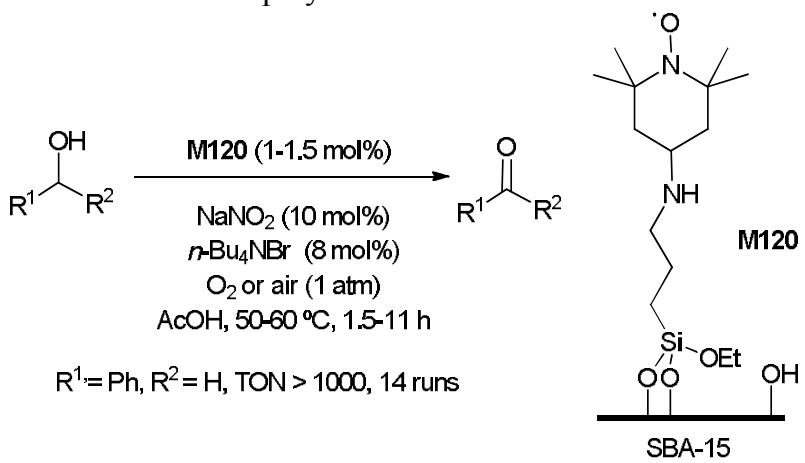

Scheme 27 Silica-supported TEMPO for aerobic oxidation

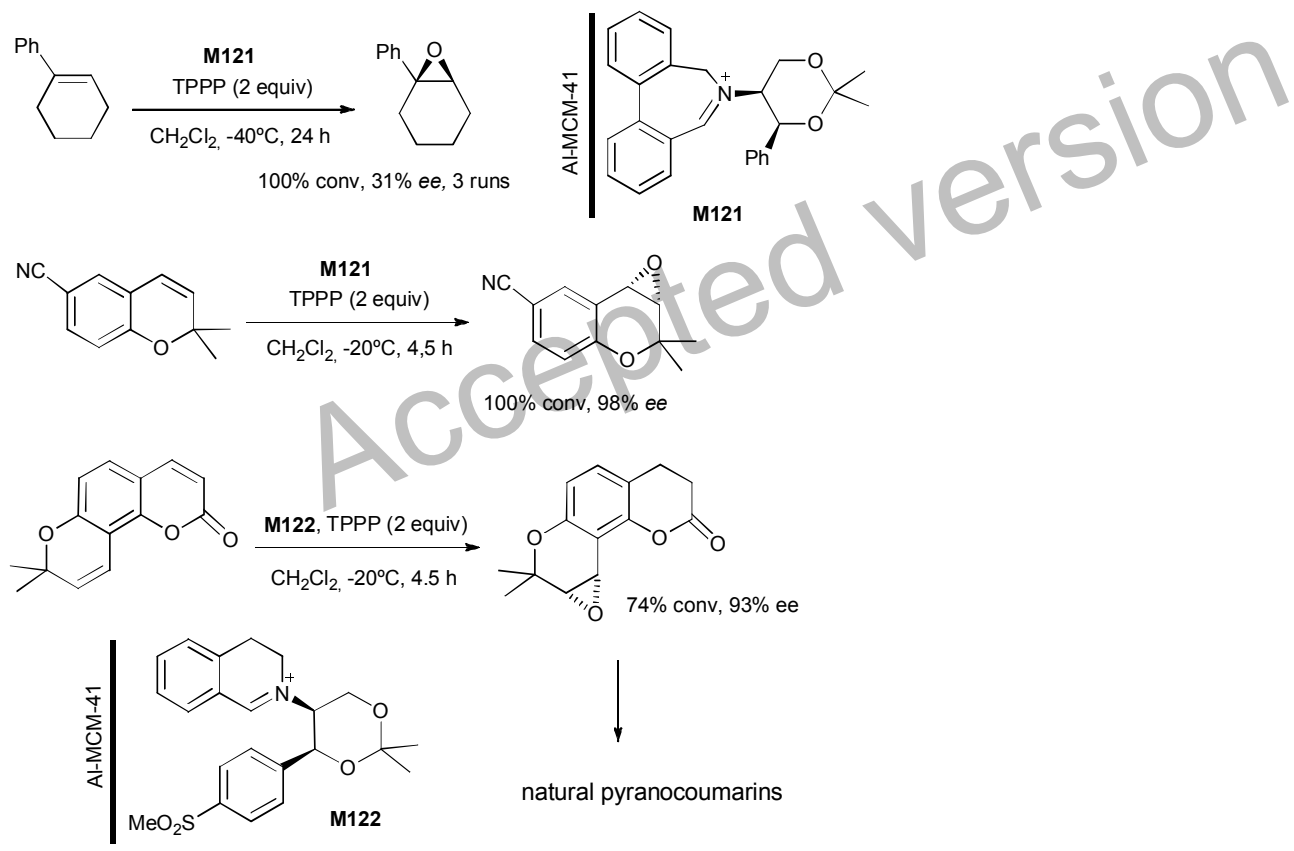

Scheme 28 Silica-supported chiral iminium salts for alkene epoxidation

\subsubsection{SILICA-SUPPORTED THIAZOLIUM SALTS}

Thiazolium salts have been grafted to different mesoporous supports (MCM-41, PMO-Ph, PMO-Et) to afford M123a,c,d. Materials M123b and M123e were obtained by further modification of the silica matrix in M123a (Figure 14). ${ }^{220,221}$

The organocatalysts $\mathbf{M 1 2 3}$ have been evaluated, in the presence of a base, in the benzoin condensation (Scheme 29) as well as in the cross-coupling of aldehydes with acyl imines to deliver $\alpha$-amidoketones (Scheme 30 ), reactions that proceed through formal acyl anion intermediates. ${ }^{220,221} \mathrm{An}$ enhancement of the catalytic activity was achieved by increasing the hydrophobicity of the surface support. Interestingly, without $\mathrm{NEt}_{3}$ as free base, the benzoin condensation proceeded with M123e although with a low yield (20\% in 48h) while with the two other MCM41-type catalysts, M123a,b no conversion was observed. This clearly indicates that even grafted tertiary amine can get involved in the reaction. 

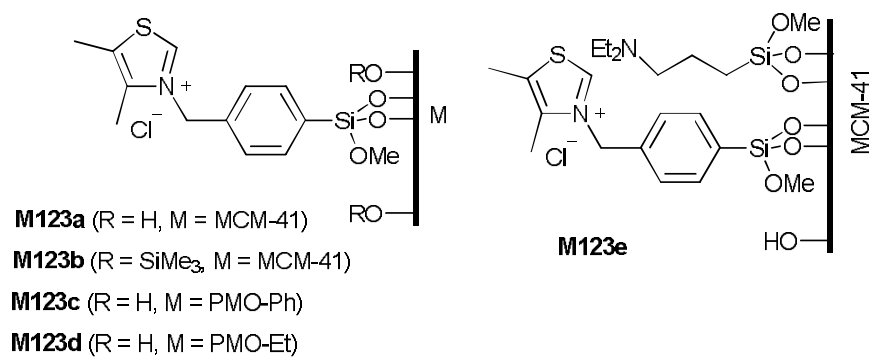

Figure 14 Silica-supported thiazolium salts for nucleophilic acylation reactions

$$
\text { cat, } \mathrm{NEt}_{3}
$$

M123a time $=48 \mathrm{~h}, 74 \%$ yield, 2 runs

M123b time $=48 \mathrm{~h}, 81 \%$ yield,

M123c time $=24 \mathrm{~h}, 85 \%$ yield, 2 runs

M123d time $=24 \mathrm{~h}, 71 \%$ yield, 2 runs

M123e time $=48 \mathrm{~h}, 20 \%$ yield, $\mathrm{NEt}_{3}$ was omitted

Scheme 29 Benzoin condensation

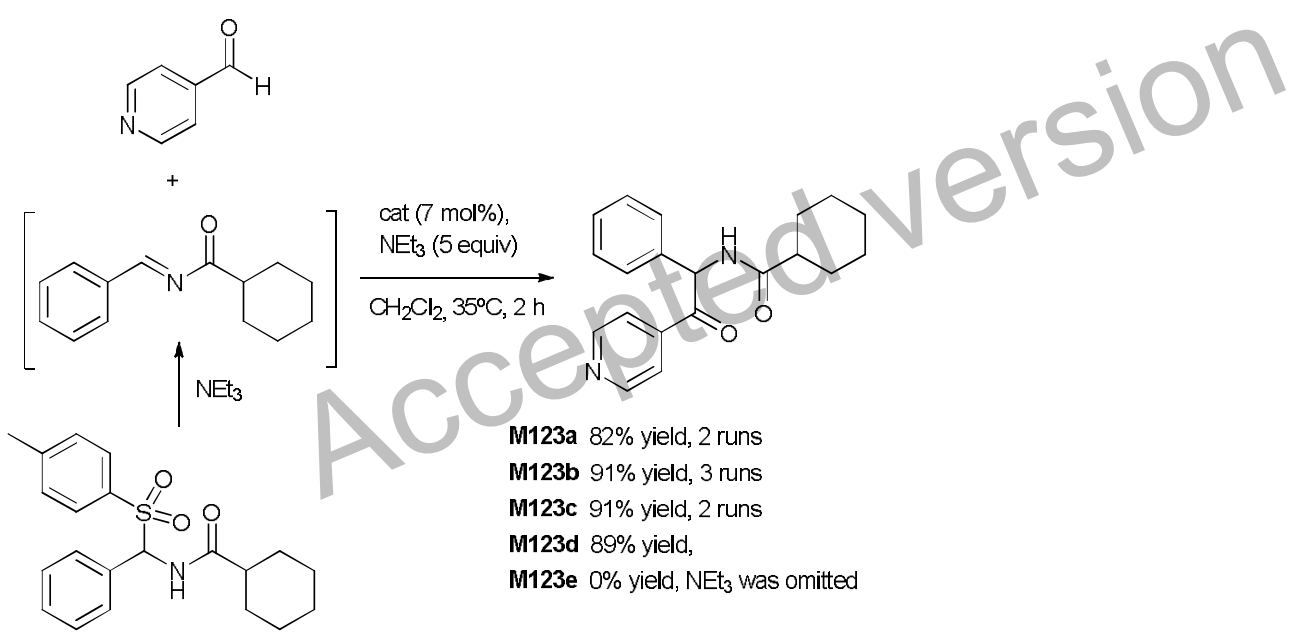

Scheme 30 Reaction of aldehydes with acylimines

\section{Conclusions}

Silica-based organocatalytic materials have known a tremendous development over the past years. This research field covers both simple achiral acids and bases supported on silicas for $\mathrm{C}-\mathrm{C}$ bond formation, but also the emerging families of chiral organocatalysts which are being used for the asymmetric synthesis of fine chemicals. Organocatalysis is complementary to organometallic catalysis, with usually lower activities, but with the advantage of cheaper operation, avoiding traces of metallic species in the products, and providing new organic transformations.

The main reasons for supporting an organocatalyst are to simplify the separation of the catalyst from the reaction mixture, to facilitate the isolation of the product and to recover and reuse the catalyst. This is especially important in the case of expensive organocatalysts which are used in relatively high amounts when compared with organometallic catalysts. For hybrid silicas, the insolubility of the materials allows not only an easy separation by filtration when working in batch-mode, but also the implementation of continuous flow processes. Moreover, working with immobilized catalysts has enabled in some cases the use of greener solvents, and avoiding the use of co-catalysts.

Several criteria should be taken into account when developing a silica-supported organocatalyst. As a decrease of chemical activity is expected upon immobilization, homogeneous organocatalysts of high catalytic efficiency should be preferably envisioned. Versatility in scope (a variety of substrates for a given reaction and/or several types of reactions) is also desirable for the homogeneous candidate. For the case of asymmetric reactions, the stereoselectivity depends on the adoption of a right and well-defined orientation of the substrate relative to the 
catalytic centre. It appears that the immediate surroundings of the active site can favour or disfavour the right approach for the stereoselection to take place. In this sense, the characteristics of the matrix and the nature and length of the linker can exert a crucial influence on the selectivity. The presence of silanol groups on the surface of the silica support placed near the active site of the immobilized organocatalyst has thus to be taken into account, as it may cause a deleterious effect. The cost of the starting material (i.e. 4-hydroxy-L-proline is more expensive than L-proline) can affect the choice of the synthetic strategy for the immobilization of the organocatalyst. The derivatization site on the catalytic moiety and the linker used to graft it on the material have also been found to influence the catalytic performance and selectivity.

The degree of functionalization of the support is another important factor in organocatalytic reactions where a high loading of catalyst is needed. In principle, the sol-gel methodologies should enable a higher number of organic motifs per gram compared with grafting procedures and, accordingly, a decrease of the weight amount of immobilized catalyst needed. On the other hand, chemically stable and robust heterogenized organocatalysts are required. The silica-supported organocatalysts usually present high chemical stability under the mild conditions employed in organocatalytic reactions, with retention of the nanostructure of the support upon recycling, especially for those where the catalytic moiety is covalently bound to the silica backbone. The leaching of the catalytic moiety is much lower than in more labile supported metal-based catalysts, where in some case the loss of the metal in appreciable amounts is still a real problem.

From the material's point of view, it is still very difficult to draw precise design criteria for preparing efficient organocatalytic materials. Indeed, very few studies have addressed the influence of the type of supporting material on the catalytic properties for a given reaction, and the few reactions studied give results that may appear counterintuitive, such as good catalytic activities for non-porous materials. Concerning mesostructured materials, though many reports and reviews mention the importance of confinement for improving the selectivity of the catalytic processes such effects have been only scarcely characterized for basic catalysis, which can often be related to the proximity between catalytic moieties and proximal silanol groups. Therefore, much work has to be done in order to find general design criteria to achieve efficient organocatalytic materials. Some recent examples have shown that mesostructured materials are not always the best solution to get high catalytic activity or asymmetric induction, and that much simpler and greener materials such as those obtained by sol-gel co-condensation can afford interesting results. $^{52,199,209}$ A wide range of supporting materials is now achievable by the various techniques summarized in Section 2, and should therefore be investigated more in depth. Another challenge to address when studying supported organocatalysts is to understand the environments of the catalytic sites and their diversity, their accessibility by the reagents, and the evolution of the catalytic materials during and after use. Spectroscopic studies would allow understanding better the processes behind the catalyst deactivation and the decrease of selectivity usually observed in order to improve further the catalytic materials and the experimental protocols for catalysis.

Supporting a given organocatalyst can therefore be viewed from two extreme perspectives. From the first point of view, one can design a material so that the organocatalysts are anchored in an inert matrix, ideally without interaction neither with the matrix nor between different catalytic sites (single-site catalysts) to reproduce the properties of a successful homogeneous catalyst with the advantages of the ease of recovery and purification of the products. In the second approach the silica-supported catalyst can be viewed as a totally new catalytic entity, in which the properties arise not only from the organic catalyst itself, but also from complementary interactions with the surface or between various catalytic sites. In this approach, several catalytic materials must be synthesized and compared to determine the lead material to be used for a given transformation.

Adopting this perspective of the catalytic material, and on the basis of the research already performed to support organocatalysts, one can now envision to design materials able to perform new catalytic transformations hardly achievable in solution, for example by placing several catalytic sites in close vicinity, eventually in confined or chiral environments to promote new transformations. This opens a vast field of research on organocatalytic materials. 


\section{Bio sketches}

Meritxell Ferré received the Degree in Chemistry from the Universitat Autònoma de Barcelona (UAB) and her Master degree from the same University in 2011. She has completed the $\mathrm{PhD}$ (2015) at the UAB under the direction of Prof. R. Pleixats working in silica-supported catalysts. During this period she made some short stays at Institut Charles Gerhardt (ICG) in Montpellier.

Roser Pleixats graduated in Chemistry and obtained her PhD from the Universitat Autònoma de Barcelona (UAB). After a postdoctoral stay at the Université des Sciences et Techniques du Languedoc (USTL) in Montpellier with Prof. R. J. P. Corriu and E. Colomer, she returned to UAB where she became Associate Professor in 1991 and Full Professor of Organic Chemistry in 2004. Her current research interests focus on metal nanoparticles and organosilica-based materials for catalysis and nanomedicine.

Michel Wong Chi Man studied at the University of Montpellier (France) before completing an AvH Postdoctoral Fellowship at the University of Heidelberg (Germany). Currently he is a CNRS Research Director working at the Institut Charles Gerhardt in Montpellier and is also serving on the Board of the ISGS (International Sol-Gel Society) since 2011. He is an expert in organosilicon and hybrid silica chemistry and over the past two decades he developed pioneering work on bridged silsesquioxanes (BS) producing significant scientific advances in this field. He was the first to report right- and left-handed helical BS and self-structured BS on the nanoscale. He has also developed BS for application in several fields: catalysis, optics, separation chemistry....

Xavier Cattoën graduated from ENS Cachan then completed his PhD in 2004 under Prof. G. Bertrand and Dr D. Bourissou in Toulouse after a one-year stay at UC Riverside (USA). He was a post-doctoral researcher at ICIQ (Tarragona, Spain) in Prof. M. A. Pericàs' group then was appointed CNRS researcher in 2007 at ICG Montpellier, and finally moved to the Néel Institute, Grenoble in 2013. His research interests focus on the organic functionalization of silica-based materials for application in nanomedicine and catalysis.

\section{Acknowledgements}

Financial support from CNRS, ENSCM, Ministerio de Ciencia e Innovación (MICINN) of Spain (Projects CTQ2009-07881, CTQ2011-22649), Ministerio de Economia y Competitividad (MINECO) of Spain (Projects CTQ2014-51912-REDC and CTQ2014-53662-P) and DURSI-Generalitat de Catalunya (SGR2014-1105) is gratefully acknowledged. M. Ferré thanks the Universitat Autònoma de Barcelona for a predoctoral scholarship.

\section{References}

1. P. I. Dalko and L. Moisan, Angew. Chem. Int. Ed., 2004, 43, 5138-5175.

2. P. I. Dalko and L. Moisan, Angew. Chem. Int. Ed., 2001, 40, 3726-3748.

3. P. Renzi and M. Bella, Chem. Commun., 2012, 48, 6881-6896.

4. D. W. C. MacMillan, Nature, 2008, 455, 304-308.

5. G. Guillena, C. Nájera and D. J. Ramón, Tetrahedron: Asymmetry, 2007, 18, 2249-2293.

6. $\quad$ H. Pellissier, Tetrahedron, 2007, 63, 9267-9331.

7. S. Bertelsen and K. A. Jørgensen, Chem. Soc. Rev., 2009, 38, 2178-2189.

8. A. Dondoni and A. Massi, Angew. Chem. Int. Ed., 2008, 47, 4638-4660.

9. $\quad$ P. Melchiorre, Angew. Chem. Int. Ed., 2012, 51, 9748-9770.

10. B. M. Trost and C. S. Brindle, Chem. Soc. Rev., 2010, 39, 1600-1632.

11. J. Alemán and S. Cabrera, Chem. Soc. Rev., 2013, 42, 774-793.

12. Ł. Albrecht, H. Jiang and K. A. Jørgensen, Chem. Eur. J., 2014, 20, 358-368.

13. M. Benaglia, A. Puglisi and F. Cozzi, Chem. Rev., 2003, 103, 3401-3430.

14. M. Benaglia, New J. Chem., 2006, 30, 1525-1533.

15. F. Cozzi, Adv. Synth. Catal., 2006, 348, 1367-1390.

16. M. Gruttadauria, F. Giacalone and R. Noto, Chem. Soc. Rev., 2008, 37, 1666-1688.

17. T. E. Kristensen and T. Hansen, Eur. J. Org. Chem., 2010, 2010, 3179-3204.

18. S. Rostamnia and E. Doustkhah, RSC Adv., 2014, 4, 28238-28248.

19. A. Puglisi, M. Benaglia and V. Chiroli, Green Chem., 2013, 15, 1790-1813.

20. C. Rodríguez-Escrich and M. A. Pericàs, Eur. J. Org. Chem., 2015, 1173-1188.

21. A. Zamboulis, N. Moitra, J. J. E. Moreau, X. Cattoën and M. Wong Chi Man, J. Mater. Chem., 2010, 20, 9322-9338.

22. A. Corma and H. Garcia, Adv. Synth. Catal., 2006, 348, 1391-1412.

23. H. L. Ngo, A. Hu and W. Lin, J. Mol. Catal. A: Chem., 2004, 215, 177-186.

24. C. T. Kresge and W. J. Roth, Chem. Soc. Rev., 2013, 42, 3663-3670.

25. C. Li, H. Zhang, D. Jiang and Q. Yang, Chem. Commun., 2007, 547-558.

26. D. Ford, M., E. Simanek, E. and D. Shantz, F. , Nanotechnology, 2005, 16, S458.

27. E. Brunet, Chirality, 2002, 14, 135-143. 
N. Baccile, F. Babonneau, B. Thomas and T. Coradin, J. Mater. Chem., 2009, 19, 8537-8559.

A. Boutin, B. Coasne, A. H. Fuchs, A. Galarneau and F. Di Renzo, Langmuir, 2012, 28, 9526-9534.

C. J. Brinker and G. W. Scherer, Sol-Gel Science: the Physics and Chemistry of Sol-Gel Processing, Academic Press, San Diego, 1990.

T. Yanagisawa, T. Shimizu, K. Kuroda and C. Kato, Bull. Chem. Soc. Jpn., 1990, 63, 988-992.

J. S. Beck, J. C. Vartuli, W. J. Roth, M. E. Leonowicz, C. T. Kresge, K. D. Schmitt, C. T. W. Chu, D. H. Olson, E. W. Sheppard, S. B. McCullen, J. B. Higgins and J. L. Schlenker, J. Am. Chem. Soc., 1992, 114, 10834-10843.

C. T. Kresge, M. E. Leonowicz, W. J. Roth, J. C. Vartuli and J. S. Beck, Nature, 1992, 359, $710-712$.

C.-Y. Chen, S. L. Burkett, H.-X. Li and M. E. Davis, Microporous Mater., 1993, 2, $27-34$.

Y. Wan and D. Zhao, Chem. Rev., 2007, 107, 2821-2860.

Q. Huo, D. I. Margolese, U. Ciesla, D. G. Demuth, P. Feng, T. E. Gier, P. Sieger, A. Firouzi, B. F. Chmelka, F. Schüth and G. D. Stucky, Chem. Mater., 1994, 6, 1176-1191.

D. Zhao, Q. Huo, J. Feng, B. F. Chmelka and G. D. Stucky, J. Am. Chem. Soc., 1998, 120, 6024-6036.

N. Coustel, F. Di Renzo and F. Fajula, J. Chem. Soc., Chem. Commun., 1994, 967-968.

M. Kruk, M. Jaroniec, Y. Sakamoto, O. Terasaki, R. Ryoo and C. H. Ko, J. Phys. Chem. B, 2000, 104, 292-301.

D. Zhao, J. Feng, Q. Huo, N. Melosh, G. H. Fredrickson, B. F. Chmelka and G. D. Stucky, Science, 1998, 279, 548-552.

R. Ryoo and S. Jun, J. Phys. Chem. B, 1997, 101, 317-320.

C. J. Gommes, H. Friedrich, M. Wolters, P. E. d. Jongh and K. P. d. Jong, Chem. Mater., 2009, 21, 13111317.

P. Yuan, L. Tan, D. Pan, Y. Guo, L. Zhou, J. Yang, J. Zou and C. Yu, New J. Chem., 2011, 35, $2456-2461$. H. Q. Yang, X. J. Han, G. Li and Y. W. Wang, Green Chem., 2009, 11, 1184-1193.

D. Yang, J. Hu and S. Fu, J. Phys. Chem. C, 2009, 113, 7646-7651.

H. Yang, S. Li, X. Wang, F. Zhang, X. Zhong, Z. Dong and J. Ma, J. Mol. Catal. A: Chem., 2012, 363364, 404-410.

F. Tang, L. Li and D. Chen, Adv. Mater., 2012, 24, 1504-1534.

A. Zamboulis, N. J. Rahier, M. Gehringer, X. Cattoën, G. Niel, C. Bied, J. J. E. Moreau and M. Wong Chi Man, Tetrahedron: Asymmetry, 2009, 20, 2880-2885.

D. Cancogni, A. Mandoli, R. P. Jumde and D. Pini, Eur. J. Org. Chem., 2012, 2012, 1336-1345.

E. A. Prasetyanto, S. C. Lee, S. M. Jeong and S. E. Park, Chem. Commun., 2008, 1995-1997.

A. Monge-Marcet, R. Pleixats, X. Cattoën, M. Wong Chi Man, D. A. Alonso, D. Almasi and C. Nájera, New J. Chem., 2011, 35, 2766-2772.

A. Monge-Marcet, X. Cattoën, D. A. Alonso, C. Nájera, M. Wong Chi Man and R. Pleixats, Green Chem., 2012, 14, 1601-1610.

F. Calderón, R. Fernández, F. Sánchez and A. Fernández-Mayoralas, Adv. Synth. Catal., 2005, 347, 13951403.

P. D. Raytchev, A. Bendjeriou, J.-P. Dutasta, A. Martinez and V. Dufaud, Adv. Synth. Catal., 2011, 353, 2067-2077.

N. Moitra, J. J. E. Moreau, X. Cattoën and M. Wong Chi Man, Chem. Commun., 2010, 46, 8416-8418.

K. Bürglová, N. Moitra, J. Hodačová, X. Cattoën and M. Wong Chi Man, J. Org. Chem., 2011, 76, 73267333.

K. Bürglová, A. Noureddine, J. Hodačová, G. Toquer, X. Cattoën and M. Wong Chi Man, Chem. Eur. J., 2014, 20, 10371-10382.

A. K. Tucker-Schwartz, R. A. Farrell and R. L. Garrell, J. Am. Chem. Soc., 2011, 133, 11026-11029.

Y. Zuo, D. Wang, J. Zhang and S. Feng, RSC Adv., 2014, 4, 62827-62834.

Y. Maegawa, N. Mizoshita, T. Tani, T. Shimada and S. Inagaki, J. Mater. Chem., 2011, 21, 14020-14024.

Y. Zhang, L. Zhao, S. S. Lee and J. Y. Ying, Adv. Synth. Catal., 2006, 348, 2027-2032.

Y. Maegawa, M. Waki, A. Umemoto, T. Shimada and S. Inagaki, Tetrahedron, 2013, 69, 5312-5318.

A. Noureddine, P. Trens, G. Toquer, X. Cattoën and M. Wong Chi Man, Langmuir, 2014, 30, 1229712305.

M. Trilla, R. Pleixats, M. Wong Chi Man and C. Bied, Green Chem., 2009, 11, 1815-1820.

D. J. Macquarrie, Chem. Commun., 1996, 1961-1962.

A. Mehdi, C. Réyé and R. Corriu, Chem. Soc. Rev., 2011, 40, 563-574.

D. A. Loy and K. J. Shea, Chem. Rev., 1995, 95, 1431-1442.

L.-C. Hu and K. J. Shea, Chem. Soc. Rev., 2011, 40, 688-695.

N. Mizoshita, T. Tani and S. Inagaki, Chem. Soc. Rev., 2011, 40, 789-800.

S. El Hankari, B. Motos-Perez, P. Hesemann, A. Bouhaouss and J. J. E. Moreau, J. Mater. Chem., 2011, 21, 6948-6955.

J. Gao, X. Zhang, S. Xu, F. Tan, X. Li, Y. Zhang, Z. Qu, X. Quan and J. Liu, Chem. Eur. J., 2014, 20, 1957-1963.

B. Guan, Y. Cui, Z. Ren, Z.-a. Qiao, L. Wang, Y. 1. Liu and Q. Huo, Nanoscale, 2012, 4, 6588-6596.

J. Croissant, D. Salles, M. Maynadier, O. Mongin, V. Hugues, M. Blanchard-Desce, X. Cattoën, M. Wong Chi Man, A. Gallud, M. Garcia, M. Gary-Bobo, L. Raehm and J.-O. Durand, Chem. Mater., 2014, 26, 7214-7220. 

Mater., 2015, 27, 145-149.

75. F. Hoffmann and M. Fröba, Chem. Soc. Rev., 2011, 40, 608-620.

76. D. Brunel, A. Cauvel, F. Di Renzo, F. Fajula, B. Fubini, B. Onida and E. Garrone, New J. Chem., 2000, 24, 807-813.

77. N. Moitra, S. Ichii, T. Kamei, K. Kanamori, Y. Zhu, K. Takeda, K. Nakanishi and T. Shimada, J. Am. Chem. Soc., 2014, 136, 11570-11573.

78. K. K. Sharma and T. Asefa, Angew. Chem. Int. Ed., 2007, 46, 2879-2882.

79. K. K. Sharma, A. Anan, R. P. Buckley, W. Ouellette and T. Asefa, J. Am. Chem. Soc., 2008, 130, $218-228$.

80. H. C. Kolb, M. G. Finn and K. B. Sharpless, Angew. Chem. Int. Ed., 2001, 40, $2004-2021$.

81. X. Cattoën, A. Noureddine, J. Croissant, N. Moitra, K. Bürglová, J. Hodačová, O. De los Cobos, M. Lejeune, F. Rossignol, D. Toulemon, S. Bégin-Colin, B. Pichon, L. Raehm, J.-O. Durand and M. Wong Chi Man, J. Sol-Gel Sci. Technol., 2014, 70, 245-253.

82. A. E. Fernandes, A. M. Jonas and O. Riant, Tetrahedron, 2014, 70, 1709-1731.

83. D. Margolese, J. A. Melero, S. C. Christiansen, B. F. Chmelka and G. D. Stucky, Chem. Mater., 2000, 12, 2448-2459.

84. B. Malvi, B. R. Sarkar, D. Pati, R. Mathew, T. G. Ajithkumar and S. Sen Gupta, J. Mater. Chem., 2009, 19, 1409-1416.

85. J. Nakazawa and T. D. P. Stack, J. Am. Chem. Soc., 2008, 130, 14360-14361.

86. N. Moitra, P. Trens, L. Raehm, J.-O. Durand, X. Cattoën and M. Wong Chi Man, J. Mater. Chem., 2011, 21, 13476-13482.

87. J. Nakazawa, B. J. Smith and T. D. P. Stack, J. Am. Chem. Soc., 2012, 134, 2750-2759.

88. J. M. Rosenholm, T. Czuryszkiewicz, F. Kleitz, J. B. Rosenholm and M. Lindén, Langmuir, 2007, 23, 4315-4323.

89. C. Yu and J. He, Chem. Commun., 2012, 48, 4933-4940.

90. L. Zhao, Y. Li, P. Yu, X. Han and J. He, ACS Catal., 2012, 2, 1118-1126.

91. J. Hong and F. Zaera, J. Am. Chem. Soc., 2012, 134, 13056-13065.

92. B. Motos-Pérez, J. Roeser, A. Thomas and P. Hesemann, Appl. Organomet. Chem., 2013, 27, $290-299$.

93. S. Shylesh, D. Hanna, J. Gomes, S. Krishna, C. G. Canlas, M. Head-Gordon and A. T. Bell, Chemcatchem, 2014, 6, 1283-1290.

94. N. A. Brunelli, S. A. Didas, K. Venkatasubbaiah and C. W. Jones, J. Am. Chem. Soc., 2012, 134, 1395013953.

95. S. Huh, H.-T. Chen, J. W. Wiench, M. Pruski and V. S. Y. Lin, J. Am. Chem. Soc., $2004,126,1010-1011$.

96. S. Huh, H.-T. Chen, J. W. Wiench, M. Pruski and V. S. Y. Lin, Angew. Chem. Int. Ed., 2005, 44, 18261830.

97. A. Puglisi, R. Annunziata, M. Benaglia, F. Cozzi, A. Gervasini, V. Bertacche and M. C. Sala, Adv. Synth. Catal., 2009, 351, 219-229.

98. A. T. Dickschat, F. Behrends, S. Surmiak, Wei, H. Eckert and A. Studer, Chem. Commun., 2013, 49, 21952197.

99. A. T. Dickschat, F. Behrends, M. Bühner, J. Ren, M. Weiß, H. Eckert and A. Studer, Chem. Eur. J., 2012, 18, 16689-16697.

100. A. Noureddine, L. Lichon, M. Maynadier, M. Garcia, M. Gary-Bobo, J. I. Zink, M. Wong Chi Man and X. Cattoën, Nanoscale, 2015, DOI: 10.1039/c5nr02620b.

101. E. L. Margelefsky, A. Bendjériou, R. K. Zeidan, V. Dufaud and M. E. Davis, J. Am. Chem. Soc., 2008, 130, 13442-13449.

102. E. L. Margelefsky, R. K. Zeidan, V. Dufaud and M. E. Davis, J. Am. Chem. Soc., 2007, 129, 13691-13697.

103. J. D. Bass and A. Katz, Chem. Mater., 2006, 18, 1611-1620.

104. W. D. Bossaert, D. E. De Vos, W. M. Van Rhijn, J. Bullen, P. J. Grobet and P. A. Jacobs, J. Catal., 1999, 182, 156-164.

105. W. M. Van Rhijn, D. E. De Vos, B. F. Sels and W. D. Bossaert, Chem. Commun., 1998, $317-318$.

106. J. Mondal, M. Nandi, A. Modak and A. Bhaumik, J. Mol. Catal. A: Chem., 2012, 363-364, $254-264$.

107. I. K. Mbaraka, D. R. Radu, V. S. Y. Lin and B. H. Shanks, J. Catal., 2003, 219, 329-336.

108. R. K. Zeidan, V. Dufaud and M. E. Davis, J. Catal., 2006, 239, 299-306.

109. A. Karam, Y. Gu, F. Jerome, J.-P. Douliez and J. Barrault, Chem. Commun., $2007,2222-2224$.

110. M. A. Naik, D. Sachdev and A. Dubey, Catal. Commun., 2010, 11, 1148-1153.

111. M. Nandi, J. Mondal, K. Sarkar, Y. Yamauchi and A. Bhaumik, Chem. Commun., 2011, 47, 6677-6679.

112. S. Ray, P. Das, A. Bhaumik, A. Dutta and C. Mukhopadhyay, Appl. Catal., A, 2013, 458, $183-195$.

113. N. T. McDougal and S. E. Schaus, J. Am. Chem. Soc., 2003, 125, 12094-12095.

114. X. Wang, P. Han, X. Qiu, X. Ji and L. Gao, Catal. Lett., 2008, 124, 418-427.

115. F. A. Luzzio, Tetrahedron, 2001, 57, 915-945.

116. D. J. Macquarrie, J. H. Clark, A. Lambert, J. E. G. Mdoe and A. Priest, React. Funct. Polym., 1997, 35, 153-158.

117. J. Lauwaert, E. De Canck, D. Esquivel, J. W. Thybaut, P. Van Der Voort and G. B. Marin, Chemcatchem, 2014, 6, 255-264.

118. D. J. Macquarrie and D. B. Jackson, Chem. Commun., 1997, 1781-1782.

119. S.-G. Wang, Catal. Commun., 2003, 4, 469-470. 
Y. Kubota, H. Yamaguchi, T. Yamada, S. Inagaki, Y. Sugi and T. Tatsumi, Top. Catal., 2010, 53, 492499.

121. K. Kandel, S. M. Althaus, C. Peeraphatdit, T. Kobayashi, B. G. Trewyn, M. Pruski and I. I. Slowing, J. Catal., 2012, 291, 63-68.

122. S. L. Hruby and B. H. Shanks, J. Catal., 2009, 263, 181-188.

123. G. Sartori, F. Bigi, R. Maggi, R. Sartorio, D. J. Macquarrie, M. Lenarda, L. Storaro, S. Coluccia and G. Martra, J. Catal., 2004, 222, 410-418.

124. K. K. Sharma, R. P. Buckley and T. Asefa, Langmuir, 2008, 24, 14306-14320.

125. Y. Xie, K. K. Sharma, A. Anan, G. Wang, A. V. Biradar and T. Asefa, J. Catal., 2009, 265, 131-140.

126. B. M. Choudary, M. L. Kantam, P. Sreekanth, T. Bandopadhyay, F. Figueras and A. Tuel, J. Mol. Catal. A: Chem., 1999, 142, 361-365.

127. M. Lakshmi Kantam and P. Sreekanth, Catal. Lett., 1999, 57, 227-231.

128. S. Shanmuganathan, L. Greiner and P. Domínguez de María, Tetrahedron Lett., 2010, 51, 6670-6672.

129. A. Cauvel, G. Renard and D. Brunel, J. Org. Chem., 1997, 62, 749-751.

130. X. Dong, Y. Hui, S. Xie, P. Zhang, G. Zhou and Z. Xie, RSC Adv., 2013, 3, 3222-3226.

131. J. D. Bass, A. Solovyov, A. J. Pascall and A. Katz, J. Am. Chem. Soc., 2006, 128, 3737-3747.

132. Q. Wang and D. F. Shantz, J. Catal., 2010, 271, 170-177.

133. A. Anan, R. Vathyam, K. Sharma and T. Asefa, Catal. Lett., 2008, 126, 142-148.

134. K. K. Sharma, A. V. Biradar and T. Asefa, Chemcatchem, 2010, 2, 61-66.

135. H. Zhao, N. Yu, Y. Ding, R. Tan, C. Liu, D. Yin, H. Qiu and D. Yin, Microporous Mesoporous Mater., 2010, 136, 10-17.

136. J. Mondal, A. Modak, M. Nandi, H. Uyama and A. Bhaumik, RSC Adv., 2012, 2, 11306-11317.

137. R. H. Tale, R. U. Siraskar and S. B. Zangade, Eur. Chem. Bull., 2013, 2, 279-282.

138. R. Baharfar and R. Azimi, Synth. Commun., 2013, 44, 89-100.

139. I. Rodriguez, S. Iborra, F. Rey and A. Corma, Appl. Catal., A, 2000, 194-195, 241-252.

140. A. Corma, S. Iborra, I. Rodriguez and F. Sánchez, J. Catal., 2002, 211, 208-215.

141. Y. V. S. Rao, D. E. De Vos and P. A. Jacobs, Angew. Chem. Int. Ed., 1997, 36, 2661-2663.

142. S. Jaenicke, G. K. Chuah, X. H. Lin and X. C. Hu, Microporous Mesoporous Mater., 2000, 35-36, 143153.

143. L. Soldi, W. Ferstl, S. Loebbecke, R. Maggi, C. Malmassari, G. Sartori and S. Yada, J. Catal., 2008, 258, 289-295.

144. A. Alizadeh, M. M. Khodaei, M. Beygzadeh, D. Kordestani and M. Feyzi, Bull. Korean Chem. Soc., 2012 , 33, 2546-2552.

145. C. Carrignon, P. Makowski, M. Antonietti and F. Goettmann, Tetrahedron Lett., 2009, 50, 4833-4837.

146. Y. Liu, J. Peng, S. Zhai, J. Li, J. Mao, M. Li, H. Qiu and G. Lai, Eur. J. Inorg. Chem., 2006, $2947-2949$.

147. G. Lai, J. Peng, J. Li, H. Qiu, J. Jiang, K. Jiang and Y. Shen, Tetrahedron Lett., 2006, 47, 6951-6953.

148. L.-W. Xu, M.-S. Yang, J.-X. Jiang, H.-Y. Qiu and G.-Q. Lai, Cent. Eur. J. Chem., 2007, 5, 1073-1083.

149. X. Zhang, D. Wang, N. Zhao, A. S. N. Al-Arifi, T. Aouak, Z. A. Al-Othman, W. Wei and Y. Sun, Catal. Commun., 2009, 11, 43-46.

150. S. Udayakumar, M.-K. Lee, H.-L. Shim, S.-W. Park and D.-W. Park, Catal. Commun., 2009, 10, 659-664.

151. S. Udayakumar, S.-W. Park, D.-W. Park and B.-S. Choi, Catal. Commun., 2008, 9, 1563-1570.

152. H. Zhou, Y.-M. Wang, W.-Z. Zhang, J.-P. Qu and X.-B. Lu, Green Chem., 2011, 13, 644-650.

153. L. Han, H.-J. Choi, S.-J. Choi, B. Liu and D.-W. Park, Green Chem., 2011, 13, 1023-1028.

154. P. Agrigento, S. M. Al-Amsyar, B. Soree, M. Taherimehr, M. Gruttadauria, C. Aprile and P. P. Pescarmona, Catal. Sci. Technol., 2014, 4, 1598-1607.

155. A. Barbarini, R. Maggi, A. Mazzacani, G. Mori, G. Sartori and R. Sartorio, Tetrahedron Lett., 2003, 44, 2931-2934.

T. Takahashi, T. Watahiki, S. Kitazume, H. Yasuda and T. Sakakura, Chem. Commun., 2006, 1664-1666. K. Motokura, M. Tomita, M. Tada and Y. Iwasawa, Chem. Eur. J., 2008, 14, 4017-4027.

K. Motokura, M. Tada and Y. Iwasawa, Angew. Chem. Int. Ed., 2008, 47, 9230-9235.

K. Motokura, S. Tanaka, M. Tada and Y. Iwasawa, Chem. Eur. J., 2009, 15, 10871-10879.

S. Shylesh, A. Wagener, A. Seifert, S. Ernst and W. R. Thiel, Chemcatchem, 2010, 2, 1231-1234.

Y. Huang, B. G. Trewyn, H.-T. Chen and V. S. Y. Lin, New J. Chem., 2008, 32, 1311-1313.

R. K. Zeidan, S.-J. Hwang and M. E. Davis, Angew. Chem. Int. Ed., 2006, 45, 6332-6335.

R. K. Zeidan and M. E. Davis, J. Catal., 2007, 247, 379-382.

N. Solin, L. Han, S. Che and O. Terasaki, Catal. Commun., 2009, 10, 1386-1389.

L. Han, J. Ruan, Y. Li, O. Terasaki and S. Che, Chem. Mater., 2007, 19, 2860-2867.

Y. Shao, J. Guan, S. Wu, H. Liu, B. Liu and Q. Kan, Microporous Mesoporous Mater., 2010, 128, 120 125.

167. X. Yu, X. Yu, S. Wu, B. Liu, H. Liu, J. Guan and Q. Kan, J. Solid State Chem., 2011, 184, 289-295.

168. S. Shylesh, A. Wagner, A. Seifert, S. Ernst and W. R. Thiel, Chem. Eur. J., 2009, 15, 7052-7062.

169. S. Shylesh, A. Wagener, A. Seifert, S. Ernst and W. R. Thiel, Angew. Chem. Int. Ed., 2010, 49, $184-187$.

170. Y. Huang, S. Xu and V. S. Y. Lin, Angew. Chem. Int. Ed., 2011, 50, 661-664.

171. W.-H. Peng, Y.-Y. Lee, C. Wu and K. C. W. Wu, J. Mater. Chem., 2012, 22, 23181-23185.

172. N. R. Shiju, A. H. Alberts, S. Khalid, D. R. Brown and G. Rothenberg, Angew. Chem. Int. Ed., 2011, 50, 9615-9619.

173. N. A. Brunelli, K. Venkatasubbaiah and C. W. Jones, Chem. Mater., 2012, 24, 2433-2442. 
E. L. Margelefsky, R. K. Zeidan and M. E. Davis, Chem. Soc. Rev., 2008, 37, 1118-1126.

N. A. Brunelli and C. W. Jones, J. Catal., 2013, 308, 60-72.

176. U. Diaz, D. Brunel and A. Corma, Chem. Soc. Rev., 2013, 42, 4083-4097.

177. E. G. Doyagüez, F. Calderón, S. F. and A. Fernández-Mayoralas, J. Org. Chem., 2007, 72, 9353-9356.

178. C. Aprile, F. Giacalone, M. Gruttadauria, A. M. Marculescu, R. Noto, J. D. Revell and H. Wennemers, Green Chem., 2007, 9, 1328-1334.

179. E. Montroni, M. Lombardo, A. Quintavalla, C. Trombini, M. Gruttadauria and F. Giacalone, Chemcatchem, 2012, 4, 1000-1006.

180. V. Srivastava, K. Gaubert, M. Pucheault and M. Vaultier, Chemcatchem, 2009, 1, 94-98.

181. J. Yan and L. Wang, Chirality 2009, 21, 413-420.

182. A. Massi, A. Cavazzini, L. D. Zoppo, O. Pandoli, V. Costa, L. Pasti and P. P. Giovannini, Tetrahedron Lett., 2011, 52, 619-622.

183. Z. An, Y. Guo, L. Zhao, Z. Li and J. He, ACS Catal., 2014, 4, 2566-2576.

184. J. Gao, J. Liu, D. Jiang, B. Xiao and Q. Yang, J. Mol. Catal. A: Chem., 2009, 313, $79-87$.

185. J. Gao, J. Liu, J. Tang, D. Jiang, B. Li and Q. Yang, Chem. Eur. J., 2010, 16, $7852-7858$.

186. O. Bortolini, L. Caciolli, A. Cavazzini, V. Costa, R. Greco, A. Massi and L. Pasti, Green Chem., 2012, 14, 992-1000.

187. A. Bañón-Caballero, G. Guillena, C. Nájera, E. Faggi, R. M. Sebastián and A. Vallribera, Tetrahedron, 2013, 69, 1307-1315.

188. S. Jebors, S. Cecillon, C. Faye, C. Enjalbal, M. Amblard, A. Mehdi, G. Subra and J. Martinez, J. Mater. Chem. B, 2013, 1, 6510-6515.

189. J. Gao, J. Liu, S. Bai, P. Wang, H. Zhong, Q. Yang and C. Li, J. Mater. Chem., 2009, 19, 8580-8588.

190. S. Sulzer-Mosse and A. Alexakis, Chem. Commun., 2007, 3123-3135.

191. Y.-B. Zhao, L.-W. Zhang, L.-Y. Wu, X. Zhong, R. Li and J.-T. Ma, Tetrahedron: Asymmetry, 2008, 19, 1352-1355.

192. P. Li, L. Wang, Y. Zhang and G. Wang, Tetrahedron, 2008, 64, 7633-7638.

193. E. Prasetyanto, S.-M. Jeong and S.-E. Park, Top. Catal., 2010, 53, 192-199.

194. E.-Y. Jeong, C.-R. Lim, H. Jin and S.-E. Park, Chem. Commun., 2012, 48, 3079-3081.

195. B. G. Wang, B. C. Ma, Q. Wang and W. Wang, Adv. Synth. Catal., 2010, 352, $2923-2928$.

196. S. Yang and J. He, Chem. Commun., 2012, 48, 10349-10351.

197. C. Palomo, M. Oiarbide and R. Lopez, Chem. Soc. Rev., 2009, 38, 632-653.

198. Q. Chen, C. Xin, L.-L. Lou, K. Yu, F. Ding and S. Liu, Catal. Lett., 2011, 141, $1378-1383$.

199. P. Garcia-Garcia, A. Zagdoun, C. Coperet, A. Lesage, U. Diaz and A. Corma, Chem. Sci., 2013, 4, 20062012.

200. P. Yu, J. He and C. X. Guo, Chem. Commun., 2008, 2355-2357.

201. H. S. Kim, Y.-M. Song, J. S. Choi, J. W. Yang and H. Han, Tetrahedron, 2004, 60, $12051-12057$.

202. K. A. Ahrendt, C. J. Borths and D. W. C. MacMillan, J. Am. Chem. Soc., 2000, 122, $4243-4244$.

203. S. A. Selkälä, J. Tois, P. M. Pihko and A. M. P. Koskinen, Adv. Synth. Catal., 2002, 344, 941-945.

204. H. Hagiwara, T. Kuroda, T. Hoshi and T. Suzuki, Adv. Synth. Catal., 2010, 352, 909-916.

205. J. Y. Shi, C. A. Wang, Z. J. Li, Q. Wang, Y. Zhang and W. Wang, Chem. Eur. J., 2011, 17, 6206-6213.

206. V. Chiroli, M. Benaglia, F. Cozzi, A. Puglisi, R. Annunziata and G. Celentano, Org. Lett., 2013, 15, 35903593.

207. R. Porta, M. Benaglia, V. Chiroli, F. Coccia and A. Puglisi, Isr. J. Chem., 2014, 54, $381-394$.

208. Z. Li, X. Li, X. Ni and J.-P. Cheng, Org. Lett., 2015, 17, 1196-1199.

209. A. Leyva-Pérez, P. García-García and A. Corma, Angew. Chem. Int. Ed., 2014, 53, 8687-8690.

210. A. Khalafi-Nezhad, E. S. Shahidzadeh, S. Sarikhani and F. Panahi, J. Mol. Catal. A: Chem., 2013, 379, 18 .

211. C. Zhi, J. Wang, B. Luo, X. Li, X. Cao, Y. Pan and H. Gu, RSC Adv., 2014, 4, 15036-15039.

212. A. Bañón-Caballero, G. Guillena and C. Nájera, J. Org. Chem., 2013, 78, 5349-5356.

213. H. Y. Kim, S. Kim and K. Oh, Angew. Chem. Int. Ed., 2010, 49, 4476-4478.

214. A. Corma, H. Garcia, A. Moussaif, M. J. Sabater, R. Zniber and A. Redouane, Chem. Commun., 2002, 1058-1059.

215. H.-T. Chen, B. Trewyn, J. Wiench, M. Pruski and V. Y. Lin, Top. Catal., 2010, 53, $187-191$.

216. W. He, F. Zhang, X. Shi and H. Li, Eur. J. Org. Chem., 2012, 2012, 3753-3758.

217. B. Karimi, A. Biglari, J. H. Clark and V. Budarin, Angew. Chem. Int. Ed., 2007, 46, 7210-7213.

218. P. C. Bulman Page, A. Mace, D. Arquier, D. Bethell, B. R. Buckley, D. J. Willock and G. J. Hutchings, Catal. Sci. Technol., 2013, 3, 2330-2339.

219. H. Sellner, J. K. Karjalainen and D. Seebach, Chem. Eur. J., 2001, 7, 2873-2887.

220. Z. Zhou, Q. Meng, A. Seifert, A. Wagener, Y. Sun, S. Ernst and W. Thiel, Microporous Mesoporous Mater., 2009, 121, 145-151.

221. S. Shylesh, Z. Zhou, Q. Meng, A. Wagener, A. Seifert, S. Ernst and W. R. Thiel, J. Mol. Catal. A: Chem., 2010, 332, 65-69. 